Supplement of Hydrol. Earth Syst. Sci., 20, 4673-4688, 2016

http://www.hydrol-earth-syst-sci.net/20/4673/2016/

doi:10.5194/hess-20-4673-2016-supplement

(C) Author(s) 2016. CC Attribution 3.0 License.

(c) (1)

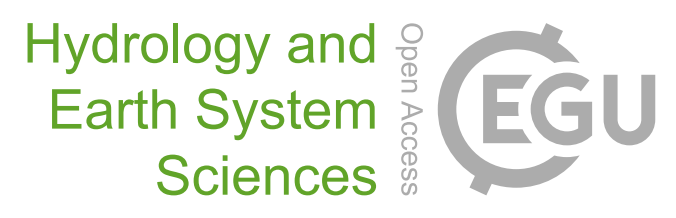

Supplement of

\title{
Reservoir storage and hydrologic responses to droughts in the Paraná River basin, south-eastern Brazil
}

Davi de C. D. Melo et al.

Correspondence to: Davi de C. D. Melo (melo.dcd@gmail.com)

The copyright of individual parts of the supplement might differ from the CC-BY 3.0 licence. 


\section{Contents}

1 Introduction 1

2 Background and Study area $2 \ldots$

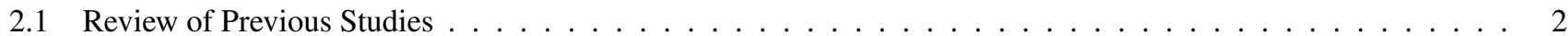

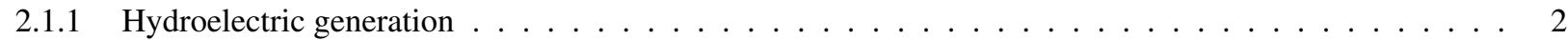

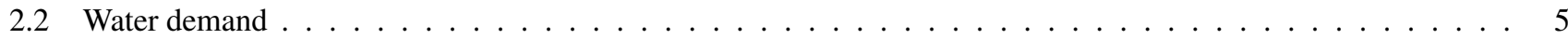

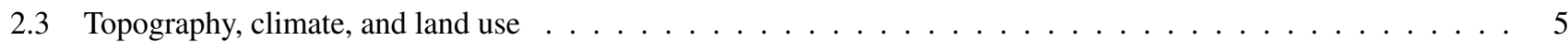

3 Data 5

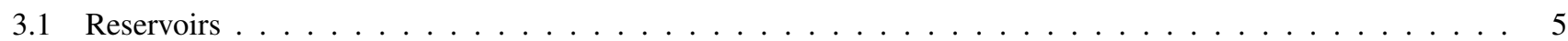

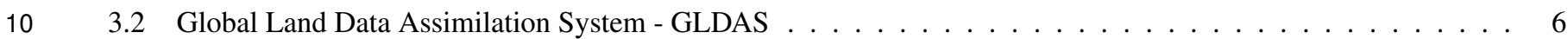

3.3 Remote sensing products and ground-based precipitation $\ldots \ldots \ldots \ldots \ldots \ldots \ldots$

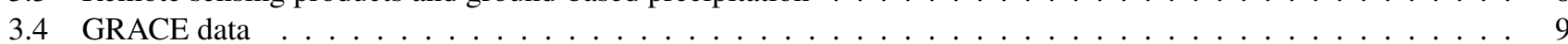

$\begin{array}{llr}4 \text { Methods } & 10\end{array}$

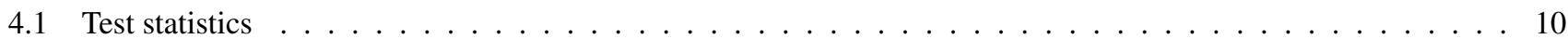

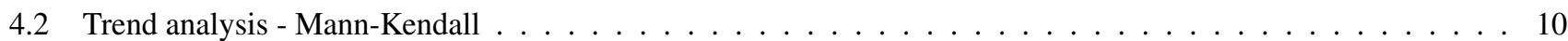

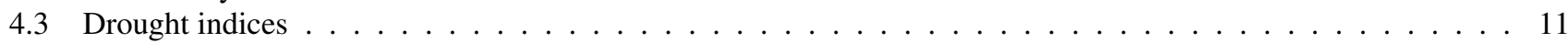

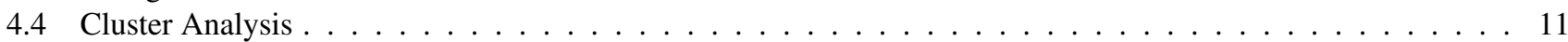

5 Results 13

5.1 Trends in GRACE Total Water Storage Anomaly (TWSA) and Soil Moisture Storage (SMS) . . . . . . . . . . 13

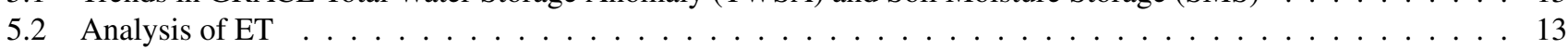

5.3 Trends in Reservoir Storage (RESS) $\ldots \ldots \ldots \ldots \ldots \ldots \ldots \ldots \ldots \ldots \ldots$

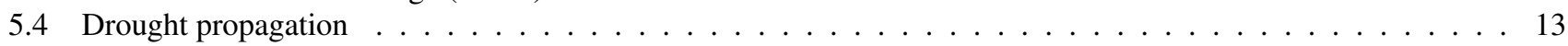

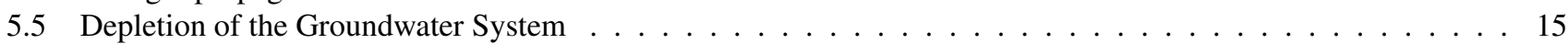

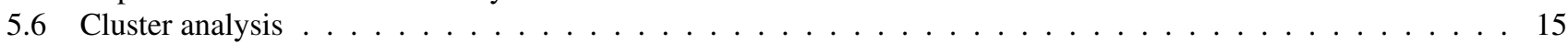

$25 \quad 5.7$ Spatial analysis of reservoir depletion/recovery $\ldots \ldots \ldots \ldots \ldots \ldots \ldots$

\begin{tabular}{|r|r|}
\hline Appendix A: Individual reservoir responses & 23 \\
\hline
\end{tabular}

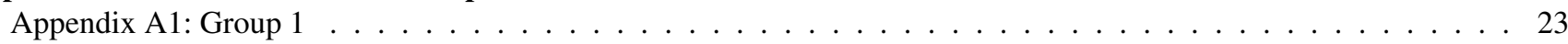

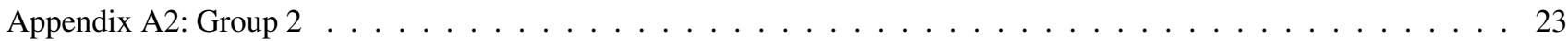

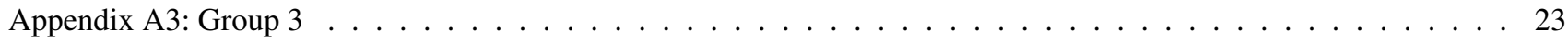

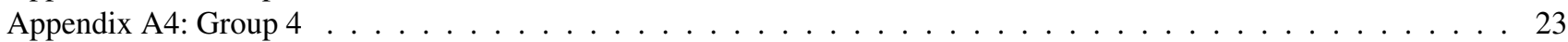

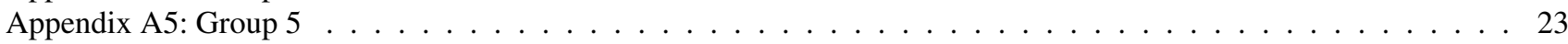

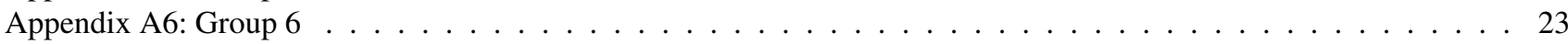

\section{Introduction}

This document consists of four sections containing supplementary information and materials about the study area (Section 2); ground-based and remotely sensed data (Section 3); methods used for data processing (Section 4); and results (Section 5). 


\section{Background and Study area}

\subsection{Review of Previous Studies}

Drought events in the Paraná Basin (PB) have large impacts, not only on human water supply, but also on crop production and hydro-power generation (Helmer and Hilhorst, 2006; Lima and Lall, 2010). About 65 million people in Brazil reside in the

$5 \mathrm{~PB}$, with a total water demand of $23 \mathrm{~km}^{3} \mathrm{yr}^{-1}$ (ANA 2010). According to São Paulo's Agricultural Institute, the agricultural losses due to the 2014 drought were the worst in the past 50 years (http://www.iea.sp.gov.br).

Coelho et al. (2016a) analyzed 55 years of rainfall records over the region of Sã Paulo city. Their findings show previous dry events since the 1960s but none exceeds the magnitude of the 2014 drought in terms of precipitation deficits, making the 2014 drought the driest event since 1962.

10 According to Coelho et al. (2016b), the 2014 drought originated from anomalous rainfall in Northern Australia, which resulted in a sequence of events that connected the tropical and extra-tropical regions of the Pacific Ocean until it reached south-east Brazil. These events caused an anomalous high pressure system over the Atlantic, forcing an oceanic trajectory of the frontal systems and the humidity from Amazon to migrate to Southern Brazil, which prevented the formation of precipitation events in the South Atlantic Convergence Zone (Coelho et al. 2016b).

15 Coutinho et al. (2015) analyzed the regime shifts in the reservoirs of the Cantareira system caused by droughts. Based on the relation between rainfall and water storage in the reservoirs, they built a mathematical model and showed that the mechanism that rules the reservoir dynamics has changed. Getirana (2015) used remotely sensed TWS anomaly (TWSA) data from GRACE to detect and quantify the impacts of the 2014 drought over south-eastern and north-eastern Brazil. According to this analysis, between 2011 and 2015, a depletion in water storage of $6.1 \mathrm{~cm} \mathrm{yr}^{-1}\left(56.4 \mathrm{~km}^{3} \mathrm{yr}^{-1}\right)$ occurred over South-eastern Brazil as a result of lower-than-usual rainfall rates, totalling $225 \mathrm{~km}^{3}$ over four years.

\subsubsection{Hydroelectric generation}

Hydroelectric plants (HEP) produce $\approx 65 \%$ of all electricity in Brazil, with higher generation rates in the South-east/MiddleWest (SE/MW) regions. The hydroelectric power plants (HEP) in São Paulo state account for $18 \%$ of Brazil's installed capacity. Most of these plants are within the Paraná basin (PB), including the bi-national Itaipú dam (Brazil-Paraguay), which is one of the largest producers ( $35 \%$ of generation in the $\mathrm{PB}$ ) of electricity globally $(\approx 2.3$ billion MWh since 1984$)$ (https://www.itaipu.gov.br/energia/geracao). Reports by the Brazilian Electric System National Operator (ONS - Operador Nacional do Sistem Elétrico) show that twelve plants among the 37 analysed in this study generate $160 \mathrm{TWh} \mathrm{yr}^{-1}$. In 2012, these plants generated 200 TWh (Fig. S1] but since 2013 the production has decreased, although the demand in the SE/MW region continued to increase (Fig. S1].

30 In Brazil, electricity is distributed through the National Interconnected System (SIN - Sistema Interligado Nacional) according to the decisions made by ONS. The following information were compiled from http://apps05.ons.org.br/procedimentorede/ procedimento_rede/procedimento_rede.aspx and http://www.ons.org.br/atuacao/index.aspx ONS bases its operation on external information from sectoral authorities, such as the National Agency of Electric Energy (ANEEL - Agência Nacional de Energia Elétrica), and owner agents of individual facilities composing SIN (hydroelectric plants, thermoelectric plants, etc). Important information, essential for electric generation planning in hydroelectric power plants (HEP), is the Natural Inflow Energy (NIE). NIE is the energy that can be produced with the natural inflow arriving at the power plant, that is, it is equivalent to the produced energy when all of the natural inflow is used to turn the turbines. Except for specific types of HEP, the actual production may be inferior to NIE as part of the discharge may be retained to control reservoir storage or run through the spillway. To determine NIE and other important information to operate SIN, ONS developed several macro processes, two of which are:

- Assessment of future conditions of operation: including the Annual Planning of Energy Operation (APEO) and Planning of the Annual Electric Operation (PAEL). 


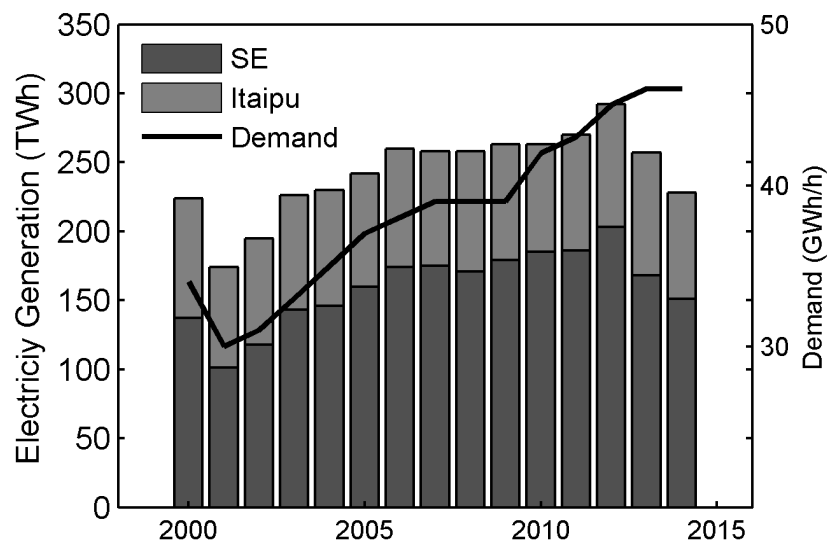

Figure S1. Electricity generation and demand in the South-east (SE) region

APEO based on the external information about future offer of energy and forecast of market consumption, ONS runs optimization and simulation models of operation "to determine operational strategies and assess SIN's supply conditions"

PAEL based on generation and transmission resources available, energy load forecast and schedule for installation of new equipment, the ONS defines actions related to SIN's infrastructure.

- Assessment of short-term operation: it consists of operational-security-related studies (OSR), short-term operations planning (STOP), and support studies (SS):

OSR aims to increase SIN's resilience to extreme contingencies originating from multiple malfunctions;

STOP are used to define goals and guidelines for daily and real-time operation;

SS include meteorological, climatological and hydrologic studies, and multiple uses of the water.

The hydrologic studies include streamflow forecast and reservoir management (flood control planning, evaluation of lake evaporation, operative hydraulics restrictions, etc). The (natural) streamflow forecasts are done periodically to assist in the decision making process of operation and promote an optimized dispatch to the power plants. This process consists of predicting natural river discharge $\left(Q_{i n}\right)$ from upstream (inflow) to the reservoirs, that is, $Q_{i n}$ that would occur without the upstream reservoirs, evaporation from the artificial lakes, or withdraws for public supply and irrigation (ONS, 2016).

Different rainfall-runoff models (lumped and distributed, depending on the basin and timescale) are used to forecast daily streamflow $\left(Q_{d_{-} i n}\right)$ for the current week and weekly streamflow $\left(Q_{w}\right)$ for the current month. Daily streamflow forecast is done once a week; depending on the forecast day, the prediction is done for different horizons ( 2 to 5 days ahead) (ONS, 2016). Specific tools (see below) use $Q_{d}$ to generate $Q_{w}$ for the following weeks of the current month. The following (also summarized in Fig. S2 details such processes.

- Acquire observed natural river discharge data, and observed and predicted meteorological data;

- Generate the prediction of mean natural daily streamflow $\left(\overline{Q_{d \_i n}}\right)$

- Those scenarios are analysed and ONS defines the values to be used in the next step

- Final values of $Q_{d}$ are derived from $\overline{Q_{d \_i n}}$ and are reported to ANEEL and other operation agents. 


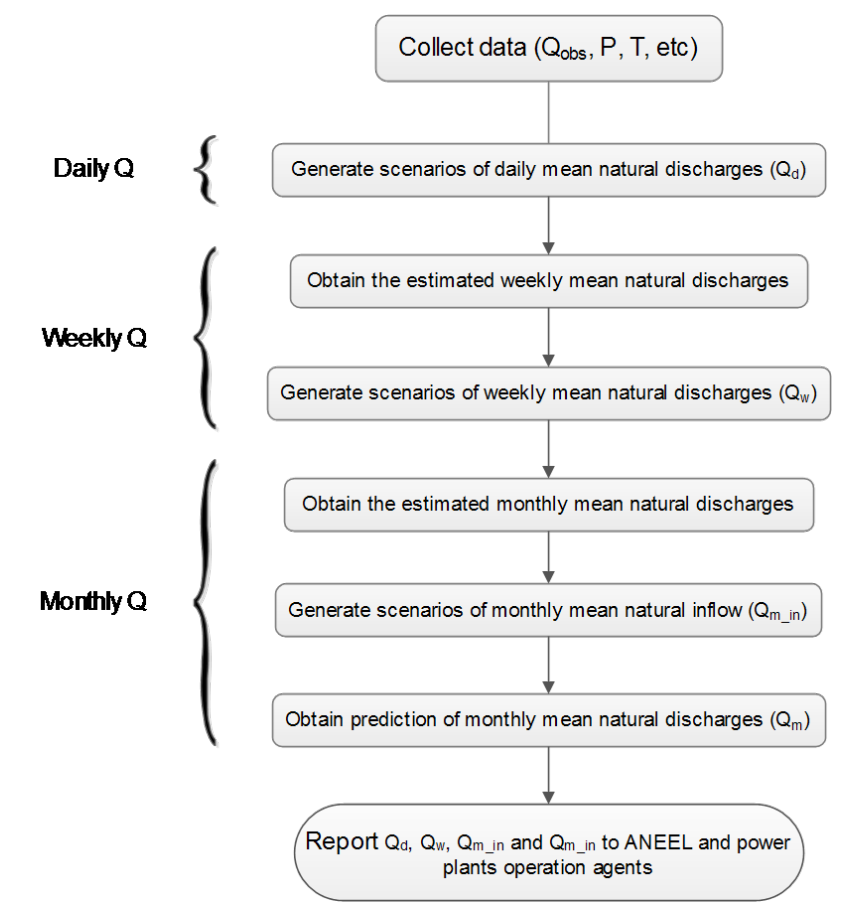

Figure S2. Summary of custom processes adopted by ONS to define natural energy inflow to power plants

- Estimate natural mean weekly river discharge $\left(\overline{Q_{w_{-} i n}}\right)$ for the current week based on the proportionality between observed and predicted daily streamflow.

- Run stochastic models to produce synthetic time series to compose the scenarios of mean weekly natural inflow $\left(Q_{w}\right)$.

- Estimate natural mean monthly river discharge $\left(\overline{Q_{m \_i n}}\right)$ for the current month based on the proportionality between observed and predicted weekly streamflow.

- Run stochastic models to produce synthetic time series to compose the scenarios of mean monthly natural inflow $\left(Q_{m}\right)$.

- $Q_{w}$ and $Q_{m}$ are reported to ANEEL and other operation agents.

- Final values of predicted natural mean monthly inflow are derived from discharge forecast models.

- Prediction of daily, weekly, and monthly mean natural discharge

- Scenarios of monthly mean natural inflow

Meteorological studies are not used to elaborate mid-term guidelines of operation. Given the limitation of weather forecast models $(\approx 7$ days), only the short-term operation considers meteorological aspects. The tools in Table 1 are used to predict daily, weekly and monthly discharges, and to generate scenarios of natural discharges.

In summary, rainfall-runoff models are forced with rainfall forecasts from the ETA model (Mesinger et al., 2012); discharge forecasts are then used in stochastic models (in general) to generate scenarios of projected natural discharges at different time scales. 
Table S1. Summary of tools adopted by ONS to determine NIE

\begin{tabular}{|c|c|c|l|}
\hline Model name & Time scale & Forecast horizon & Method to forecast Q \\
\hline PREVIVAZH & Daily & 14 days & $\begin{array}{l}\text { Disaggregation of weekly forecast based on past } \\
\text { discharge trends and synthetic series of daily nat- } \\
\text { ural discharge }\end{array}$ \\
\hline CPINS & Daily & 30 days & $\begin{array}{l}\text { Propagation of observed and predicted Q at up- } \\
\text { stream gauges }\end{array}$ \\
\hline DIANA & Daily & ND & Multivariate stochastic modelling \\
\hline PREVIVAZ & Weekly & 6 weeks & Univariate stochastic modelling \\
\hline MPCV & Weekly & ND & Data mining \\
\hline PREVIVAS & Monthly & 12 months & Univariate stochastic modelling \\
\hline GEVAZP & Monthly & ND & ND \\
\hline
\end{tabular}

ND $=$ Not Defined

\subsection{Water demand}

The Paraná basin $(\mathrm{PB})$ contains $\approx 30 \%$ of the Brazilian population. Historic data published by Brazilian Water Agency (ANA - Agência Nacional de Águas) shows that the water demand for human supply was $2.85 \mathrm{~km}^{3} \mathrm{yr}^{-1}$ in 2005 and is expected to

5 reach $3.8 \mathrm{~km}^{3} \mathrm{yr}^{-1}$ in 2025. The PB encompasses areas of seven Brazilian states, two of which (Sã Paulo and Minas Gerais) account for $90 \%\left(835,000 \mathrm{~km}^{2}\right)$ of the SE region and have $77 \%$ (65 million people) of the region's population. The water supply in the SE region is composed $47 \%$ of surface water, $39 \%$ groundwater and $14 \%$ mixed (groundwater + surface water) sources. Approximately $50 \%$ of all central pivots in Brazil $(\approx 8,850)$ are in this basin, which is responsible for $72 \%$ of national water demand to this end. The total irrigated area inside PB is 530,000 ha, corresponding to $45 \%$ of all irrigation in Brazil. The irrigated area inside $\mathrm{PB}$ accounts for $\approx 1 \%$ of the basin.

The Paraná hydrographic region is composed by the following sub-basins: Paranaíba, Paraná, Tietê, Paranapanema, Iguacu and Rio Grande basin (Fig. S3). According to the Brazilian National Water Agency (ANA - Agência Nacional de Águas) the total surface water delivery $\left(\sum \mathrm{Q}_{\mathrm{del}}\right)$ is $15 \mathrm{~km}^{3} \mathrm{yr}^{-1}$ (ANA. 2006). The demand in the Tietê sub-basin corresponded to $50 \%$, most of which is for urban and industrial uses ( $40 \%$ of $\left.\sum Q_{\text {del }}\right)$ (Fig. $[$ S3 $)$.

15 In Brazil, surface water availability is often assessed by means of Q95 discharge, that is, the discharge equalled or exceeded $95 \%$ of the time. The ratio between delivered discharge $\left(Q_{\text {del }}\right)$ and $Q_{95}$ indicates how stressed the surface water resources are. The most critical situation occurs in the Tietê sub-basin, where $\mathrm{Q}_{\text {del }} / \mathrm{Q}_{95} \approx 65 \%$ (Fig. $\mathrm{S3}$ b, $\mathrm{S3}$ ) ). This sub-basin has the lowest surface water availability inside the Paraná basin: $8 \%$ of PB-Q95 (Fig.S3F). Most of PB-Q 95 is found in the Rio Grande and Paraná sub-basins (20 and $29 \%$, respectively) (ANA. 2006).

20 Recent data (http://www2.ana.gov.br/Paginas/portais/bacias/parana.aspx) indicate the total water demand in 2010 increased to $23 \mathrm{~km}^{3} \mathrm{yr}^{-1}$, which correspond to $13 \%$ of PB-Q $Q_{95}$.

\subsection{Topography, climate, and land use}

Additional maps of the study area are provided in Fig. S4 to complement those shown in the manuscript.

\section{Data}

\subsection{Reservoirs}

Daily data on inflow, water level, and storage in 50 reservoirs were downloaded from the Brazilian Water Agency (ANA Agência Nacional de Águas) web site for the period Jan 1995-Jun 2015. The data can be accessed from http://sar.ana.gov. br/MedicaoSIN (last access in 05 Oct 2016). The 37 reservoirs selected after a screening process, geographical coordinates, 


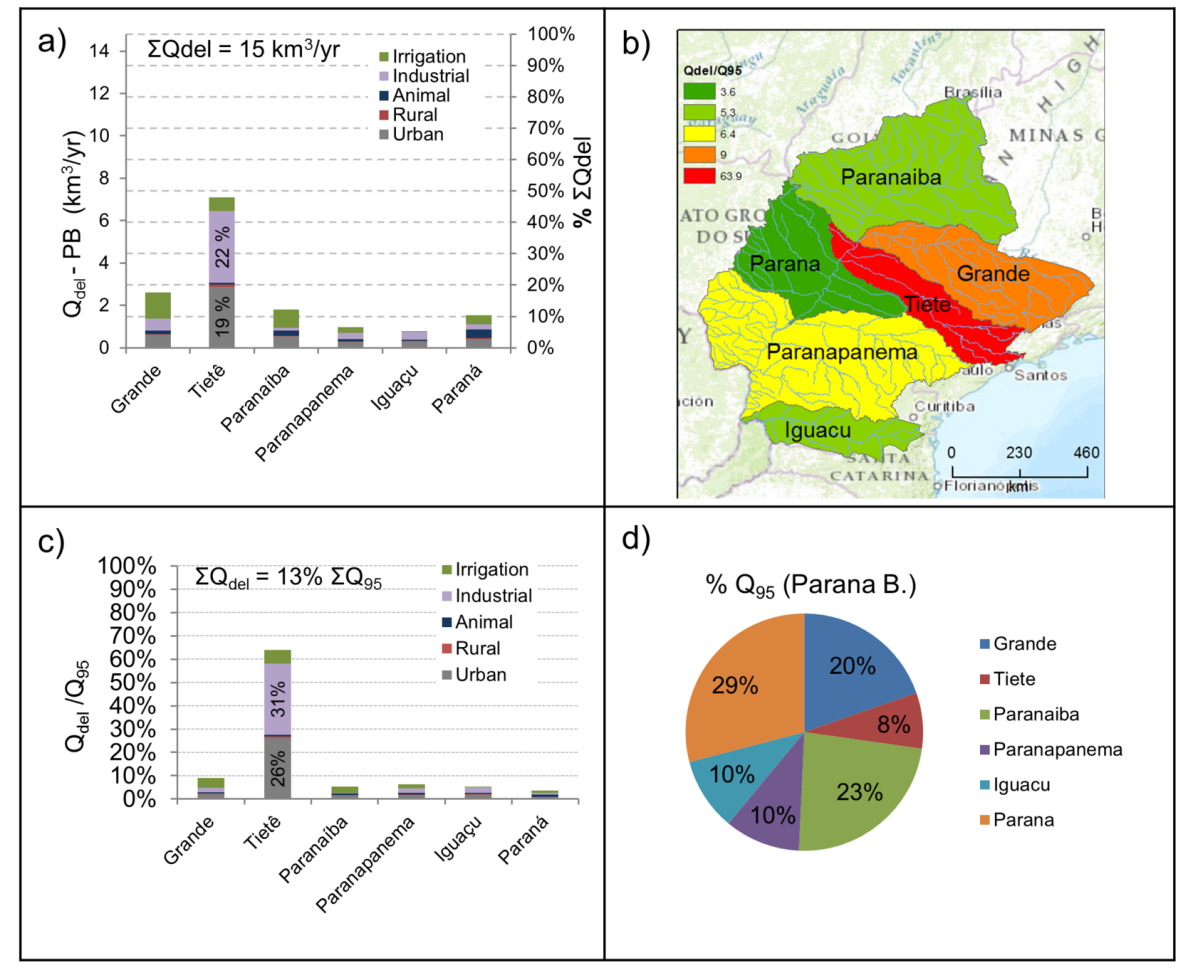

Figure S3. Summary of surface water deliveries $\left(\mathrm{Q}_{\mathrm{del}}\right)$ for different uses per sub-basin (a); $\mathrm{Q}_{\mathrm{del}} / \mathrm{Q}_{95}$ per sub-basin (b); distribution of $\mathrm{Q}_{\mathrm{del}} / \mathrm{Q}_{95}$ for different uses; contribution of each sub-basin to $\mathrm{Q}_{95}$ in the Paraná Hydrographic region

Brazilian state where they are located, surface area and storage capacity (volume) are listed in Table $\mathbf{S 2}$. Among the remaining reservoirs, only eight had gaps in the time series: Billings (30\%), Funil (18\%), Jaguari (18\%), Paraibuna (18\%), Três Marias (17\%), Miranda (15\%), Cachoeira Dourada (9\%) and Corumbá I (9\%). The following informartion are provided for each reservoir: geographical coordinates, Brazilian state where they are located, surface area and storage capacity (volume).

\subsection{Global Land Data Assimilation System - GLDAS}

The Global Land Data Assimilation System is a global, high resolution modelling system (of the Earth land surface) that compines satellite and ground-based observations to constrain the modelled land surface by Land Surface Models (LSM) (Rodell et al. 2004). The LSMs used by GLDAS include the Community Land Model (CLM) (Dai et al. 2003), NOAH (Chen et al., 1996, Ek et al., 2003); the Variable Infiltration Capacity (VIC) model (Liang et al., 1994) and MOSAIC (Koster and Suarez, 1996). GLDAS outputs and forcing data are available in GRIB and NETCDF formats from http://mirador.gsfc.nasa.gov/.

GLDAS includes four land surface and several atmospheric forcing datasets to produce outputs from these LSMs at $1^{\circ}$ (CLM, NOAH, MOSAIC and VIC) and $0.25^{\circ}$ (NOAH) horizontal resolutions and 3-hourly or monthly time resolutions for the period from 1979 to present (GLDAS 1.0) and from 1948 to 2010 (GLDAS 2.0). The land surface datasets consist of high resolution vegetation classification maps $(1 \mathrm{~km})$, soils database $\left(5^{\prime}\right)$, elevation database $\left(30^{\prime}\right)$ and Leaf Area Index map $(1 \mathrm{~km})$ (Rodell et al. 2004). Some examples of atmospheric forcing datasets used by GLDAS are the National Centers for Environmental Prediction's (NCEP) Global Data Assimilation System (GDAS) meteorological data (Derber et al. 1991 ) and National Aeronautics and Space Administration's (NASA) Goddard Space Flight Center (GSFC) Tropical Rainfall Measuring 5 Mission (TRMM) 3B42V6 rainfall data product (Huffman et al., 2007). 


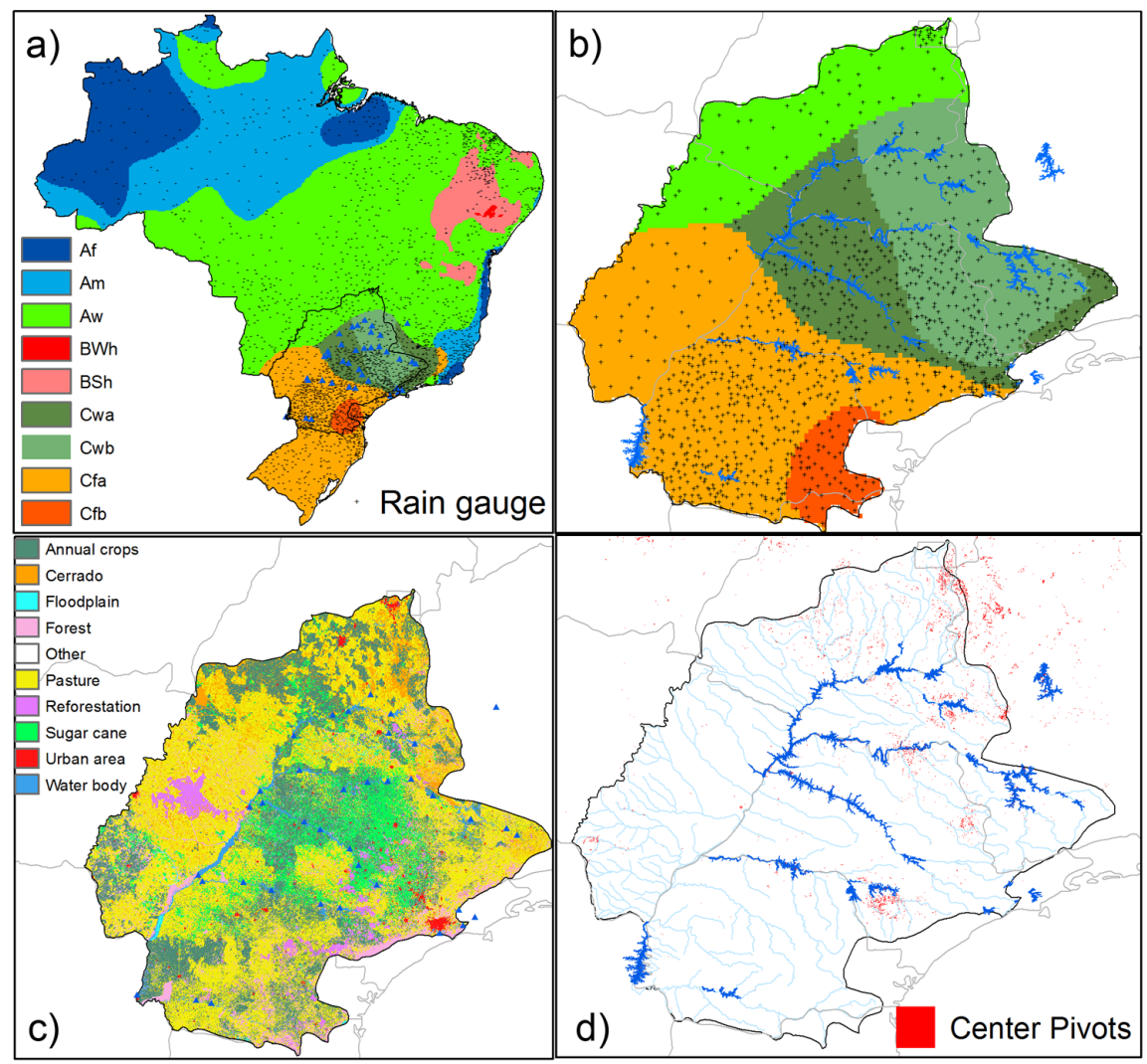

Figure S4. Updated version of Koppen-Geiger climate classification of Brazil (a) and PB (b); land use map of PB (c); map of PB and center pivots (f). Climate classification: Af: Tropical rainforest, Am: tropical monsoon, Aw: tropical wet and dry (savanna climate), BWh: hot desert, BSh: hot steppe climate (semi-arid), Cwa: humid subtropical with dry winter, Cwb: temperate highland tropical with dry winters, Cfa: humid subtropical with hot summer, $\mathrm{Cfb}$ : maritime temperate with warm summer.

The data are available for both the first version (GLDAS 1.0) and that released in 2013 (GLDAS 2.0). The main difference between these versions is the forcing datasets. In the first version, the forcing data is a (non-overlapping) combination of multiple data sets whereas GLDAS 2.0 uses the Global Meteorological Forcing Dataset from Princeton University (Sheffield et al., 2006). A newer version (GLDAS 2.1) is expected to be released in the near future. Given the time period considered in this study, only the data from GLDAS 1.0 were used. The outputs from NOAH were averaged to a $1^{\circ}$ grid to match the grid of the other LSMs. Runoff and soil moisture time series simulated by all four LSMs were extracted and averaged over the contributing basin of each reservoir, excluding the contributing area of up-stream reservoirs, when present.

\subsection{Remote sensing products and ground-based precipitation}

Tropical Rainfall Measuring Mission (TRMM) data are derived from the measurements of a Precipitation Radar (PR), Microwave imager (TMI) and Visible Infrared Scanner aboard on the satellite. TRMM Multisatellite Precipitation Analysis

5 (TMPA) rainfall estimates are based on a combination of TRMM data with high quality passive-microwave-based rain estimates from orbiting satellites calibrated by TRMM's PR and TMI (NASA, 2011). To fill in eventual remaining gaps, IR data from five geosynchronous satellites covering the tropics are used. TMPA monthly estimates were selected to complete the rainfall time series because they showed satisfactory performance (index of agreement $\approx 0.75$ ) compared to ground-based gridded data in the study area (Melo et al., 2015). 
Table S2. General information of the analyzed reservoirs

\begin{tabular}{|c|c|c|c|c|c|c|}
\hline ID & Hydroelectric Plant & Latitude & Longitude & State & Area $\left(\mathrm{km}^{2}\right)$ & $\operatorname{Vol}\left(\mathrm{hm}^{3}\right)$ \\
\hline $\mathrm{R} 1$ & Agua Vermelha & -19.86 & -50.34 & MG & 647 & 16883 \\
\hline R2 & Bariri & -22.15 & -48.75 & $\mathrm{SP}$ & 45 & 1089 \\
\hline R3 & Barra Bonita & -22.64 & -48.27 & SP & 310 & 4191 \\
\hline R4 & Billings & -23.79 & -46.57 & SP & 88 & 995 \\
\hline R5 & Cachoeira Dourada & -18.5 & -49.49 & MG & 59 & 523 \\
\hline R6 & Camargos & -21.33 & -44.62 & MG & 60 & 792 \\
\hline R37 & Cantareira System & - & - & SP & 86 & 990 \\
\hline R8 & Chavantes & -23.13 & -49.73 & SP & 363 & 8795 \\
\hline R7 & Capivara & -22.8 & -51.04 & SP & 564 & 10541 \\
\hline R9 & Corumbá I & -17.99 & -48.53 & GO & 44 & 1030 \\
\hline R10 & Emborcação & -18.44 & -47.99 & GO & 382 & 17725 \\
\hline R12 & Furnas & -20.96 & -45.85 & MG & 1203 & 22950 \\
\hline R11 & Funil & -21.16 & -44.9 & MG & 31 & 541 \\
\hline R14 & Ibitinga & -21.76 & -48.99 & SP & 92 & 981 \\
\hline R15 & Itaipu & -25.41 & -54.59 & PR & 1338 & 29000 \\
\hline R13 & Ilha Solteira & -20.38 & -51.36 & MS & 1165 & 21060 \\
\hline R16 & Itumbiara & -18.41 & -49.1 & MG & 702 & 17000 \\
\hline R17 & Jaguará & -20.02 & -47.43 & MG & 33 & 460 \\
\hline R19 & Jupiá & -20.78 & -51.63 & MS & 297 & 3353 \\
\hline R18 & Jaguari & -23.19 & -46.08 & SP & 38 & 1236 \\
\hline R20 & Jurumirim & -23.21 & -49.23 & SP & 414 & 7008 \\
\hline $\mathrm{R} 21$ & Marechal Mascarenhas de Moraes & -20.42 & -46.85 & MG & 233 & 4040 \\
\hline R22 & Marimbondo & -20.31 & -49.19 & SP & 363 & 6150 \\
\hline R23 & Miranda & -18.91 & -48.04 & MG & 46 & 1120 \\
\hline R24 & Nova Avanhandava & -21.12 & -50.2 & SP & 195 & 2775 \\
\hline $\mathrm{R} 25$ & Nova Ponte & -19.16 & -47.36 & MG & 406 & 12792 \\
\hline R27 & Paraibuna & -23.37 & -45.66 & SP & 132 & 4732 \\
\hline R26 & Porto Colômbia & -22.44 & -52.97 & MS & 128 & 2335 \\
\hline R28 & Promissão & -21.3 & -49.78 & SP & 519 & 7759 \\
\hline R29 & Rosana & -22.59 & -52.86 & SP & 196 & 1912 \\
\hline R30 & Salto Osŕio & -25.53 & -53.01 & PR & 47 & 1124 \\
\hline R31 & Salto Santiago & -25.61 & -52.62 & PR & 192 & 6756 \\
\hline R32 & Sao Simão & -19.02 & -50.5 & GO & 609 & 12540 \\
\hline R36 & Taquaraçu & -22.62 & -51.78 & SP & 85 & 674 \\
\hline R33 & Três Irmãos & -20.67 & -51.3 & SP & 651 & 13373 \\
\hline R34 & Três Marias & -18.21 & -45.26 & MG & 856 & 23778 \\
\hline $\mathrm{R} 35$ & Volta Grande & -20.09 & -48.04 & MG & 182 & 4220 \\
\hline
\end{tabular}

$\mathrm{Vol}=$ Total Volume capacity $\left(1000 \mathrm{hm}^{3}=1 \mathrm{~km}^{3}\right)$

Remotely sensed rainfall estimates $\left(P_{\text {Sat }}\right)$ were derived from TMPA 3B43 version 7 product, which merges 3B42 estimates 5 and gauge-data into a single rain product (Huffman et al. 2007). Past studies have shown satisfactory performance of TMPA rainfall estimates and, thus, it was selected to complete the rainfall series for the study period. Melo et al. (2015) compared monthly rainfall estimates from TMPA 3B42 Version 7 to a ground-based gridded rainfall and found an index of agreement $\left(d_{r}\right)$ ranging from 0.65 to 0.8 within the study area.

The ground-based gridded rainfall product interpolated by Xavier et al. (2015) uses data provided by the National Institute 10 of Meteorology (Instituto Nacional de Meteorologia - INMET), the Water and Electric Energy Department of São Paulo state (Departamento de Águas e Energia Eletrica do Estado de São Paulo - DAEE) and ANA. 
Two ET datasets were used in this study. For the period from 1995 to 2006, we used the ET data from a global ET algorithm $\left(\mathrm{ET}_{\mathrm{Glob}}\right)$ developed by Zhang et al. (2010). The $\mathrm{ET}_{\mathrm{Glob}}$ algorithm applies the Priestley-Taylor method to quantify open water evaporation and a modified Penman-Monteith method to quantify canopy transpiration and soil evaporation (Zhang et al.

2010). It uses Normalized Difference Vegetation Index (NDVI) to derive biome-specific canopy conductance values. The input data used to calculate $\mathrm{ET}_{\mathrm{Glob}}$ are daily meteorology from NCEP/NCAR (National Center for Atmospheric Research) reanalysis data, NDVI from the AVHRR (Advanced Very High Resolution Radiometer) GIMMS (Global Inventory Modelling and Mapping Studies), and solar radiation from NASA's GEWEX (Global Energy and Water Exchanges) Surface Radiation Budget Release 3.0 (Zhang et al. 2010). To parametrise the NDVI-based conductance model, measurements of 34 representative

20 FLUXNET towers of major global vegetation types were used. Then, 48 additional independent towers were used to validate the $\mathrm{ET}_{\mathrm{Glob}}$ algorithm (Zhang et al., 2010). According to Zhang et al. (2010), monthly estimates from $\mathrm{ET}_{\mathrm{Glob}}$ showed good agreement $\left(\mathrm{R}^{2}=0.8-0.84\right)$ with observed tower fluxes located in representative land cover types globally. The $\mathrm{ET}_{\mathrm{Glob}}$ outputs are available at an $8 \mathrm{~km}$ resolution grid globally.

For an overlapping period of six years (2000-2006) and the remaining period (until 2010), ET estimates based on MODIS

25 (MODerate resolution Imaging Spectroradiometer) satellite were used. The MOD16 algorithm (Mu et al., 2007, 2011) combines information of land cover, albedo LAI (Leaf Area Index), EVI (Enhanced Vegetation Index) retrieved from MODIS with daily meteorological reanalysis data from NASA's Global Modelling and Assimilation Office (GMAO) to derive 8-day ET based on Penman-Monteith equation in a regular $1 \mathrm{~km}$-horizontal resolution grid. MOD16 is an improved version of the previous ET algorithm developed by (Mu et al., 2007) in which the following improvements are highlighted by Mu et al. (2011): (i) simplification of the vegetation cover fraction calculation; (ii) ET is calculated as the sum of daytime and night-time components; (iii) a soil heat flux calculation was added; (iv) improved estimates of stomatal conductance, aerodynamic and boundary layer resistances; (v) separation between dry and wet canopy surfaces; and (vi) creation of moist and saturated wet surfaces from the previous single soil surface.

The algorithm was validated by comparing global ET estimates against measurements from 46 eddy flux towers, being found

35 mean absolute bias of daily ET of $0.33 \mathrm{~mm} \mathrm{day}^{-1}$ (Mu et al. 2011). A regional evaluation inside the Paraná basin of MOD16 ET estimates (ET $\mathrm{MOD}$ ) was reported by Ruhoff et al. (2013). Their analysis comprised a local and regional scale comparison between the remotely sensed energy fluxes and that derived from eddy covariance measurements and from a hydrological model (MGB-IPH). The flux towers are located at two sites within the Rio Grande basin in areas of sugar cane and pasture, respectively. Their findings show a good correlation (0.8) between the 8-day averaged $\mathrm{ET}_{\mathrm{MOD}}$ and flux tower data. However, the annual ET at local scale was $\approx 20 \%$ overestimated by MOD16 in the pasture area and, at basin scale, the average annual ET from MOD16 was $\approx 20 \%$ lower than those derived from the MGB-IPH model (Ruhoff et al., 2013).

\subsection{GRACE data}

The GRACE-based monthly time variable gravity (TVG) fields used in this study are the latest release (RL05), generated as spherical harmonic (SH) Stokes coefficients up to degree and order 60 released by the Center of Space Research (CSR) of the University of Texas at Austin (Bettadpur, 2012). The time span considered is from Apr 2002 through Apr 2015. Numerical model-based atmospheric and oceanic mass redistribution and tidal effects were removed for de-aliasing prior to analysis. Anomalous fields in SH format were obtained by removing a static field (GGM05S), thus GRACE TVG over land should reflect primarily changes in TWS, and other unmodeled geophysical signals such as post-glacial rebound (PGR) or tectonic mass transports.

GRACE TVG fields data are noisy, including North-South stripes and increased errors in high degree and order SH coeffi5 cients. Following the filtering method adopted by Zhang et al. (2015), we used a de-correlation filter Swenson and Wahr (2006) to suppress stripes and a fan filter (Zhang et al. 2009) with spatial resolution of $250 \mathrm{~km}$ to reduce noise. The degree 2 order 0 (C20) coefficient is replaced by higher quality satellite laser ranging solutions (Cheng et al., 2011). The post glacial rebound effect is removed using model outputs (Geruo et al., 2012). Filtered monthly TVG fields in SH format are converted to gridded $1^{\circ} \times 1^{\circ}$ solutions to match outputs from land surface models spatially. 


\subsection{Test statistics}

The non-parametric Mann-Whitney U-test (Mann and Whitney, 1947) is a common alternative to the parametric Student's t-test for testing whether two independent samples, $X$ and $Y$, are derived from the same population. It is equivalent to the Wilcoxon rank-sum test or Wilcoxon-Mann-Whitney rank-sum test and consists of calculating the statistic U (Eq. 1), which is

$U_{S}=W-\frac{N_{S}\left(N_{S}+1\right)}{2}$

where $U_{S}$ is the lesser of $U_{X}$ and $U_{Y}, W$ is the sum of the ranks in each sample, $N_{S}$ is size of sample $\mathrm{S}$ ( $X$ or $Y$ ). If the null hypothesis $\left(H_{0}\right)$ that the two samples are derived from the same population is rejected, it means that $X$ and $Y$ are statistically different from each other. Here, $X$ represents the reservoir(s) mean storage at various time scales for each water year (WY) tested and $Y$ is the mean monthly storage for the entire period less the tested one. We tested $H_{0}$ using raw monthly data, monthly moving average and seasonal mean (March-April-May) at $5 \%$ significance level.

\subsection{Trend analysis - Mann-Kendall}

As noted by Cox and Stuart (1955), time series with positive serial correlation (such as most of hydrological variables) may increase the chance of trend detection even in the absence of a real trend. To avoid this, the serial correlation should be removed (pre-whitening) prior to applying the test or the test should be modified to account for serial correlation (Hamed 2008). Although the first option has been widely adopted (Gao et al., 2011; Burn and Hag Elnur, 2002, Zhang et al., 2001), it is not suitable if the time series is not an autoregressive model AR(1) such as the analysed data here. In such cases, the pre-whitening process is insufficient (Storch. 1999). In other cases, pre-whitening cannot improve trend identification as it may weaken the magnitude of the trend (Sang et al., 2014). Hence, we adopted the modified Mann-Kendall trend test for seasonal data with serial correlation proposed by Hirsch and Slack (1984). The Mann-Kendall test statistic $(S)$ is given by:

$S=\sum_{i<j} \operatorname{sng}\left(x_{j}-x_{i}\right)$

Where $x_{i}$ are the observations of the time series $\mathrm{X} ; \operatorname{sng}(x)=-1$ if $x_{j}<x_{j} ; \operatorname{sng}(x)=0$ if $x_{j}=x_{j}$ and $\operatorname{sng}(x)=1$ if $x_{j}>x_{j}$. The significance of the trend is tested by comparing the test statistic $Z_{S}$ (Eq. 3) with a certain significance level $\alpha$ (Kendall, 1975).

$Z_{S}=\left\{\begin{array}{l}(S-1) / \sqrt{\operatorname{VAR}(S)} \text { if } S>0 \\ 0 \text { if } S=0 \\ (S+1) / \sqrt{\operatorname{VAR}(S)} \text { if } S<0\end{array}\right.$

Where, $\operatorname{Var}(\mathrm{S})$ is the variance of $S$. If $\left|Z_{S}\right|<Z_{\alpha}$, no trend was detected. In the modified version, the test is performed individually for each season (in this study, months) and $H_{0}$ is tested only if all seasons have the same direction.

\subsection{Drought indices}

5 The Standardized Precipitation Index (SPI) was selected as the meteorological drought index because it is a common choice for monitoring wet and dry conditions over a region (Vicente-Serrano and López-Moreno, 2005; Fiorillo and Guadagno, 2009). SPI uses historical rainfall data to determine, at different timescales, the periods of positive and negative anomalies in rainfall based on the cumulative probability of rainfall occurrence over an area or at point (McKee et al., 1993). The gamma probability 

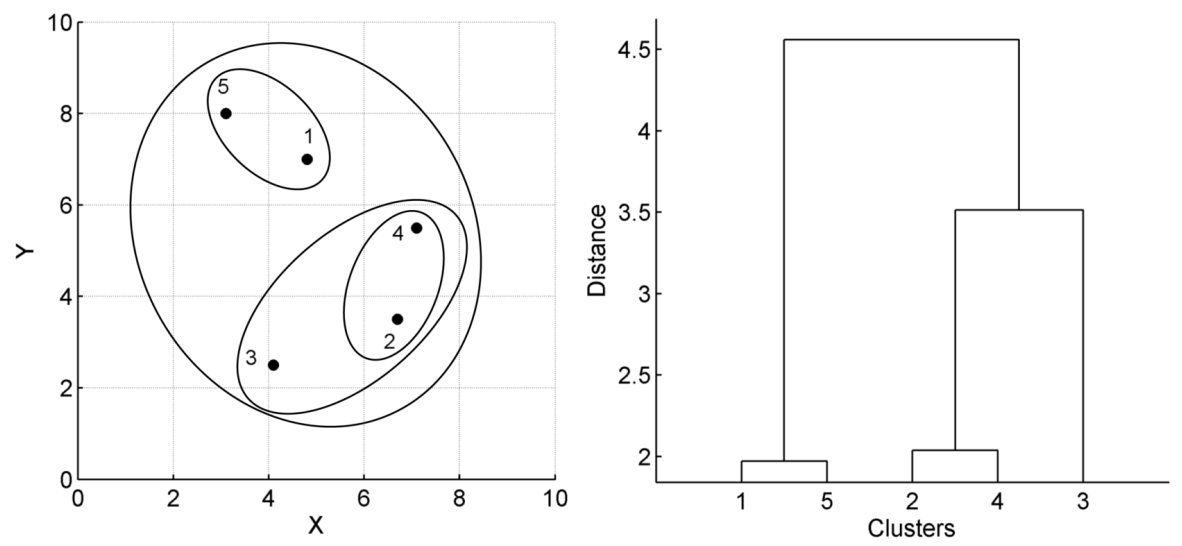

Figure S5. Example of the clustering of 5 random elements and the resulting hierarchical tree.

function is frequently selected for describing the rainfall over an area (Teodoro et al., 2015); hence, it was used in this study for fitting the rainfall data relative to a 35-year time span (1980-2015). The Streamflow Drought Index (SDI) (Nalbantis and Tsakiris, 2008) was used for characterizing hydrologic drought events in the study area. This index is analogous to SPI in that it is computationally inexpensive, easy to implement, and reduces the drought characterization to a simple severity versus frequency relationship (Nalbantis and Tsakiris, 2008). In addition, it is not data demanding as it requires only streamflow data. $\mathrm{SDI}$ is defined for each $\mathrm{i}$-th hydrological year and $\mathrm{k}$-th reference period, with $\mathrm{k}=1$ for Sep-Jan, $\mathrm{k}=2$ for Sep-Apr, $\mathrm{k}=3$ for Sep-Jul and k $=4$ for Sep-Aug.

$S D I_{i, k}=\frac{V_{i, k}-V_{k}}{\sigma_{k}}$

where $V_{i, k}=\sum_{j=1}^{3 k} Q_{i, j}$ is the cumulative streamflow volume, with $i=1,2, \ldots ; j=1,2, \ldots ; k=1,2,3,4 . \overline{V_{k}}$ and $\sigma_{k}$ are the mean and standard deviation of the cumulative streamflow volumes.

There are several reservoirs along the mainstream, which implies that the inflow to a downstream reservoir is the combination of its own (exclusive) contributing basin to and the outflow from an upstream reservoir (S4). Thus, for most of the analysed reservoirs, the SDI does not reflect solely the natural drought condition but the degree of drought condition of the observed inflow. Discharge records from the dams are available only after 1995. A SDI calculated considering a longer time period ( $\geq 30$ years) would better identify the events of hydrological drought. The reader should be aware that the results for SDI indicate the occurrence of dry periods relative to a 20-year window.

\subsection{Cluster Analysis}

Cluster analysis can be very useful for identifying distinct patterns among large samples. There are several techniques of data clustering in which distinct criteria are used to group the data, usually involving some type of similarity. An approach commonly adopted to identify similar groups among hydrological time series (Brito Neto et al. 2015; Gong and Richman 1995) is hierarchical clustering; in which the similarities among elements is measured by a distance function (Bailey, 1994).

30 The distance between pairs of elements (objects) define the first clusters of the hierarchical tree (Fig. S5). Then, the distance between clusters is computed and new clusters of higher hierarchy are formed and so on until there are only two groups. The hierarchy of the clusters can be readily represented using a dendrogram (Fig. S5), where the distance between objects (or clusters) is represented in the Y-axis.

Two decisions that need to be made to compute the clusters are: which distance function is used and which linkage criterion. In this study, Ward's method (Ward, 1963) was selected as a linkage criterion. This method uses a minimum variance algorithm 


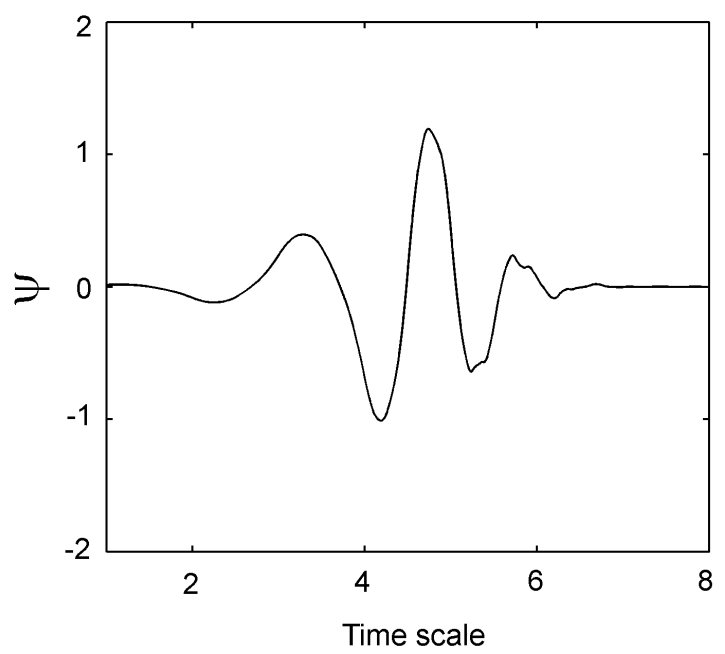

Figure S6. Daubechies wavelet with order $5(\mathrm{db} 5)$

to compute inner squared distance between two objects (a, b) (Eq. 5) (Ward, 1963). Among the distance functions available in Matlab, one popular choice that usually give good results (Ramoni et al., 2002) is the Euclidean distance $\left(\left\|\overline{x_{a}}-\overline{x_{b}}\right\|_{2}\right)$.

$d(a, b)=\sqrt{\frac{2 n_{a} n_{b}}{\left(n_{a}+n_{b}\right.}}\left\|\overline{x_{a}}-\overline{x_{b}}\right\|_{2}$

In this study, the so called objects used to generate the clusters are time series of monthly storage. Because some of these signals contain significant noise that can disrupt the clustering algorithm, it is useful to reduce the noise prior to computing the clusters. To this end, the use of a wavelet-denoising approach is a better option compared to other classical methods, such as Fourier Analysis (Chou, 2011).

The signal decomposition is achieved by applying a Discrete Wavelet Transform (DWT), which consist of a digital filtering 5 process through time-domain that allows high and low frequencies to be separated from the original signal. In this process, two complementary filters (low pass, h[.], and high pass filter, g[.]) are applied to the original signal, resulting in two signals for each level: Approximations (APP) and Details (DET). The APP contains the high-frequency components of the signal and DET the low-frequency components. The $\mathrm{h}[$.$] and \mathrm{g}[$.$] filters are the only elements necessary to calculate a DWT of a signal.$

These filters are defined according to the selected mother wavelet $(\psi)$ which, in turn, depends on the data being analysed.

10 A common choice in many hydrologic studies is the Daubechies wavelet transform (Ramana et al., 2013; Nalley et al., 2012 Wei et al. 2012) because of its ability for denoising signals and its intrinsic features that make it capable of localizing events in time-dependent signals (Popivanov and Miller, 2002) (Vonesch et al., 2007). Following the choice of past studies (Nalley] et al., 2012, Wei et al., 2012), we used the Daubechies wavelet with order $\mathrm{N}=5$ (db5) to decompose the signals (Fig. S6). Based on the number of vanishing moments $(\nu)$ of db5 and the number of data points $(n)$, the maximum decomposition level $(\mathrm{L})$ is 5 (de Artigas et al. 2006), thus, we adopted $\mathrm{L}=5$. We used the Multilevel 1-D wavelet decomposition function from the Matlab Wavelet Toolbox to perform the DWT of the signals of monthly storage time series. 
TWSA
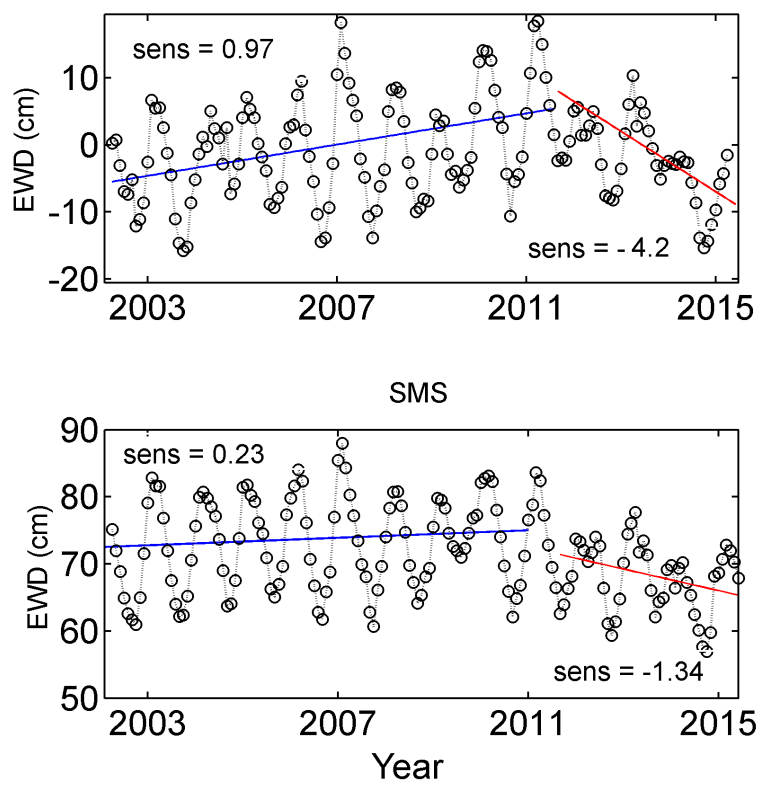

Figure S7. Trends in TWSA and SMS

\section{Results}

\subsection{Trends in GRACE Total Water Storage Anomaly (TWSA) and Soil Moisture Storage (SMS)}

The trends in GRACE TWSA and SMS are shown in Fig. S7. Between Apr 2002 and Jan 2011, GRACE TWSA shows a rapid 5 recovery $\left(0.97 \mathrm{~cm} \mathrm{yr}^{-1}\right)$ compared to that in SMS $\left(0.23 \mathrm{~cm} \mathrm{yr}^{-1}\right)$. After 2010/2011 both signals show a negative trend but GRACE TWS responds faster $\left(-4.2 \mathrm{~cm} \mathrm{yr}^{-1}\right)$ to the dry conditions than the SM signal $\left(-1.34 \mathrm{~cm} \mathrm{yr}^{-1}\right)$.

\subsection{Analysis of ET}

Analysis of ET includes verification of short-term trends (Fig. S8) and spatial changes of the mean annual ET between two selected periods (Fig. 6 in the main text).

\subsection{Trends in Reservoir Storage (RESS)}

Fig. S9 shows the positive/negative trends in total reservoir storage (RESS) during recovery/depletion periods since 1995.

\subsection{Drought propagation}

A preliminary assessment of the propagation of droughts in the Paraná basin is provided here. As mentioned in the Future research section, further analysis is necessary to characterize the drought in each component of the hydrological system;

15 hence, in the present section we analyse the propagation of the drought by means of the propagation of the negative anomalies in those components. 


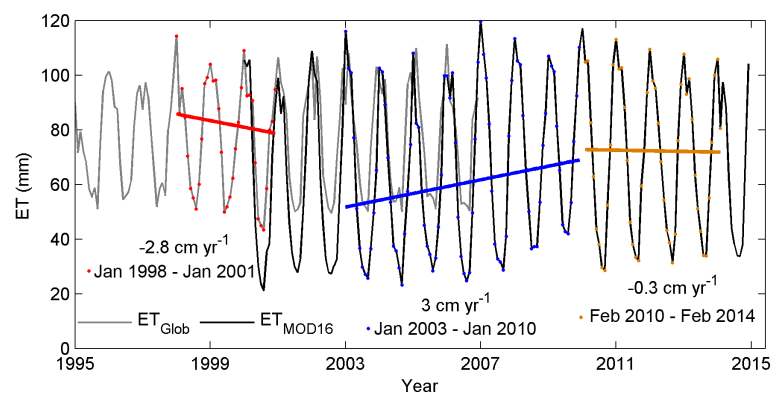

Figure S8. Trends in ET from MOD16 (Mu et al. 2011) and ET Global Evapotranspiration Algorithm by Zhang et al. (2009) for three selected periods: Jan 1998-Jan 2001 (red), Jan 2003-Jan 2010 (blue) and Feb 2010-Feb 2014 (yellow).

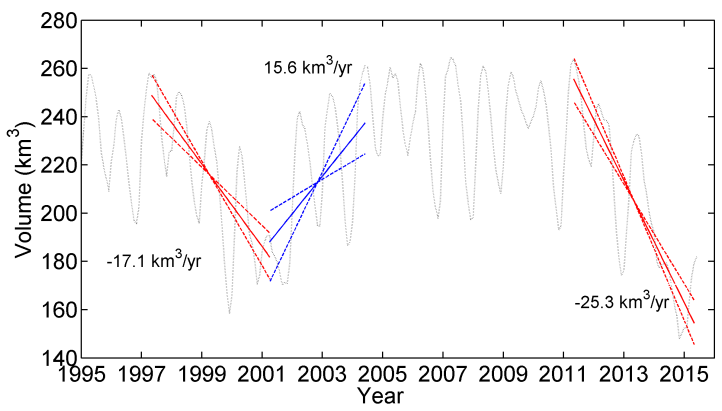

Figure S9. Trends in reservoir storage

To explore the severity of drought events, we removed the seasonal signals (annual + semi-annual) in TWSA time series and obtained the residual. A similar process was applied to SMS, RESS, rainfall and ET. Given the uncertainties in remote sensing ET, long-term trends in ET were removed further.

In the early 2000s drought, there is a progression (indicated by the grey arrow) from rainfall deficits through SMS, ET, and $R_{\text {off }}$ resulting in depletion in RESS (Fig. S10). This supports the explanation presented in Sec. 3.4 of the main text, summarized as follows: due to rainfall deficits, water storage was not replenished in the surface, reducing SMS. Because runoff results from infiltration excess or saturation excess and SMS decreased, the lack of excess resulted in reduced $R_{o f f}$. Low SMS reduced water available for vegetation transpiration, causing negative ET anomalies captured by ETGlob. Finally, the reduction in $R_{o f f}$ impacted river inflows to reservoirs, which, combined with operation aspects (Melo and Wendland, 2016), resulted in RESS depletion. Some observations can be made regarding the timing of such propagation, by taking the instant when the anomalies become negative in Fig. S10. Both SMS and $R_{o f f}$ anticipate the rainfall deficits because, as mentioned in Sec. 3.4, antecedent conditions are critical for these variables. This shows the importance of monitoring them as part of a strategy to anticipate the impacts of droughts. A qualitative analysis of SMS and $\mathrm{ET}_{\mathrm{Glob}}$ anomaly signals indicate a time lag of $\approx 1$ year before the effects of SMS depletion are noticed in the ET rates. Considering $\mathrm{ET}_{\mathrm{MOD}}$ signal, this lag is $\approx 1.5$ year.

As mentioned in Sec. 3.4, the rainy season in 2010 was insufficient to recover the water stores. As a result, SMS was already low in 2012, with negative anomaly values prior to the 2014 drought and, then, rapidly responding to the rainfall deficits during the 2014 rainy season. ET and Roff also anticipated the 2014 drought (Fig. S10). These deficits resulted in the indicated depletion in RESS and, ultimately, in total water storage, represented by the TWSA residual signal. 


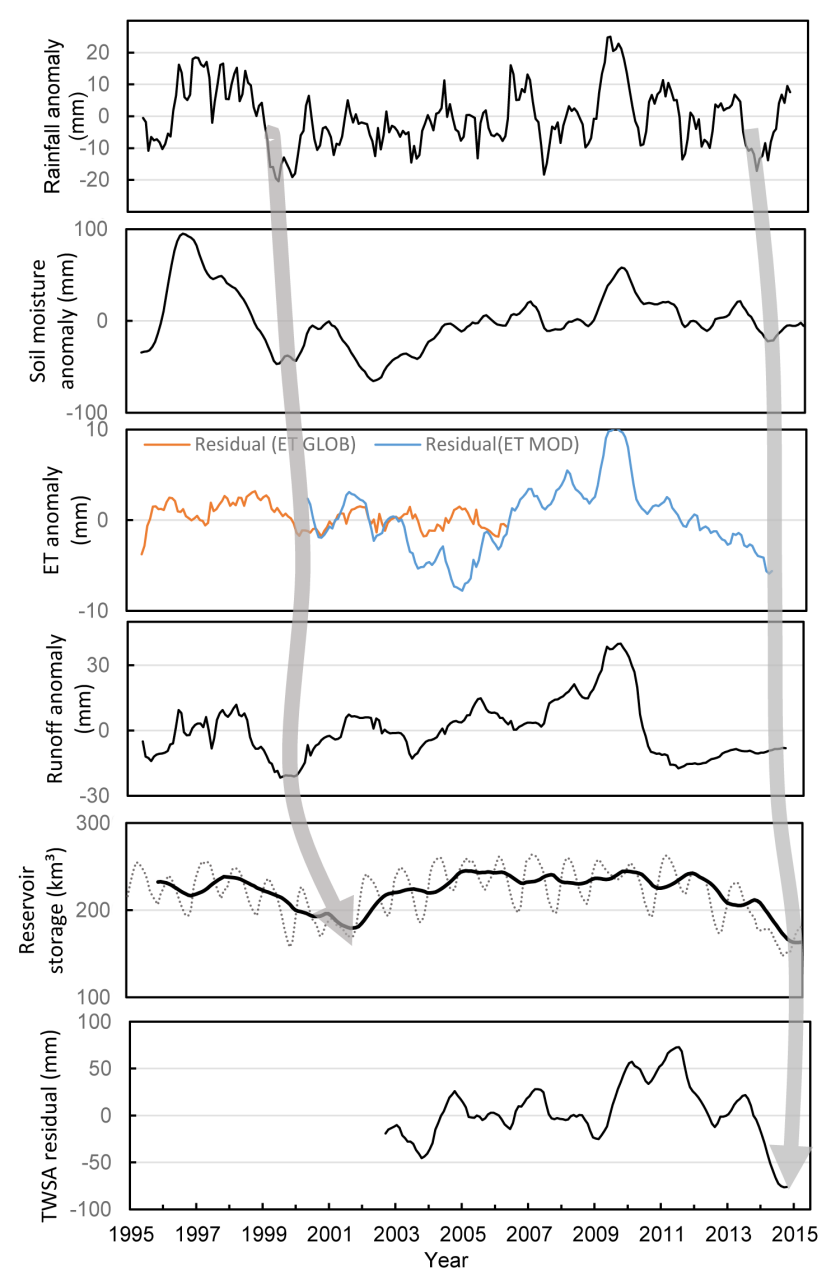

Figure S10. Time series of the Paraná basin showing the propagation of rainfall anomalies (SPI) through the components of the terrestrial hydrologic system.

\section{5.5 Depletion of the Groundwater System}

Here we seek to provide proof that the 2013/2014 drought also affected the groundwater system. Although deep soil moisture data are not available, groundwater monitoring well levels show the depletion of groundwater storage as a consequence of such drought (Fig. S11).

\subsection{Cluster analysis}

20 To determine the cluster, the user can either set a desired number of clusters or optimize this number based on link consistency. In the first option, the maximum within-cluster distance is determined in order to form a pre-defined number of cluster whereas in the second approach, the distance is gradually reduced seeking to form clusters whose links have approximately the same height as the links below it. Note that the quality of the clustering analysis depends on the data itself, that is, if the sample is too heterogeneous the distance among clusters will generally be large, reducing consistency and the feasibility of such method. In other words, some data cannot be grouped because there are not enough similarities among the samples. 


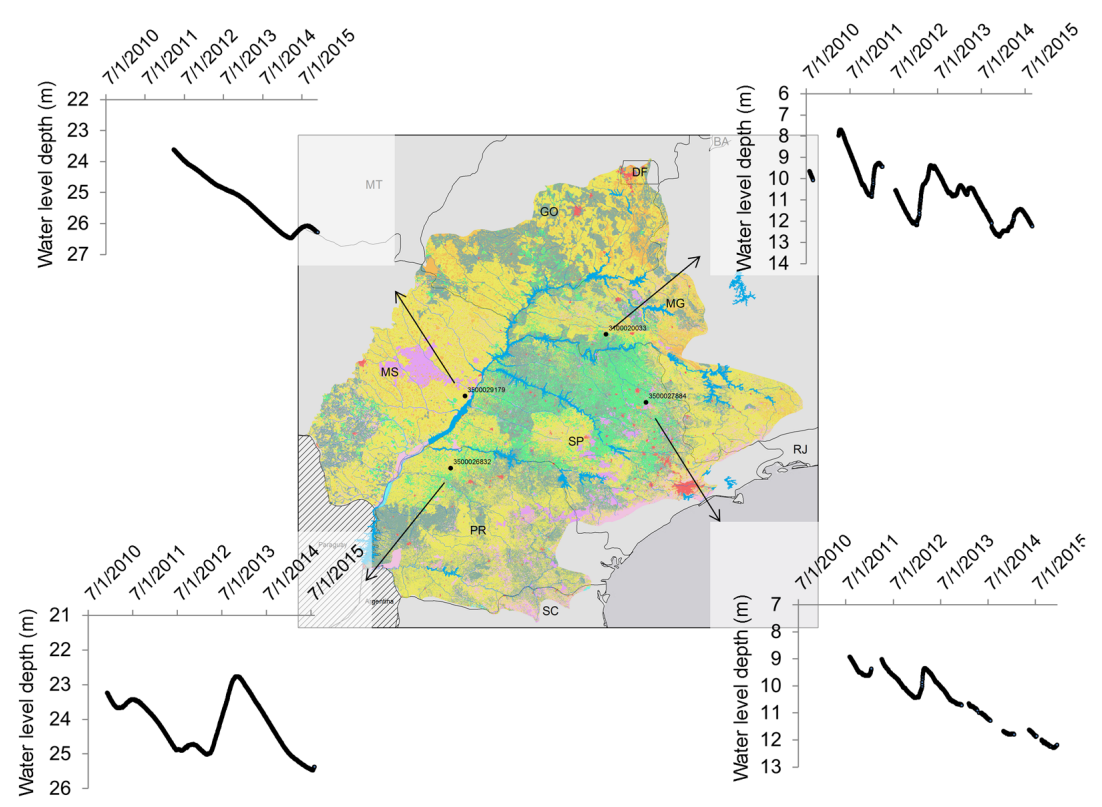

Figure S11. Groundwater hydrographs of selected wells in the Paraná Basin.

Here, the reservoirs were clustered in six groups $(\mathrm{G} 1, \mathrm{G} 2, \ldots, \mathrm{G} 6)$ based on the time series signal of monthly storage. The 5 hierarchical tree showing the groups and the linkages between them is illustrated by the dendrogram in Fig. 8 in the main text. The dendrogram illustrates how the groups relate to each other and how the maximum cluster distance (MCD) controls the definition of the groups. The two main features intended to be highlighted by creating those clusters are: seasonality and changes in time.

Although the dendrogram may suggest higher link consistency for MCD $\approx 0.5$, the similar seasonal signal characteristic of G1 would be present in the new groups formed from G1. For this reason, the configuration in Fig. ?? was maintained.

The inconvenience of such choice relies on the fact that the distance between the two main clusters in G1 (G1.1 and G1.2) is almost the same as that between G4 and G6. However, the comparison between G4 and G6 from Fig. 6 (manuscript) and G1.1 and G1.2 from Fig. $\mathrm{S} 12$ reveals that the main differences between the objects in G4 and G6 are mostly related to the timing and magnitude of changes while G1.1 and G1.2 differ in terms of sensitivity to changes. This can be exemplified by how the storage varies in the years that follow the 2000/2001 (black dashed circles) and 2013/2014 (green dashed circles) droughts. Note that after the 2013/2014, the reservoirs in G1.1 recover rapidly compared to those in G1.2.

\subsection{Spatial analysis of reservoir depletion/recovery}

Given the large extension of our study area, different responses of reservoir storage change to climatic variations are expected. In order to assess such responses to the two main droughts that occurred in the Paraná basin since 1995, we performed a trend analysis using storage data for each reservoir (Figs S13 S15, Table S3). The following periods were considered: May 1997Apr 2001, Apr 2001-Jun 2004 and May 2011-May 2015. During the first period (1997-2001), most of the reservoirs depleted, especially those with larger dimensions. Between 2001 and 2004, only a few reservoirs continued to deplete, including all of those in the Paranapanema sub-basin. Comparing Figs. S13 and S15, the greater impacts of the 2013/2014 drought became evident compared to that in 2000/2001. Between 1997 and 2001, only one reservoir had a drastic depletion of more than $75 \%$ 

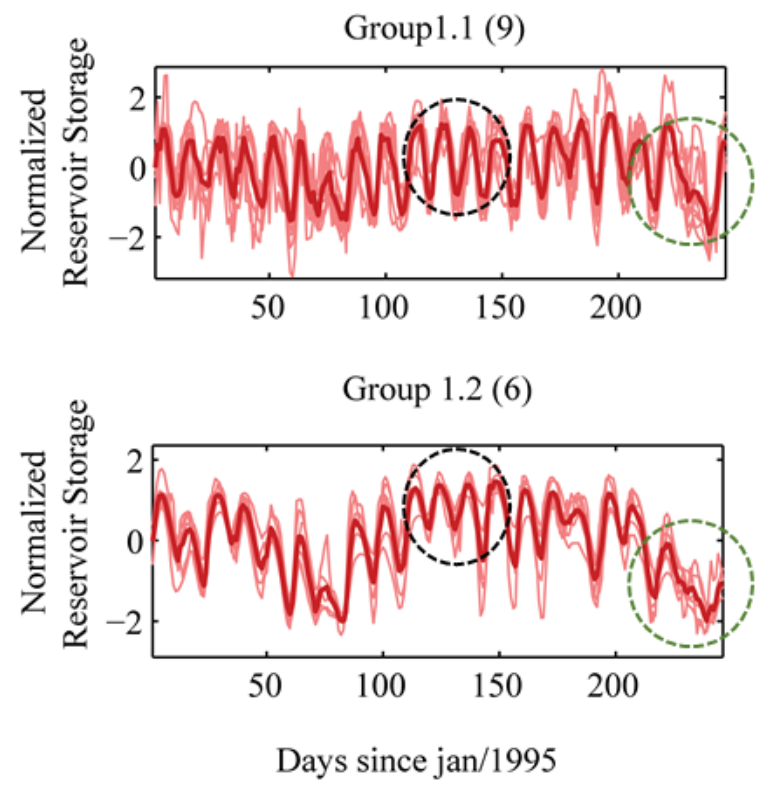

Figure S12. Subdivision of group 1 in two clusters

(red). Between 2011 and 2015, a large number of reservoirs depleted more than $50 \%$. Only one reservoir had an increase $(0-25 \%)$ of storage during that last period. 


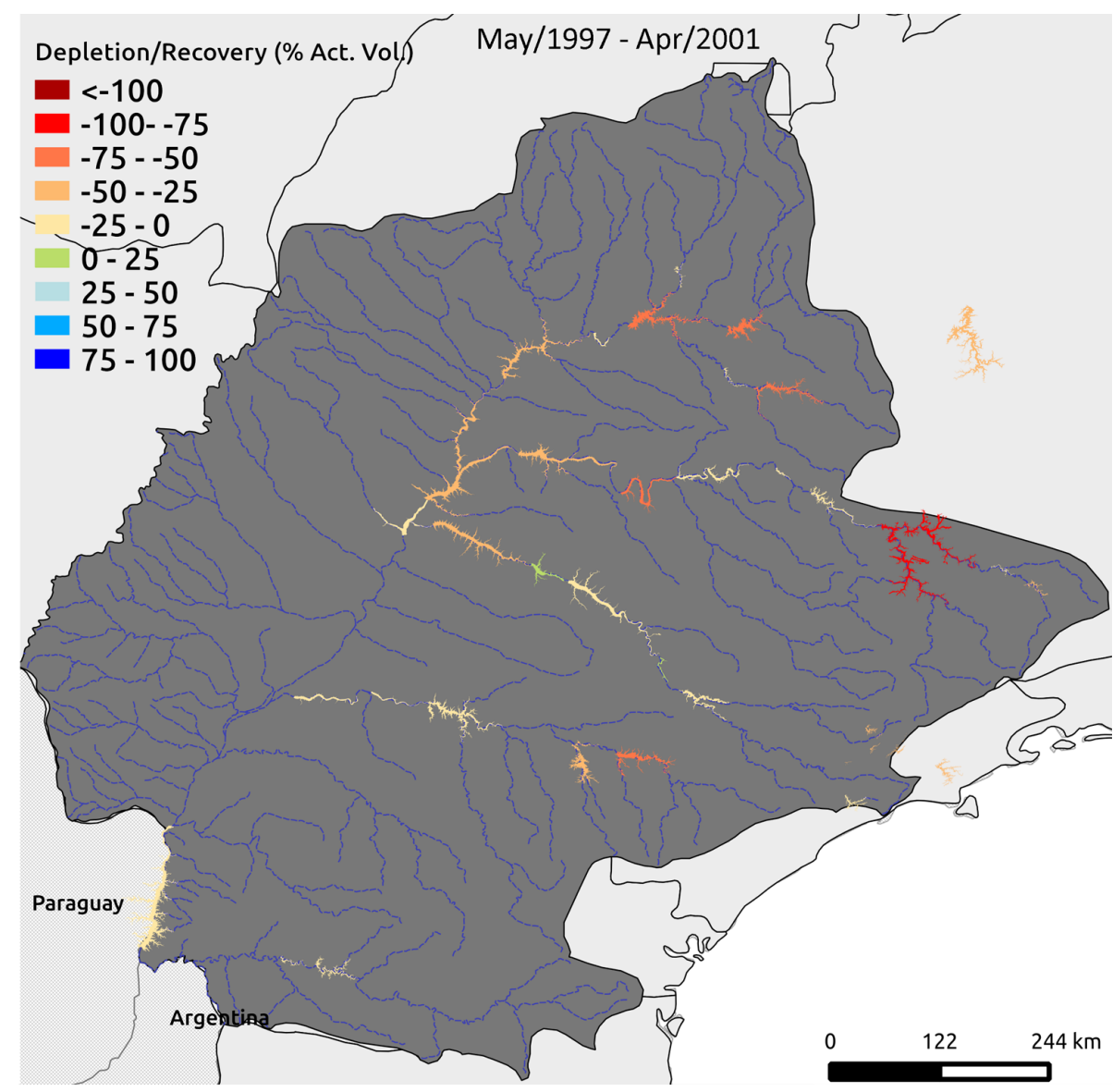

Figure S13. Trends in reservoir storage between May 1997 and Apr 2001

\section{References}

ANA: Caderno da Região Hidrográfica do Paraná, Tech. rep., Ministério do Meio Ambiente, Secretaria de Recursos Hídricos, Brasília, 2006. ANA: Atlas Brasil: abastecimento urbano de água: panorama nacional, Tech. rep., Agencia Nacional de Aguas, Brasilia, 2010.

5 Bailey, K. D.: Tipologies and taxonomies: an introduction to classification techniques, Sage University Paper series on Quantitative Applications in the Social Sciences, Thousand Oaks, CA, 1994.

Bettadpur, S.: UTCSR Level-2 Processing standards document, Tech. rep., Center for Space Research University of Texas, 2012.

Brito Neto, R. T., Santos, C. A. G., Mulligan, K., and Barbato, L.: Spatial and temporal water-level variations in the Texas portion of the Ogallala Aquifer, Natural Hazards, 80, 351-365, doi 10.1007/s11069-015-1971-8, http://dx.doi.org/10.1007/s11069-015-1971-8 2015.

10 Burn, D. H. and Hag Elnur, M. A.: Detection of hydrologic trends and variability, Journal of Hydrology, 255, 107-122, doi:10.1016/S00221694(01)00514-5, http://www.sciencedirect.com/science/article/pii/S0022169401005145, 2002.

Chen, F., Mitchell, K., Schaake, J., Xue, Y., Pan, H.-L., Koren, V., Duan, Q. Y., Ek, M., and Betts, A.: Modeling of land surface evaporation by four schemes and comparison with FIFE observations, Journal of Geophysical Research: Atmospheres, 101, 7251-7268, doi 10.1029/95JD02165, http://dx.doi.org/10.1029/95JD02165, 1996.

15 Cheng, M., Ries, J. C., and Tapley, B. D.: Variations of the Earth's figure axis from satellite laser ranging and GRACE, Journal of Geophysical Research: Solid Earth, 116, n/a-n/a, doi:10.1029/2010JB000850 http://dx.doi.org/10.1029/2010JB000850, b01409, 2011.

Chou, C.-m.: A Threshold Based Wavelet Denoising Method for Hydrological Data Modelling, Water Resources Management, 25, 1809_ 1830, doi 10.1007/s11269-011-9776-3, http://link.springer.com/article/10.1007/s11269-011-9776-3 2011. 


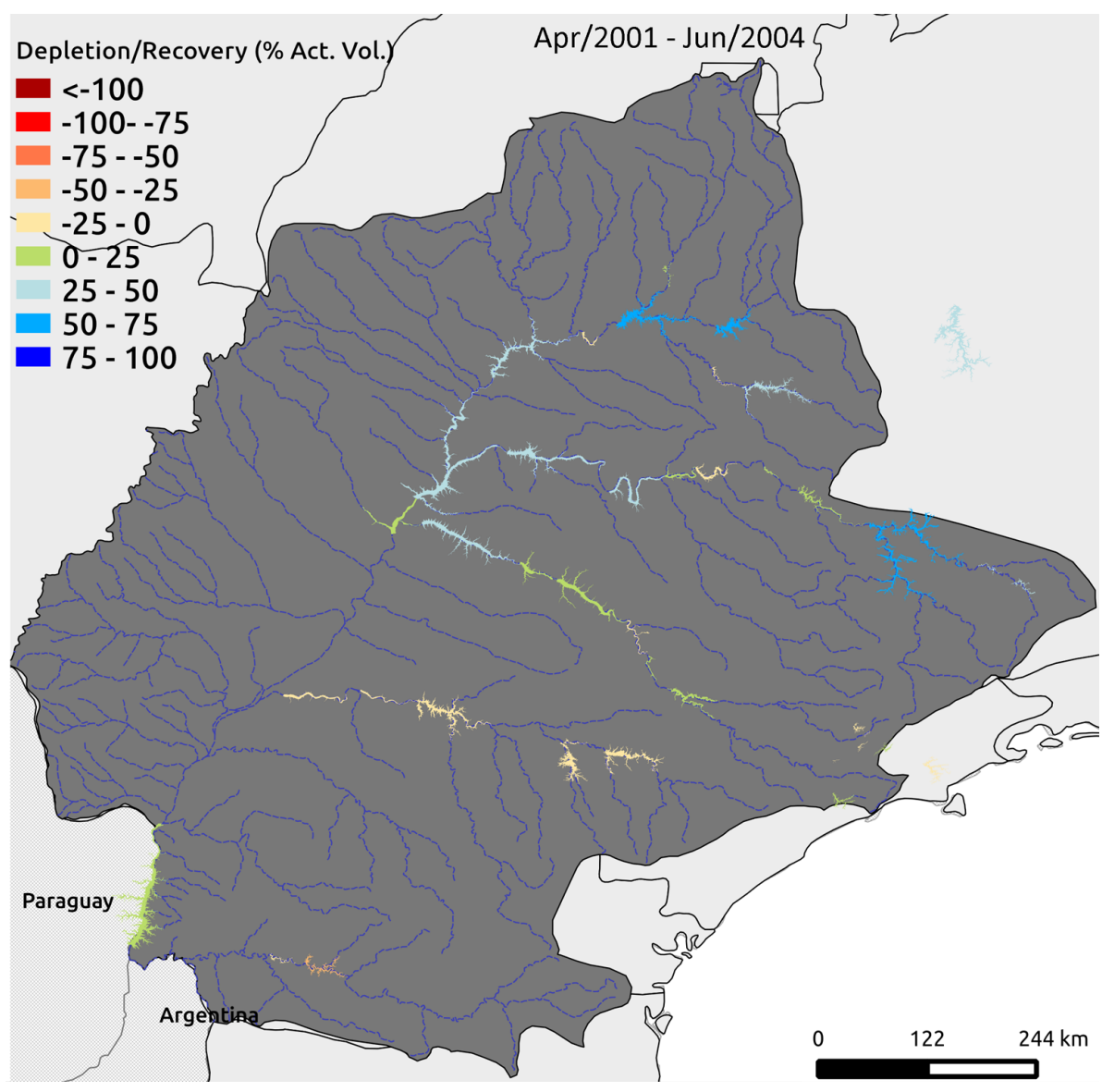

Figure S14. Trends in reservoir storage between Apr 2001 and Jun 2004

Coelho, C. A. S., Cardoso, D. H. F., and Firpo, M. A. F.: Precipitation diagnostics of an exceptionally dry event in São Paulo, Brazil, Theoretical and Applied Climatology, 125, 769-784, doi 10.1007/s00704-015-1540-9 http://dx.doi.org/10.1007/s00704-015-1540-9. 2016a.

Coelho, C. A. S., de Oliveira, C. P., Ambrizzi, T., Reboita, M. S., Carpenedo, C. B., Campos, J. L. P. S., Tomaziello, A. C. N., Pampuch, L. A., Custódio, M. d. S., Dutra, L. M. M., Da Rocha, R. P., and Rehbein, A.: The 2014 southeast Brazil austral summer drought: regional scale mechanisms and teleconnections, Climate Dynamics, 46, 3737-3752, doi 10.1007/s00382-015-2800-1, http://dx.doi.org/10.1007/ s00382-015-2800-1, 2016b.

25 Coutinho, R. M., Kraenkel, R. A., and Prado, P. I.: Catastrophic Regime Shift in Water Reservoirs and São Paulo Water Supply Crisis, PLoS ONE, 10, e0138 278, doi 10.1371/journal.pone.0138278 http://dx.doi.org/10.1371/journal.pone.0138278 2015.

Cox, D. R. and Stuart, A.: Some Quick Sign Tests for Trend in Location and Dispersion, Biometrika, 42, 80-95, doi 10.2307/2333424 http://www.jstor.org/stable/2333424, 1955.

Dai, Y., Zeng, X., Dickinson, R. E., Baker, I., Bonan, G. B., Bosilovich, M. G., Denning, A. S., Dirmeyer, P. A., Houser, P. R., Niu, G., Oleson, K. W., Schlosser, C. A., and Yang, Z.-L.: The Common Land Model, Bulletin of the American Meteorological Society, 84, 1013-1023, doi 10.1175/BAMS-84-8-1013 http://dx.doi.org/10.1175/BAMS-84-8-1013, 2003.

de Artigas, M. Z., Elias, A. G., and de Campra, P. F.: Discrete wavelet analysis to assess long-term trends in geomagnetic activity, Physics and Chemistry of the Earth, Parts A/B/C, 31, 77-80, doi 10.1016/j.pce.2005.03.009, http://www.sciencedirect.com/science/article/pii/ S147470650600012X, 2006. 


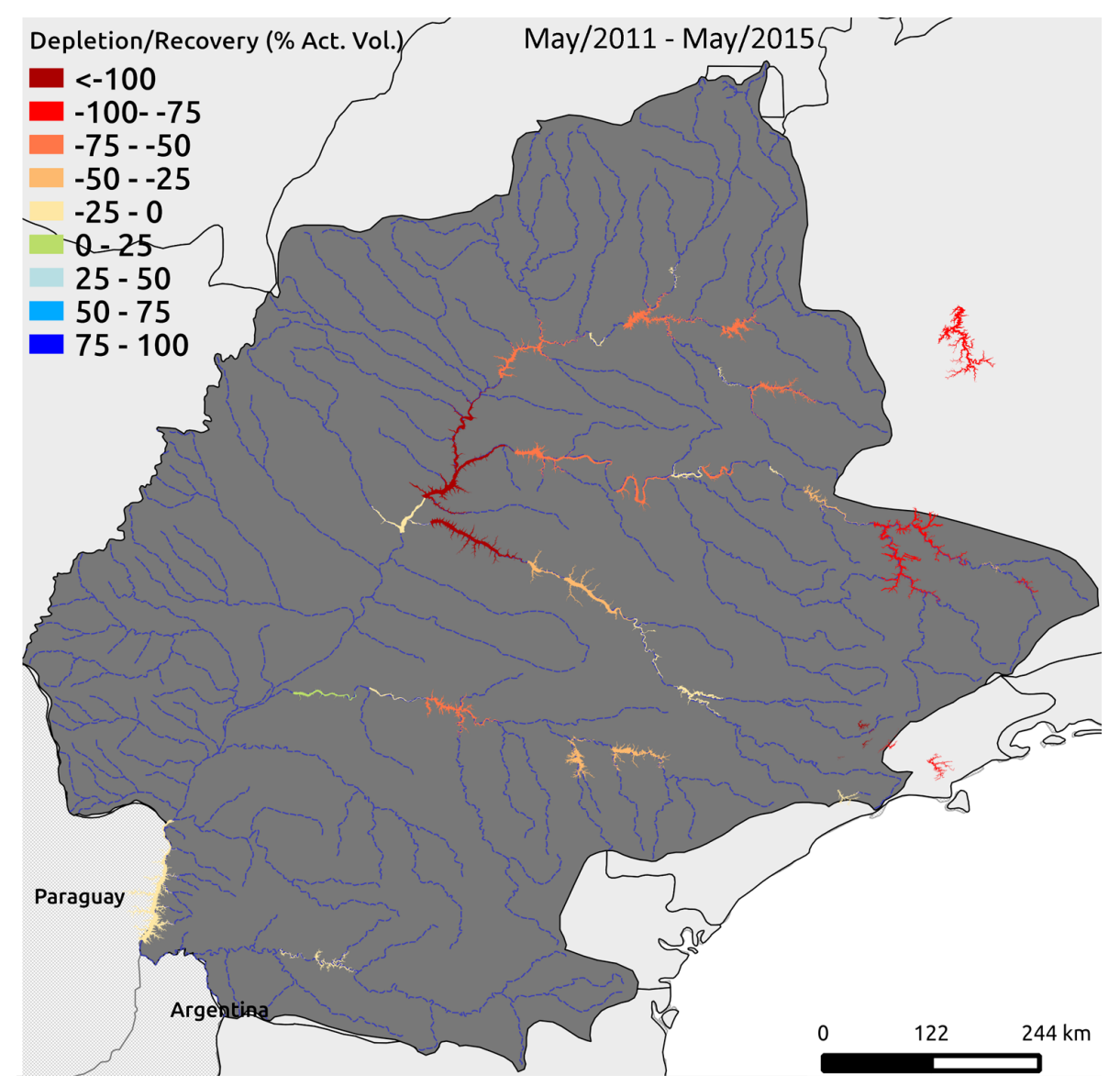

Figure S15. Trends in reservoir storage between May 2011 and M 2015

10 Derber, J. C., Parrish, D. F., and Lord, S. J.: The New Global Operational Analysis System at the National Meteorological Center, Weather 1] and Forecasting, 6, 538-547, doi 10.1175/1520-0434(1991)006<0538:TNGOAS>2.0.CO;2. http://dx.doi.org/10.1175/1520-0434(1991) 006<0538:TNGOAS>2.0.CO;2, 1991.

Ek, M. B., Mitchell, K. E., Lin, Y., Rogers, E., Grunmann, P., Koren, V., Gayno, G., and Tarpley, J. D.: Implementation of Noah land surface model advances in the National Centers for Environmental Prediction operational mesoscale Eta model, Journal of Geophysical Research, 108, 8851, 2003.

Fiorillo, F. and Guadagno, F. M.: Karst Spring Discharges Analysis in Relation to Drought Periods Using the SPI, Water Resources Management, 24, 1867-1884, doi 10.1007/s11269-009-9528-9. http://link.springer.com/article/10.1007/s11269-009-9528-9 2009.

Gao, P., Mu, X.-M., Wang, F., and Li, R.: Changes in streamflow and sediment discharge and the response to human activities in the middle reaches of the Yellow River, Hydrol. Earth Syst. Sci., 15, 1-10, doi 10.5194/hess-15-1-2011, http://www.hydrol-earth-syst-sci.net/15/1/ 2011/. 2011.

5 Geruo, A., Wahr, J., and Zhong, S.: Computations of the viscoelastic response of a 3-D compressible Earth to surface loading: an apn plication to Glacial Isostatic Adjustment in Antarctica and Canada, Geophysical Journal International, doi 10.1093/gji/ggs030, http: //gji.oxfordjournals.org/content/early/2012/11/16/gji.ggs030.abstract 2012.

Getirana, A. C. V.: Extreme water deficit in Brazil detected from space, Journal of Hydrometeorology, 17, 591-599, doi 10.1175/JHM-D15-0096.1, http://journals.ametsoc.org/doi/abs/10.1175/JHM-D-15-0096.1, 2015.

10 Gong, X. and Richman, M. B.: On the Application of Cluster Analysis to Growing Season Precipitation Data in North America East of the

1. Rockies, Journal of Climate, 8, 897-931, doi 10.1175/1520-0442(1995)008<0897:OTAOCA>2.0.CO;2 http://journals.ametsoc.org/doi/ abs/10.1175/1520-0442(1995)008\%3C0897\%3AOTAOCA\%3E2.0.CO\%3B2, 1995. 
Table S3. Summary of individual trend analysis of reservoir storage change

\begin{tabular}{|c|c|c|c|c|c|c|c|c|c|c|c|c|c|}
\hline \multirow[b]{2}{*}{ Group } & \multirow[b]{2}{*}{ ID } & \multirow[b]{2}{*}{ Name } & \multirow{2}{*}{$\begin{array}{l}\text { Active Volume } \\
\text { Capacity }\left(\mathrm{km}^{3}\right)\end{array}$} & \multirow{2}{*}{$\begin{array}{l}\text { \% Total } \\
\text { Capacity }\end{array}$} & \multicolumn{3}{|c|}{ Depletion/Recovery (km3) } & \multicolumn{6}{|c|}{ Depletion/Recovery (\% Act. Vol) } \\
\hline & & & & & May/97-Apr/01 & Apr/01 -Jun/04 & May/11-Apr/15 & & y/97-Apr/01 & Apr & $01-J u n / 04$ & $\mathrm{Ma}$ & //11-Apr/15 \\
\hline \multirow{15}{*}{1} & R1 & Água Vermelha & 11.02 & $65 \%$ & -5.30 & 3.30 & -6.88 & $\nabla$ & $-48 \%$ & $\Delta$ & $30 \%$ & $\nabla$ & $-62 \%$ \\
\hline & R3 & Barra Bonita & 3.62 & $86 \%$ & -0.06 & 0.47 & -0.33 & $\square$ & $-2 \%$ & $\square$ & $13 \%$ & $\square$ & $-9 \%$ \\
\hline & $\mathrm{R} 4$ & Billings & 0.99 & - & & 0.06 & -0.17 & & & $\square$ & $6 \%$ & $\square$ & $-17 \%$ \\
\hline & R6 & Camargos & 0.67 & $85 \%$ & -0.23 & 0.18 & -0.56 & $\nabla$ & $-34 \%$ & $\Delta$ & $27 \%$ & $\nabla$ & $-84 \%$ \\
\hline & R9 & Corumbá I & 0.56 & $54 \%$ & -0.13 & 0.02 & -0.05 & $\nabla$ & $-23 \%$ & $\square$ & $4 \%$ & $\square$ & $-8 \%$ \\
\hline & $\mathrm{R} 10$ & Emborcação & 13.06 & $74 \%$ & -8.44 & 8.98 & -7.18 & $\nabla$ & $-65 \%$ & $\Delta$ & $69 \%$ & $\nabla$ & $-55 \%$ \\
\hline & R11 & Funil & 0.26 & $48 \%$ & -0.03 & 0.10 & -0.11 & $\square$ & $-11 \%$ & $\triangle$ & $40 \%$ & $\nabla$ & $-41 \%$ \\
\hline & $\mathrm{R} 12$ & Furnas & 17.22 & $75 \%$ & -13.01 & 11.78 & -14.29 & $\nabla$ & $-76 \%$ & $\Delta$ & $68 \%$ & $\nabla$ & $-83 \%$ \\
\hline & R16 & Itumbiara & 12.45 & $73 \%$ & -8.03 & 8.21 & -6.68 & $\nabla$ & $-64 \%$ & $\Delta$ & $66 \%$ & $\nabla$ & $-54 \%$ \\
\hline & $\mathrm{R} 22$ & Marimbondo & 5.26 & $86 \%$ & -3.05 & 1.76 & -3.16 & $\nabla$ & $-58 \%$ & $\Delta$ & $34 \%$ & $\nabla$ & $-60 \%$ \\
\hline & $\mathrm{R} 25$ & Nova Ponte & 10.38 & $81 \%$ & -7.35 & 4.66 & -7.39 & $\nabla$ & $-71 \%$ & $\Delta$ & $45 \%$ & $\nabla$ & $-71 \%$ \\
\hline & $\mathrm{R} 26$ & Porto Colômbia & 1.52 & $65 \%$ & 0.00 & 0.33 & -0.30 & $\square$ & $0 \%$ & $\Delta$ & $22 \%$ & $\nabla$ & $-20 \%$ \\
\hline & $\mathrm{R} 28$ & Promissão & 2.48 & $32 \%$ & -0.45 & 0.24 & -1.09 & $\square$ & $-18 \%$ & $\square$ & $10 \%$ & $\nabla$ & $-44 \%$ \\
\hline & $\mathrm{R} 32$ & São Simão & 5.54 & $44 \%$ & -1.59 & 2.54 & -3.35 & $\nabla$ & $-29 \%$ & $\Delta$ & $46 \%$ & $\nabla$ & $-60 \%$ \\
\hline & R34 & Três Marias & 19.53 & $82 \%$ & -8.98 & 5.15 & -18.90 & $\nabla$ & $-46 \%$ & $\Delta$ & $26 \%$ & $\nabla$ & $-97 \%$ \\
\hline \multirow{5}{*}{2} & $\mathrm{R} 2$ & Bariri & 0.61 & $56 \%$ & 0.02 & 0.01 & -0.06 & $\square$ & $4 \%$ & $\square$ & $1 \%$ & $\square$ & $-10 \%$ \\
\hline & R14 & Ibitinga & 0.05 & $5 \%$ & 0.00 & 0.00 & -0.01 & $\square$ & $10 \%$ & $\square$ & $-2 \%$ & $\nabla$ & $-29 \%$ \\
\hline & R17 & Jaguará & 0.10 & $22 \%$ & -0.02 & 0.02 & 0.00 & $\nabla$ & $-24 \%$ & $\square$ & $16 \%$ & $\square$ & $-4 \%$ \\
\hline & R19 & Jupiá & 0.90 & $27 \%$ & -0.01 & 0.04 & 0.00 & $\square$ & $-1 \%$ & $\square$ & $5 \%$ & $\square$ & $0 \%$ \\
\hline & R35 & Volta Grande & 2.24 & $53 \%$ & -0.24 & 0.50 & 0.02 & $\square$ & $-11 \%$ & $\Delta$ & $22 \%$ & $\square$ & $1 \%$ \\
\hline \multirow{4}{*}{3} & R7 & Capivara & 5.72 & $54 \%$ & -1.24 & -1.00 & -2.91 & $\nabla$ & $-22 \%$ & $\square$ & $-18 \%$ & $\nabla$ & $-51 \%$ \\
\hline & $\mathrm{R} 8$ & Chavantes & 3.04 & $35 \%$ & -1.36 & -0.63 & -1.49 & $\nabla$ & $-45 \%$ & $\nabla$ & $-21 \%$ & $\nabla$ & $-49 \%$ \\
\hline & $\mathrm{R} 20$ & Jurumirim & 3.16 & $45 \%$ & -1.87 & -0.17 & -1.48 & $\nabla$ & $-59 \%$ & $\square$ & $-5 \%$ & $\nabla$ & $-47 \%$ \\
\hline & R31 & Salto Santiago & 4.09 & $61 \%$ & -0.63 & -1.81 & -0.39 & $\square$ & $-15 \%$ & $\nabla$ & $-44 \%$ & $\square$ & $-10 \%$ \\
\hline \multirow{6}{*}{4} & R13 & Ilha Solteira & 5.52 & $26 \%$ & -2.32 & 2.33 & -7.69 & $\nabla$ & $-42 \%$ & $\Delta$ & $42 \%$ & $\nabla$ & $-139 \%$ \\
\hline & R15 & Itaipú & 19.00 & $66 \%$ & -0.51 & 0.34 & -3.81 & $\square$ & $-3 \%$ & $\square$ & $2 \%$ & $\nabla$ & $-20 \%$ \\
\hline & $\mathrm{R} 21$ & M. M. Moraes & 2.50 & $62 \%$ & -0.41 & 0.58 & -0.78 & $\square$ & $-16 \%$ & $\Delta$ & $23 \%$ & $\nabla$ & $-31 \%$ \\
\hline & R24 & N. Avanhandava & 0.43 & $15 \%$ & 0.02 & 0.03 & -0.16 & $\square$ & $4 \%$ & $\square$ & $8 \%$ & $\nabla$ & $-36 \%$ \\
\hline & R30 & Salto Osório & 0.40 & $36 \%$ & -0.02 & 0.00 & -0.01 & $\square$ & $-5 \%$ & $\square$ & $1 \%$ & $\square$ & $-2 \%$ \\
\hline & R33 & Três Irmãos & 3.45 & $26 \%$ & -1.35 & 1.27 & -4.32 & $\nabla$ & $-39 \%$ & $\Delta$ & $37 \%$ & $\nabla$ & $-125 \%$ \\
\hline \multirow{4}{*}{5} & R5 & Cachoeira Dourada & 0.22 & $42 \%$ & & -0.05 & -0.01 & & & $\nabla$ & $-24 \%$ & $\square$ & $-5 \%$ \\
\hline & $\mathrm{R} 23$ & Miranda & 0.14 & $13 \%$ & 0.00 & -0.02 & -0.01 & & & $\square$ & $-12 \%$ & $\square$ & $-4 \%$ \\
\hline & R29 & Rosana & 0.41 & $21 \%$ & -0.01 & -0.03 & 0.03 & $\square$ & $-4 \%$ & $\square$ & $-6 \%$ & $\square$ & $6 \%$ \\
\hline & R36 & Taquaraçu & 0.13 & $19 \%$ & 0.00 & 0.00 & 0.00 & $\square$ & $-3 \%$ & $\square$ & $-2 \%$ & $\square$ & $-1 \%$ \\
\hline \multirow{3}{*}{6} & R18 & Jaguari & 0.79 & $64 \%$ & -0.27 & 0.04 & -0.76 & $\nabla$ & $-34 \%$ & $\square$ & $5 \%$ & $\nabla$ & $-96 \%$ \\
\hline & R27 & Paraibuna & 2.63 & $56 \%$ & -1.06 & -0.13 & -2.29 & $\nabla$ & $-40 \%$ & $\square$ & $-5 \%$ & $\nabla$ & $-87 \%$ \\
\hline & R37 & Cantareira Syst. & 0.99 & - & -0.31 & -0.18 & -1.15 & $\nabla$ & $-31 \%$ & $\square$ & $-18 \%$ & $\nabla$ & $-116 \%$ \\
\hline
\end{tabular}

Hamed, K. H.: Trend detection in hydrologic data: The Mann-Kendall trend test under the scaling hypothesis, Journal of Hydrology, 349, 350-363, doi 10.1016/j.jhydrol.2007.11.009 http://www.sciencedirect.com/science/article/pii/S0022169407006865. 2008.

15 Helmer, M. and Hilhorst, D.: Natural disasters and climate change, Disasters, 30, 1-4, doi 10.1111/j.1467-9523.2006.00302.x. http://dx.doi. org/10.1111/j.1467-9523.2006.00302.x 2006.

Hirsch, R. M. and Slack, J. R.: A non parametric trend test for seasonal data with serial correlation, Water Resources Research, 20, 727-732, 1984.

Huffman, G. J., Adler, R. F., Bolvin, D. T., Gu, G., Nelkin, E. J., Bowman, K. P., Hong, Y., Stocker, E. F., and Wolff, D. B.: The TRMM Multi-satellite Precipitation Analysis: Quasi-Global, Multi-Year, Combined-Sensor Precipitation Estimates at Fine Scale, J. Hydrometeor, 8, 38-55, 2007.

5 Koster, R. and Suarez, M.: Energy and water balance calculations in the Mosaic LSM, Tech. Memo 9, NASA, 1996.

Liang, X., Lettenmaier, D. P., Wood, E. F., and Burges, S. J.: A simple hydrologically based model of land surface water and energy ๓ fluxes for general circulation models, Journal of Geophysical Research: Atmospheres, 99, 14 415-14 428, doi 10.1029/94JD00483, http: //dx.doi.org/10.1029/94JD00483. 1994. 
Lima, C. H. and Lall, U.: Climate informed monthly streamflow forecasts for the Brazilian hydropower network using a periodic ridge regression model, Journal of Hydrology, 380, 438 - 449, doi:http://dx.doi.org/10.1016/j.jhydrol.2009.11.016, http://www.sciencedirect. com/science/article/pii/S0022169409007252, 2010.

Mann, H. B. and Whitney, D. R.: On a Test of Whether one of Two Random Variables is Stochastically Larger than the Other, The Annals of Mathematical Statistics, 18, 50-60, http://www.jstor.org/stable/2236101. 1947.

McKee, T. B., Doesken, N. J., and Kleist, J.: Drought Monitoring with Multiple Time Scales, in: 9th AMS Conference on Applied Climatology, pp. 233-236, 1993.

Melo, D. d. C. D. and Wendland, E.: Hydrological system time lag responses to meteorological shifts, Brazilian Journal of Water Resources, 21, http://www.scielo.br/scielo.php?script=sci_arttext\&pid=S2318-03312016005001107\&nrm=iso 2016.

Melo, D. d. C. D., Xavier, A. C., Bianchi, T., Oliveira, P. T. S., Scanlon, B. R., Lucas, M. C., and Wendland, E.: Performance evaluation of rainfall estimates by TRMM Multi-satellite Precipitation Analysis 3B42V6 and V7 over Brazil, Journal of Geophysical Research: Atmospheres, 120, 2015JD023 797, doi 10.1002/2015JD023797. http://onlinelibrary.wiley.com/doi/10.1002/2015JD023797/abstract 2015.

5 Mesinger, F., Chou, S. C., Gomes, J. L., Jovic, D., Bastos, P., Bustamante, J. F., Lazic, L., Lyra, A. A., Morelli, S., Ristic, I., and Veljovic,

K.: An upgraded version of the Eta model, Meteorology and Atmospheric Physics, 116, 63-79, doi 10.1007/s00703-012-0182-z, http: //dx.doi.org/10.1007/s00703-012-0182-z, 2012.

Mu, Q., Heinsch, F. A., Zhao, M., and Running, S. W.: Development of a global evapotranspiration algorithm based on \{MODIS $\}$ and

global meteorology data, Remote Sensing of Environment, 111, 519 - 536, doi http://dx.doi.org/10.1016/j.rse.2007.04.015. http://www. sciencedirect.com/science/article/pii/S0034425707001903, 2007.

Mu, Q., Zhao, M., and Running, S. W.: Improvements to a MODIS global terrestrial evapotranspiration algorithm, Remote Sensing of Environment, 115, 1781-1800, doi:10.1016/j.rse.2011.02.019 http://www.sciencedirect.com/science/article/pii/S0034425711000691, 2011.

Nalbantis, I. and Tsakiris, G.: Assessment of Hydrological Drought Revisited, Water Resources Management, 23, 881-897, doi 10.1007/s11269-008-9305-1, http://link.springer.com/article/10.1007/s11269-008-9305-1 2008.

15 Nalley, D., Adamowski, J., and Khalil, B.: Using discrete wavelet transforms to analyze trends in streamflow and precipitation in Quebec and

n Ontario (1954-2008), Journal of Hydrology, 475, 204-228, doi 10.1016/j.jhydrol.2012.09.049. http://www.sciencedirect.com/science/ article/pii/S0022169412008669 2012.

NASA: Tropical Rainfall Measuring Mission, TRMM, senior review proposal, Tech. rep., National Aeronautics and Space Administration, http://pmm.nasa.gov/sites/default/files/document_files/TRMMSenRevProp_v1.2.pdf. 2011.

20 ONS: Diretrizes para a Operação Eletroenergética [Guidelines for eletroenergetic operations], http://www.ons.org.br/operacao/diretrizes_ operacao 2016.

Popivanov, I. and Miller, R.: Similarity search over time-series data using wavelets, in: 18th International Conference on Data Engineering, 2002. Proceedings, pp. 212-221, doi 10.1109/ICDE.2002.994711, 2002.

Ramana, R. V., Krishna, B., Kumar, S. R., and Pandey, N. G.: Monthly Rainfall Prediction Using Wavelet Neural Network Analysis, Water Resources Management, 27, 3697-3711, doi 10.1007/s11269-013-0374-4, http://link.springer.com/article/10.1007/s11269-013-0374-4 2013.

Ramoni, M. F., Sebastiani, P., and Kohane, I. S.: Cluster analysis of gene expression dynamics, Proceedings of the National Academy of Sciences, 99, 9121-9126, doi 10.1073/pnas.132656399. http://www.pnas.org/content/99/14/9121, 2002.

Rodell, M., Houser, P. R., Jambor, U., Gottschalck, J., Mitchell, K., Meng, C.-J., Arsenault, K., Cosgrove, B., Radakovich, J., Bosilovich, M., Entin*, J. K., Walker, J. P., Lohmann, D., and Toll, D.: The Global Land Data Assimilation System, Bulletin of the American Meteorological Society, 85, 381-394, doi:10.1175/BAMS-85-3-381. http://journals.ametsoc.org/doi/abs/10.1175/BAMS-85-3-381, 2004.

Ruhoff, A. L., Paz, A. R., Aragao, L. E. O. C., Mu, Q., Malhi, Y., Collischonn, W., Rocha, H. R., and Running, S. W.: Assessment of the MODIS global evapotranspiration algorithm using eddy covariance measurements and hydrological modelling in the Rio Grande basin, Hydrological Sciences Journal, 58, 1658-1676, doi 10.1080/02626667.2013.837578 http://dx.doi.org/10.1080/02626667.2013.837578 2013.

Sang, Y.-F., Wang, Z., and Liu, C.: Comparison of the MK test and EMD method for trend identification in hydrological time series, Journal of Hydrology, 510, 293-298, doi:10.1016/j.jhydrol.2013.12.039. http://www.sciencedirect.com/science/article/pii/S0022169413009360 2014.

Storch, H.: Analysis of Climate Variability: Applications of Statistical Techniques Proceedings of an Autumn School Organized by the Commission of the European Community on Elba from October 30 to November 6, 1993, chap. Misuses of Statistical Analysis in Cli-

1. mate Research, pp. 11-26, Springer Berlin Heidelberg, Berlin, Heidelberg, doi:10.1007/978-3-662-03744-7_2 http://dx.doi.org/10.1007/ 978-3-662-03744-7_2. 1999.

Swenson, S. and Wahr, J.: Post-processing removal of correlated errors in GRACE data, Geophysical Research Letters, 33, n/a-n/a, doi 10.1029/2005GL025285 http://dx.doi.org/10.1029/2005GL025285 108402, 2006. 
Teodoro, P. E., Correa, C. C. G., Torres, F. E., de Oliveira-Junior, J. F., da Silva Junior, C. A., Gois, G., and Delgado, R. C.: Analysis of the Occurrence of Wet and Drought Periods Using Standardized Precipitation Index in Mato Grosso do Sul State, Brazil, Journal of Agronomy, 14, 80-86, doi:10.3923/ja.2015.80.86, 2015.

Vicente-Serrano, S. M. and López-Moreno, J. I.: Hydrological response to different time scales of climatological drought: an evaluation of the Standardized Precipitation Index in a mountainous Mediterranean basin, Hydrol. Earth Syst. Sci., 9, 523-533, doi:10.5194/hess-9523-2005 http://www.hydrol-earth-syst-sci.net/9/523/2005/, 2005.

Vonesch, C., Blu, T., and Unser, M.: Generalized Daubechies Wavelet Families, IEEE Transactions on Signal Processing, 55, 4415-4429, doi $10.1109 /$ TSP.2007.896255 2007.

Ward, J. H.: Hierarchical Grouping to Optimize an Objective Function, Journal of the American Statistical Association, 58, 236-244, doi 10.1080/01621459.1963.10500845. http://www.tandfonline.com/doi/abs/10.1080/01621459.1963.10500845. 1963.

Wei, S., Song, J., and Khan, N. I.: Simulating and predicting river discharge time series using a wavelet-neural network hybrid modelling approach, Hydrological Processes, 26, 281-296, doi 10.1002/hyp.8227. http://onlinelibrary.wiley.com/doi/10.1002/hyp.8227/abstract 2012.

Xavier, A. C., King, C. W., and Scanlon, B. R.: Daily gridded meteorological variables in Brazil (1980-2013), International Journal of Climatology, 36, 2644-2659, doi 10.1002/joc.4518. http://dx.doi.org/10.1002/joc.4518. 2015.

Zhang, K., Kimball, J. S., Nemani, R. R., and Running, S. W.: A continuous satellite-derived global record of land surface evapotranspiration from 1983 to 2006, Water Resources Research, 46, W09 522, doi/10.1029/2009WR008800 http://onlinelibrary.wiley.com/doi/10.1029/ 2009WR008800/abstract, 2010.

Zhang, X., Harvey, K. D., Hogg, W. D., and Yuzyk, T. R.: Trends in Canadian streamflow, Water Resources Research, 37, 987-998, doi 10.1029/2000WR900357, http://onlinelibrary.wiley.com/doi/10.1029/2000WR900357/abstract. 2001.

Zhang, Z., Chao, B., Chen, J., and Wilson, C.: Terrestrial water storage anomalies of Yangtze River Basin droughts observed by GRACE

口 and connections with ENSO, Global and Planetary Change, 126, 35 - 45, doi http://dx.doi.org/10.1016/j.gloplacha.2015.01.002, http: //www.sciencedirect.com/science/article/pii/S092181811500017X 2015.

Zhang, Z.-Z., Chao, B. F., Lu, Y., and Hsu, H.-T.: An effective filtering for GRACE time-variable gravity: Fan filter, Geophysical Research Letters, 36, n/a-n/a, doi 10.1029/2009GL039459 http://dx.doi.org/10.1029/2009GL039459 117311, 2009.

\section{Appendix A: Individual reservoir responses}

The natural discharge was estimated as the difference between total inflow and outflow from the upstream reservoirs. The main limitation to this approach is that the available records of reservoir outflows are in daily basis and, as the distance between upstream and downstream dams grows, the difference between the discharge registered on the upstream dam and the actual discharge arriving at the downstream reservoir increases. For example, there is $190 \mathrm{~km}$ between the Marimbondo dam and Água Vermelha reservoir, which implies that there is actually no accurate data of how much of the total inflow in Água Vermelha corresponds to the outflow from Marimbondo. For those reservoirs located downstream of other dams, we applied the moving average of discharges (total inflow, outflow from upstream) to reduce the differences caused by such lag time and, then, estimate the natural component of the total inflow $\left(Q_{\text {nat }}\right)$. There were some situations in which we only analysed the SDI relative to the total inflow such as when there was a significant difference between total inflow $\left(Q_{i n}\right)$ and outflow from upstream $\left(Q_{u p}\right)$ or there is insufficient data to compute SDI relative $Q_{\text {nat }} ; Q_{\text {in }}=Q_{\text {nat }}$.

The following figures are provided to complement the discussion provided in the Results section of the main manuscript. Plots of monthly storage, SPI, SDI or discharge are provided for 36 reservoirs and the Cantareira equivalent system. 

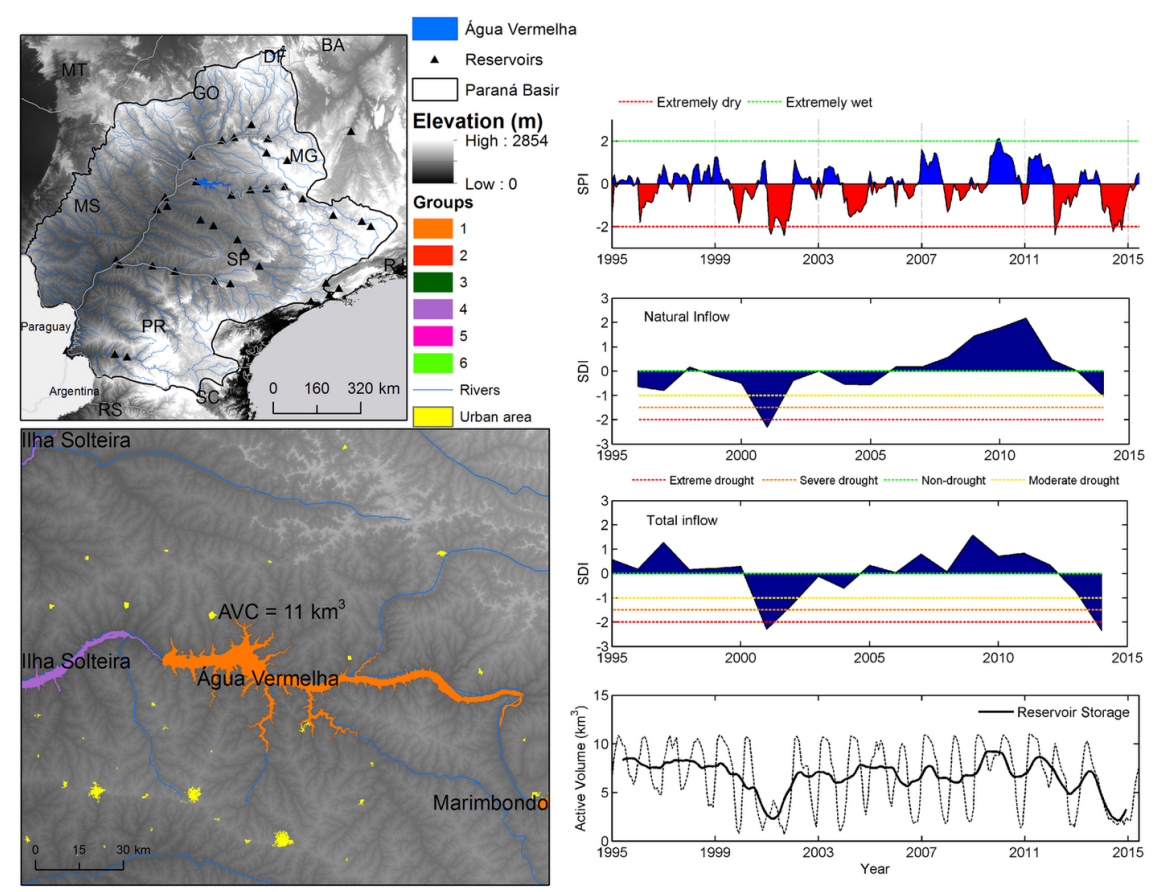

Figure S16. Time series of SDI, SPI and monthly storage: Água Vermelha Hydroelectric Plant (HEP)

\section{A1 Group 1}

$30 \quad$ A2 Group 2

A3 Group 3

A4 Group 4

A5 Group 5

A6 Group 6 

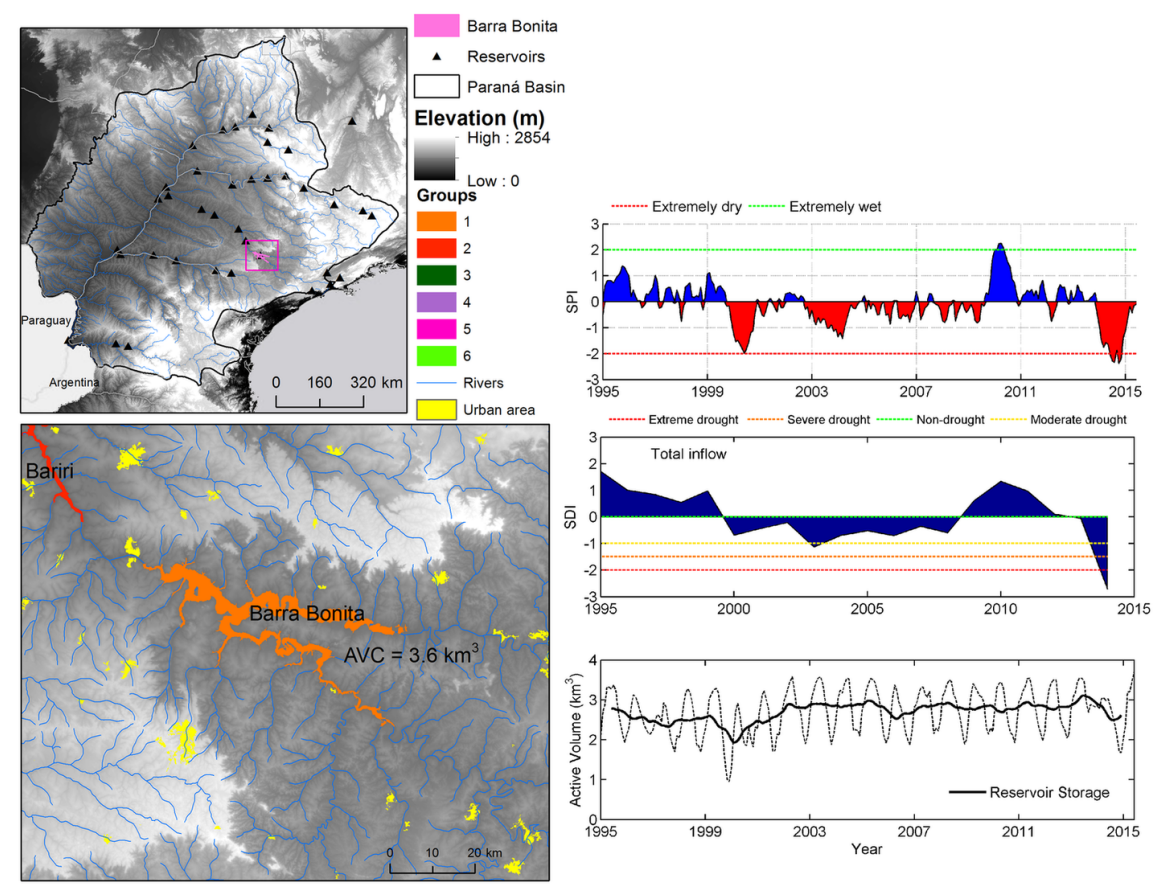

Figure S17. Time series of SDI, SPI and monthly storage: Barra Bonita HEP
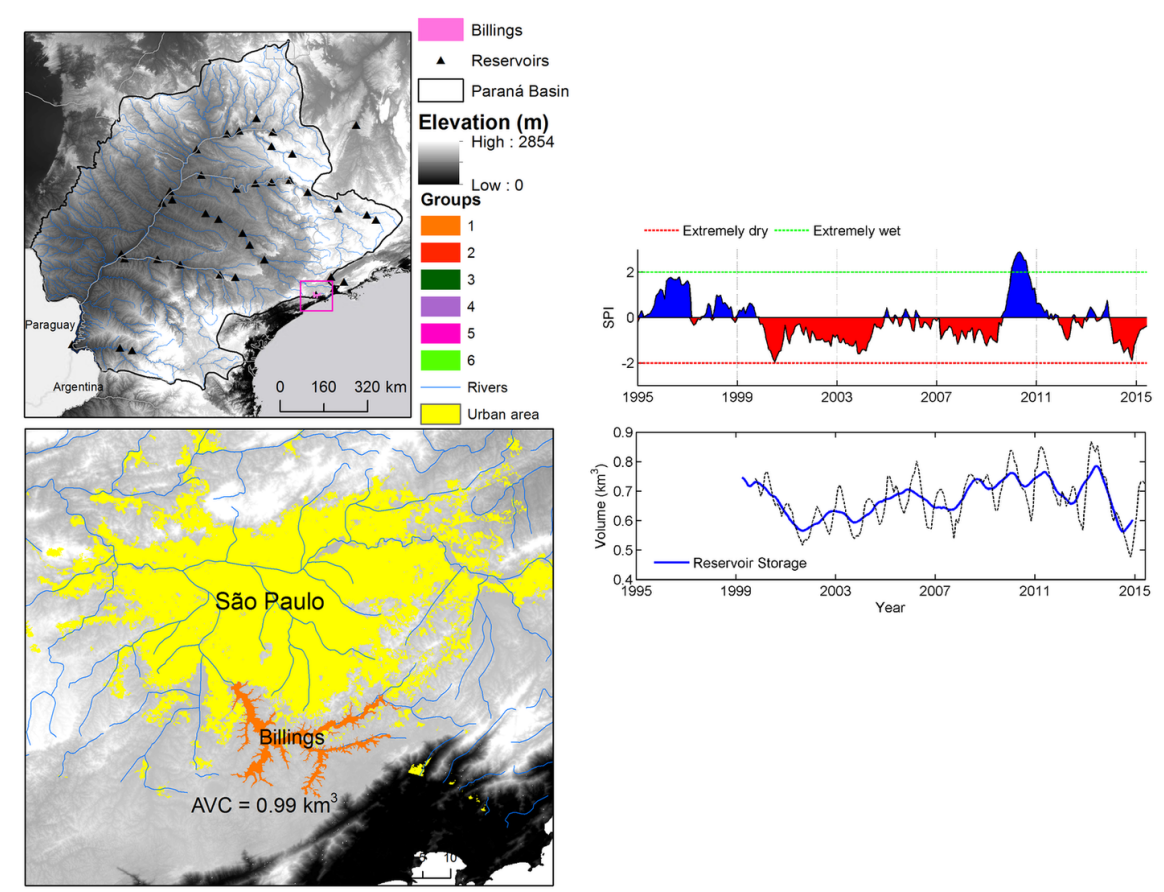

Figure S18. Time series of SDI, SPI and monthly storage: Billings 

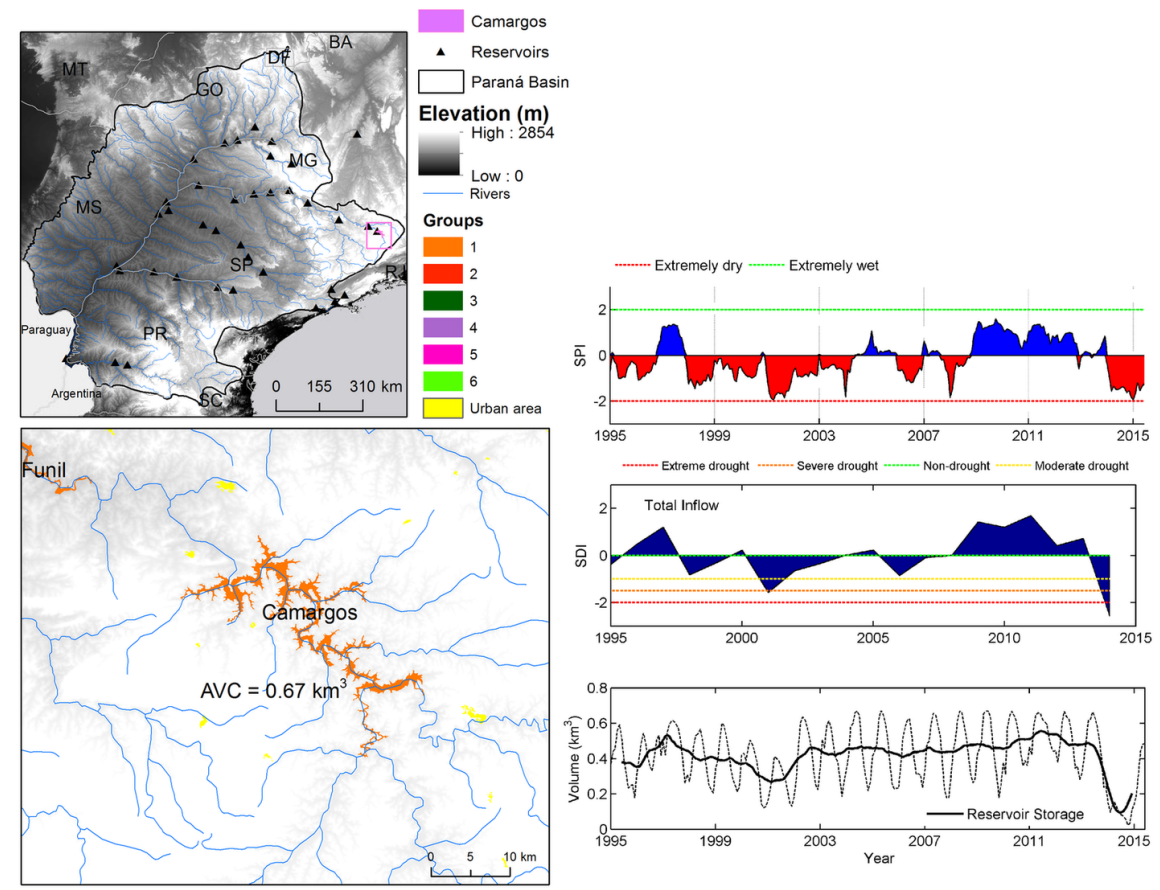

Figure S19. Time series of SDI, SPI and monthly storage: Camargos HEP
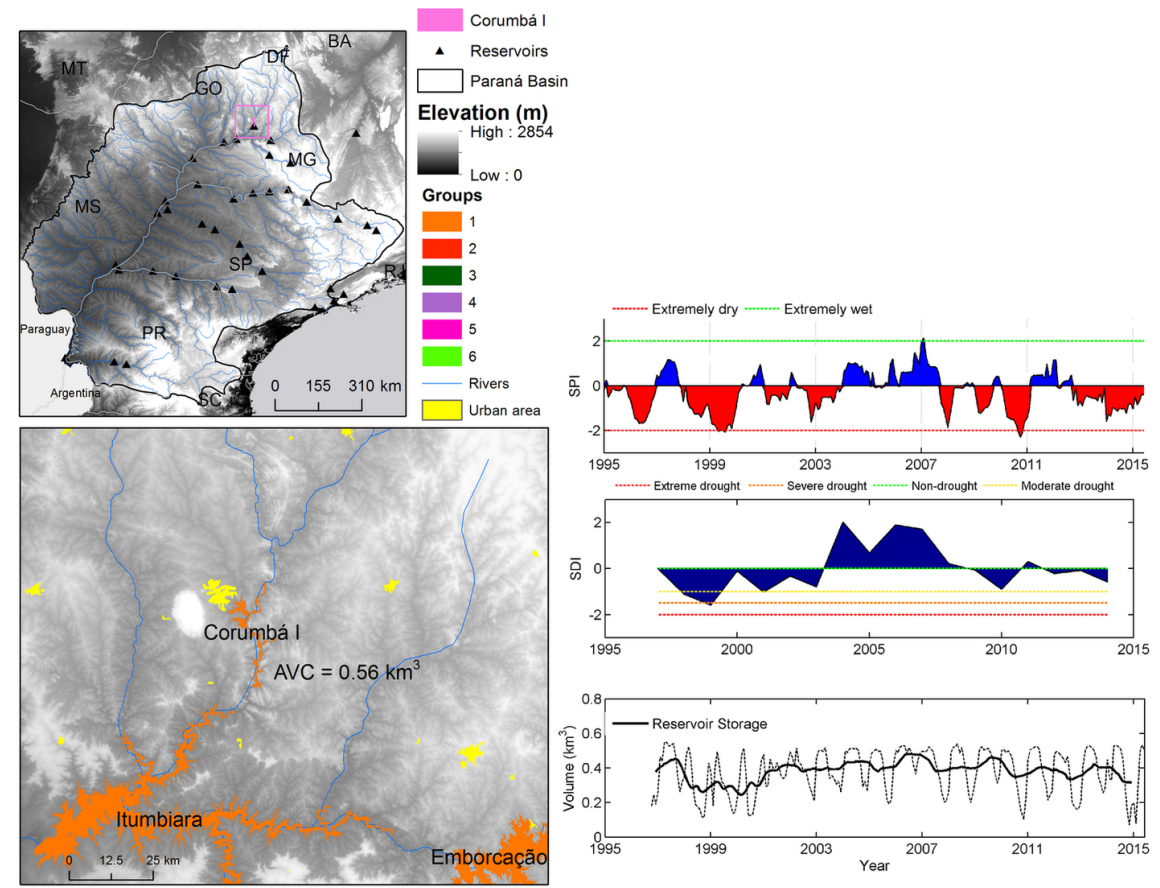

Figure S20. Time series of SDI, SPI and monthly storage: Corumbá I HEP 

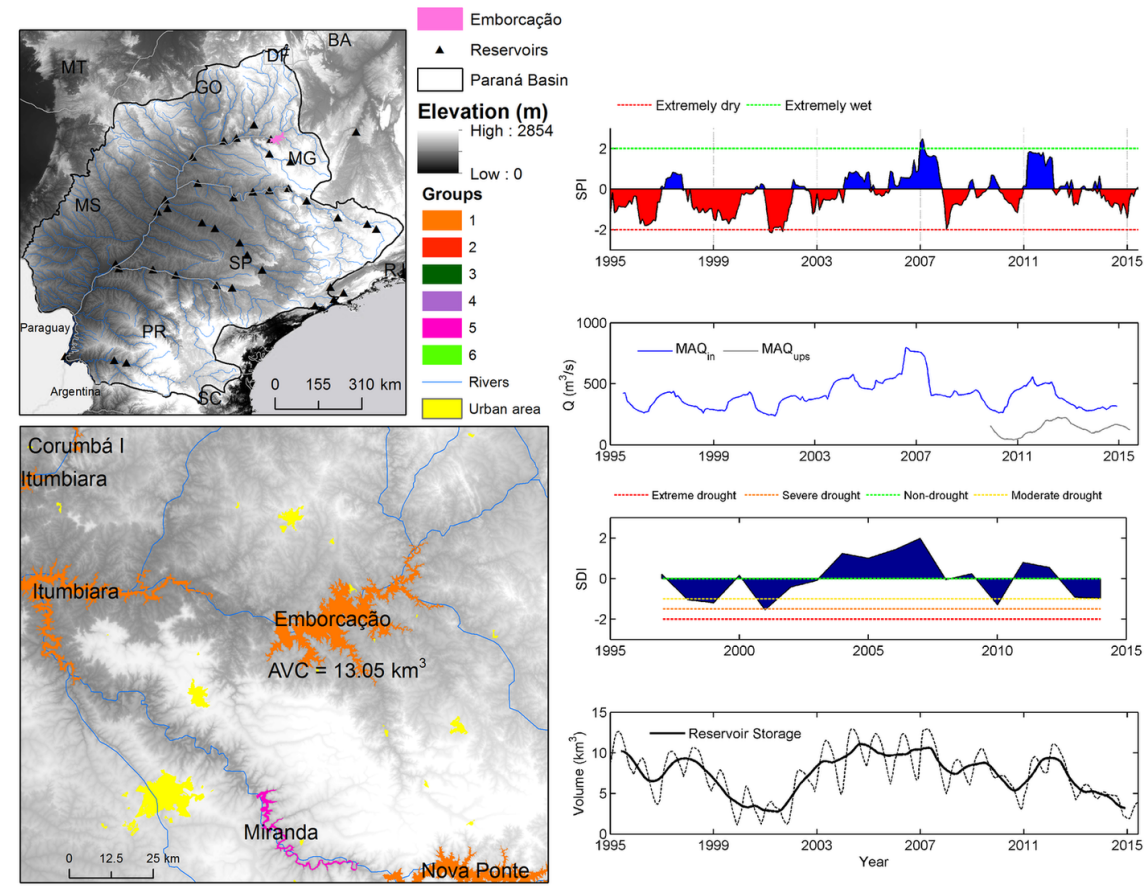

Figure S21. Time series of SDI, SPI and monthly storage: Emborcaćão HEP

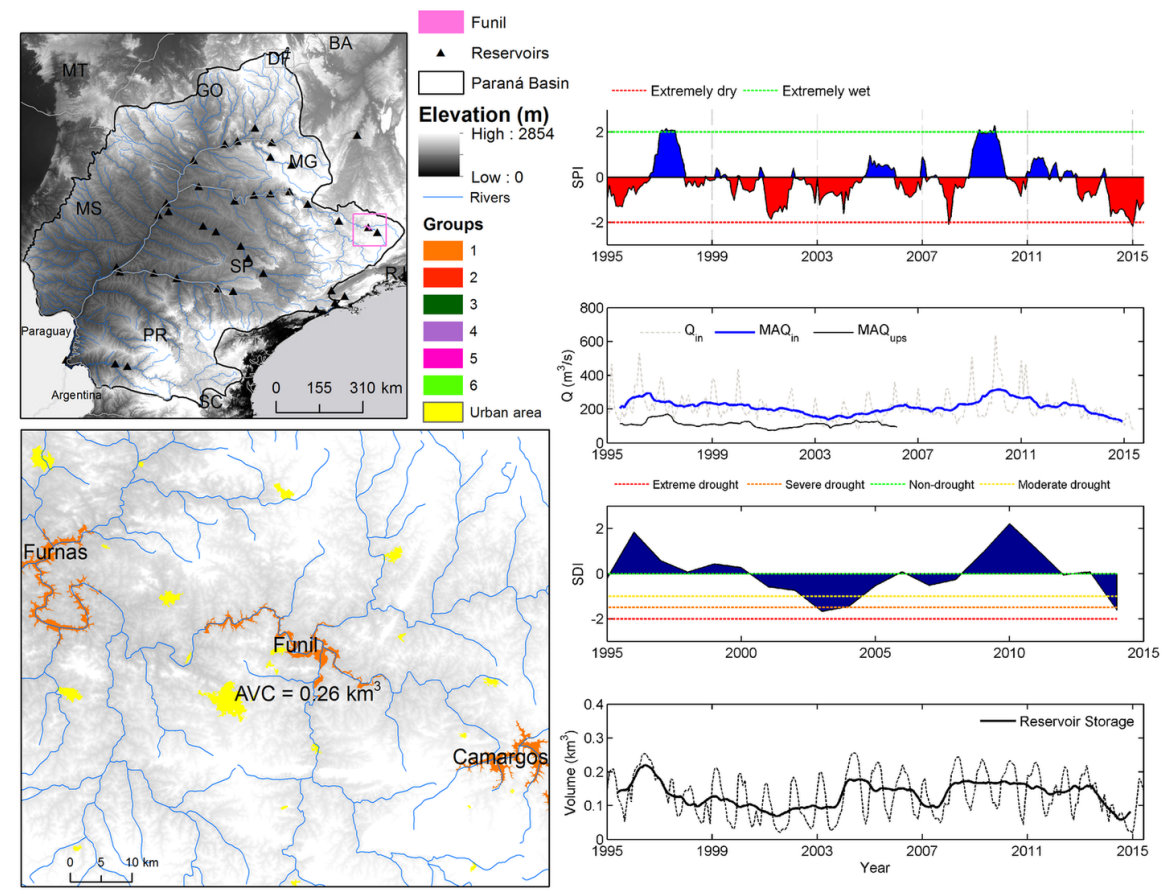

Figure S22. Time series of SDI, SPI and monthly storage: Funil HEP 

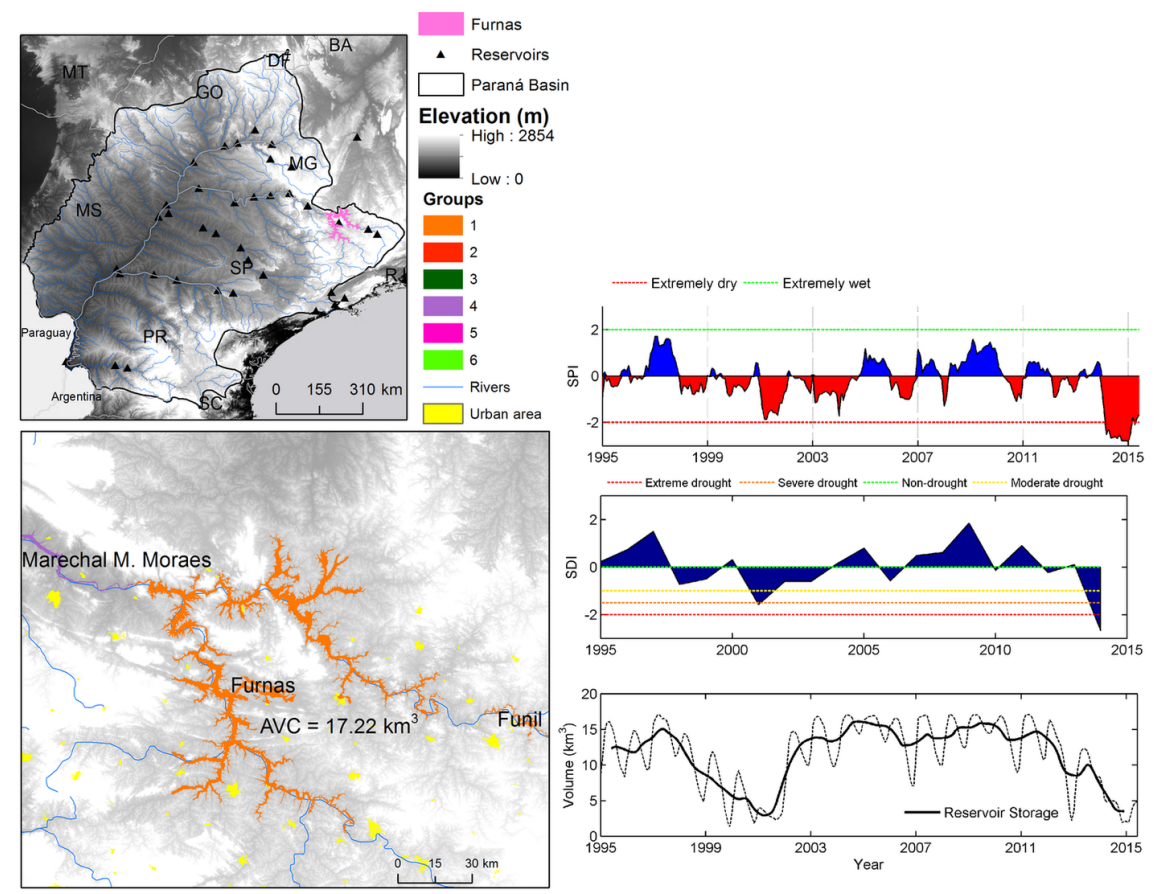

Figure S23. Time series of SDI, SPI and monthly storage: Furnas HEP
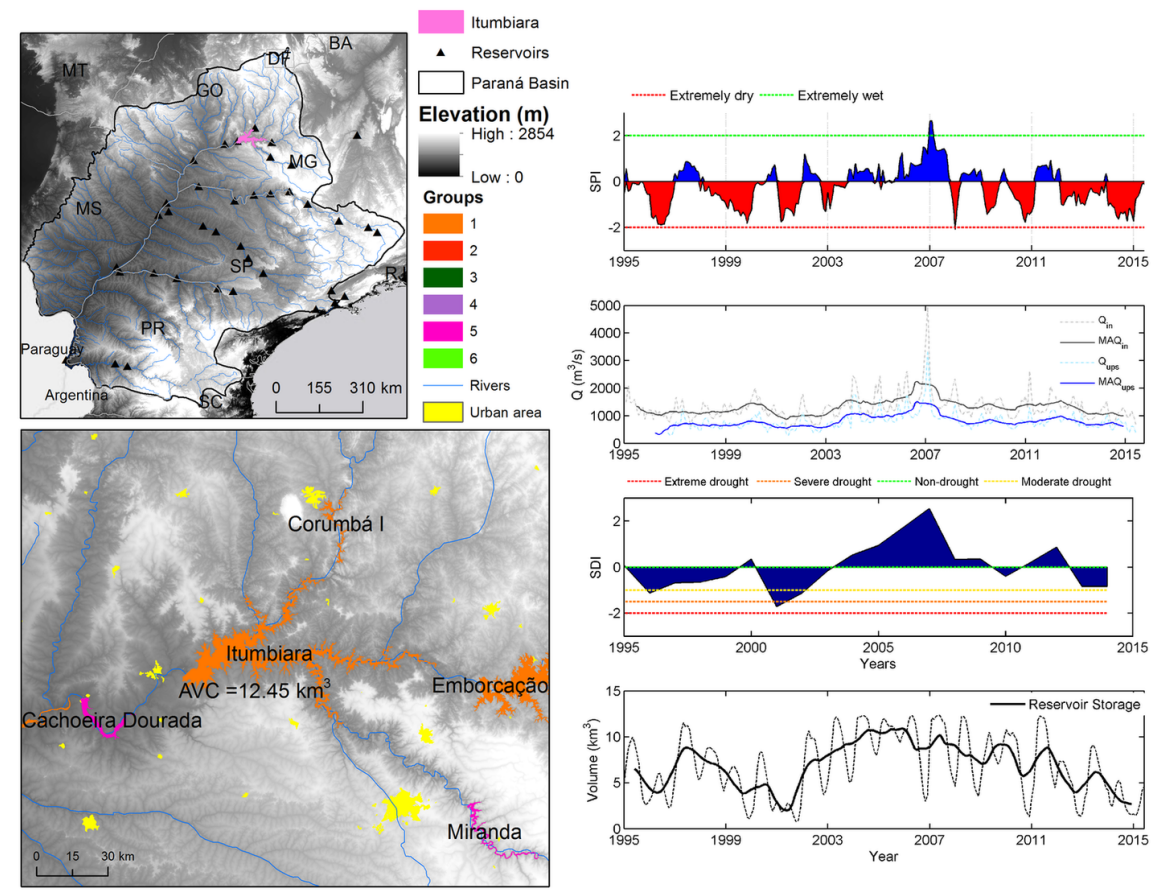

Figure S24. Time series of SDI, SPI and monthly storage: Itumbiara HEP 

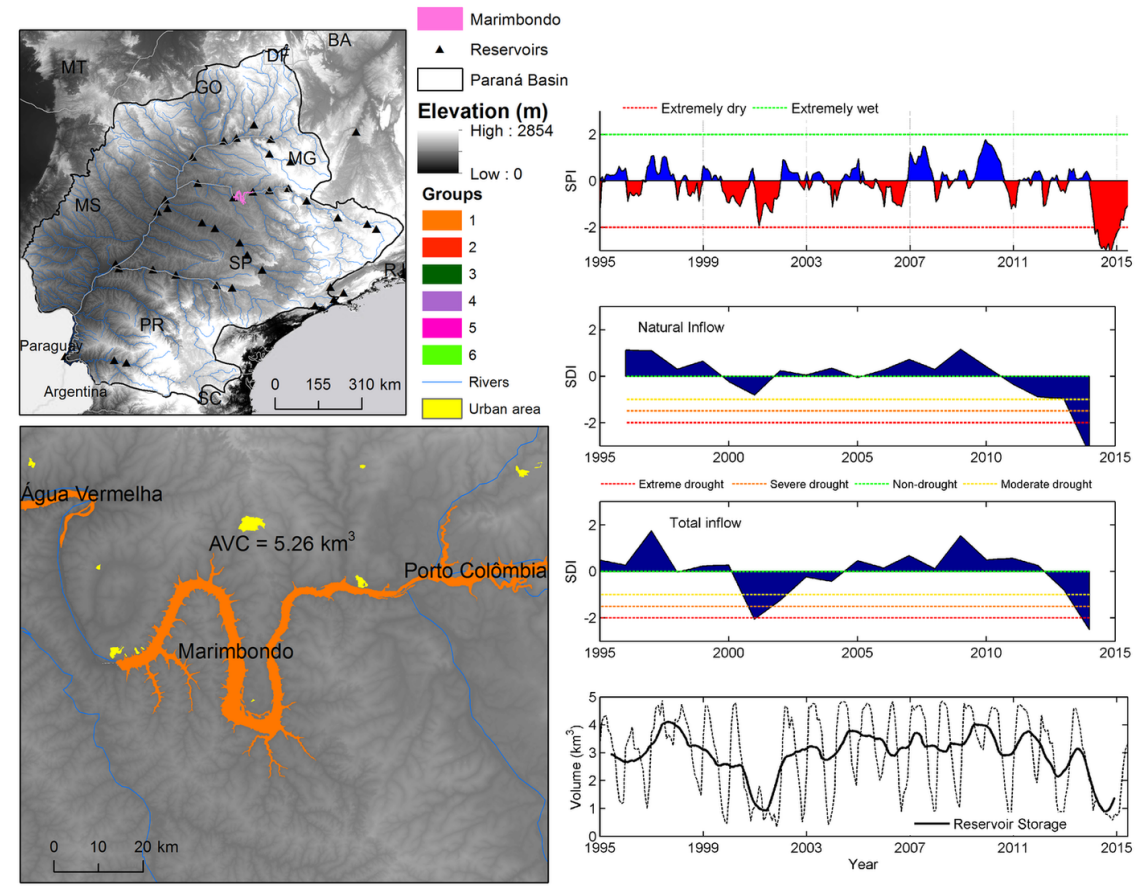

Figure S25. Time series of SDI, SPI and monthly storage: Marimbondo HEP
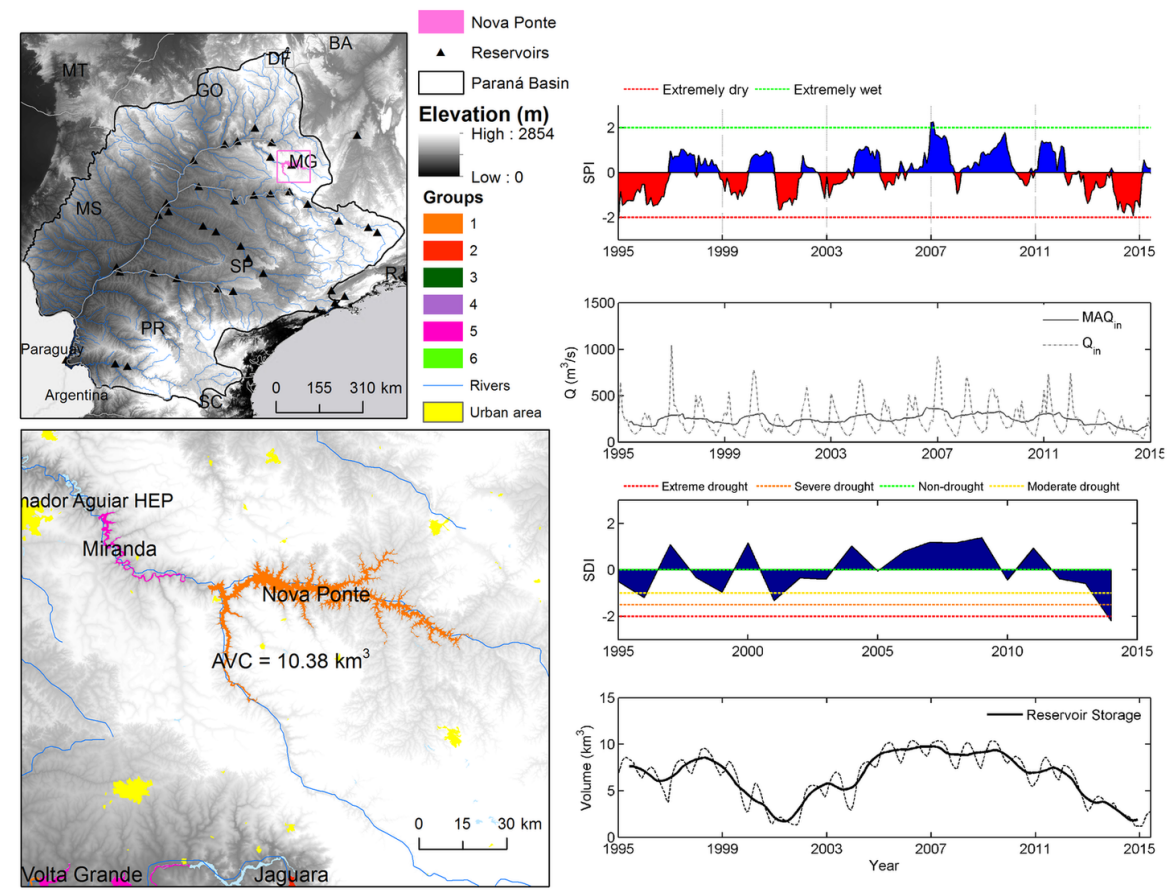

Figure S26. Time series of SDI, SPI and monthly storage: Nova Ponte HEP 

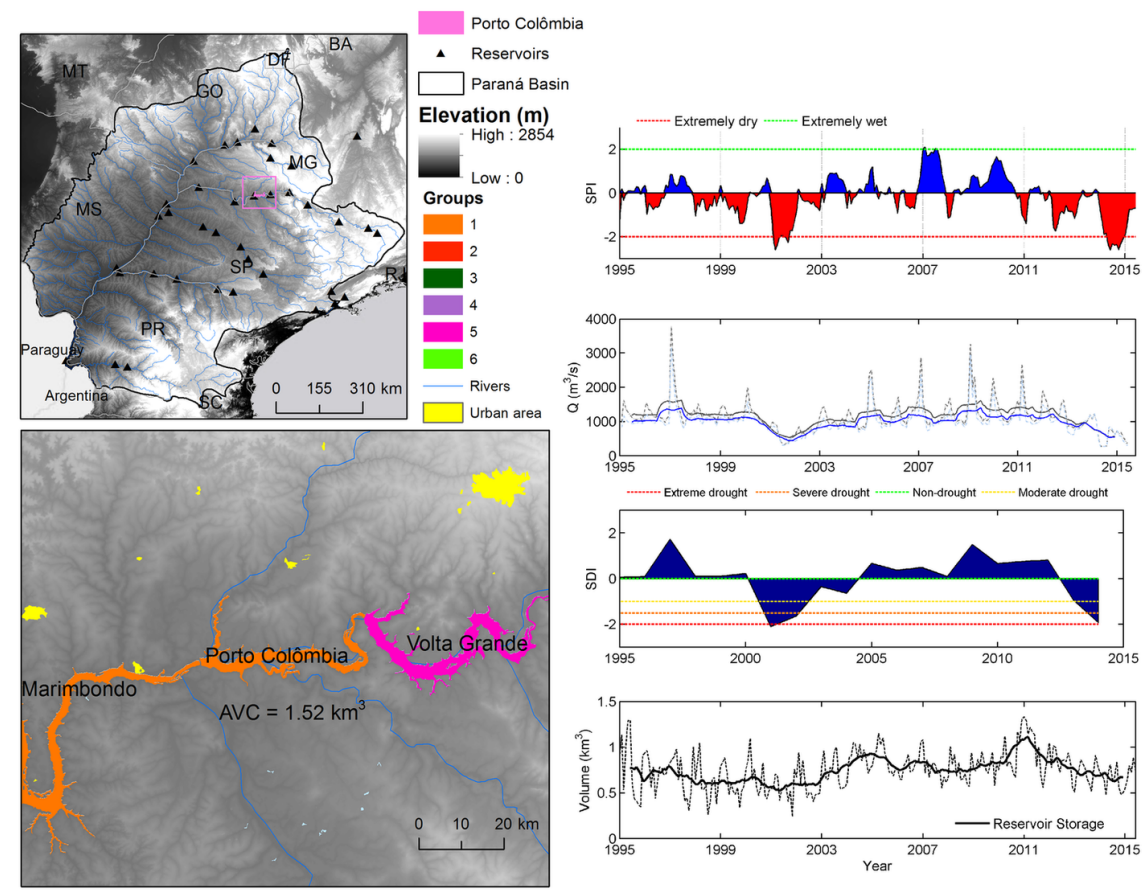

Figure S27. Time series of SDI, SPI and monthly storage: Porto Colômbia HEP
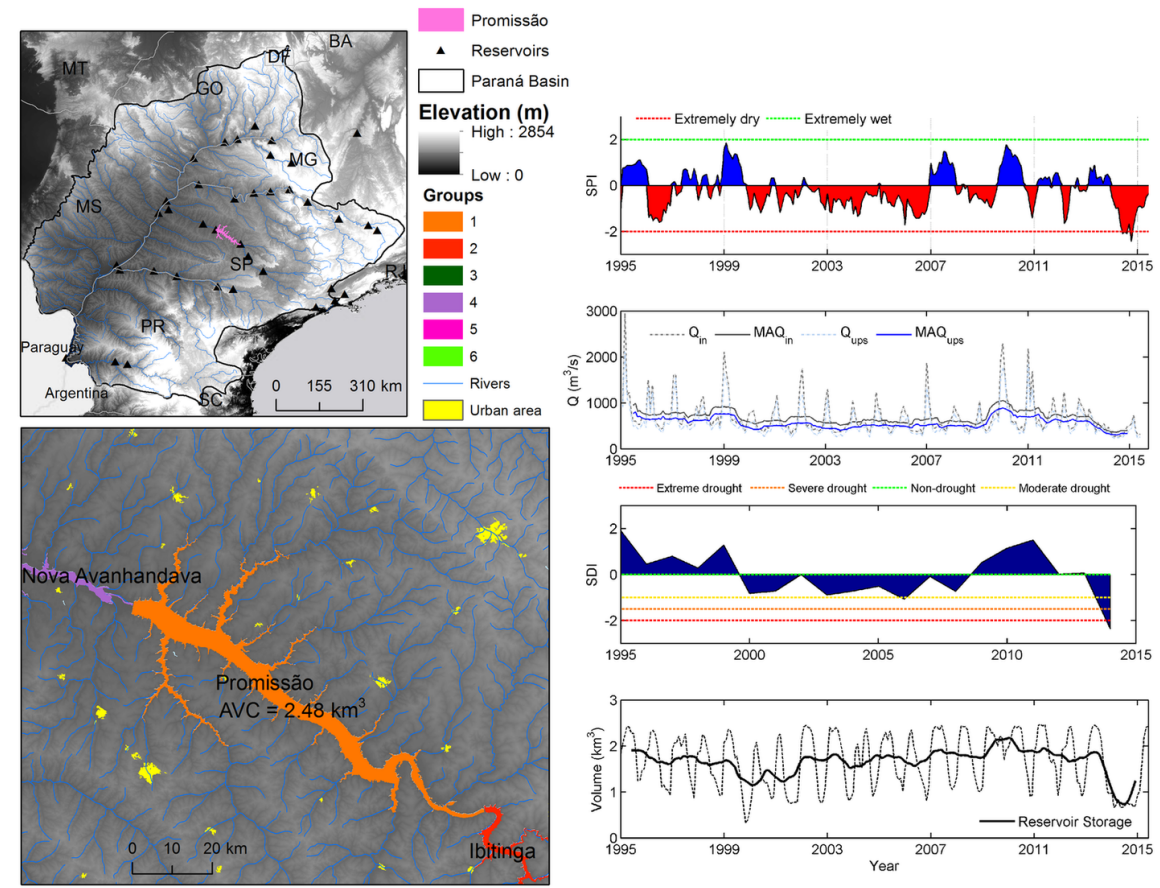

Figure S28. Time series of SDI, SPI and monthly storage: Promissão HEP 

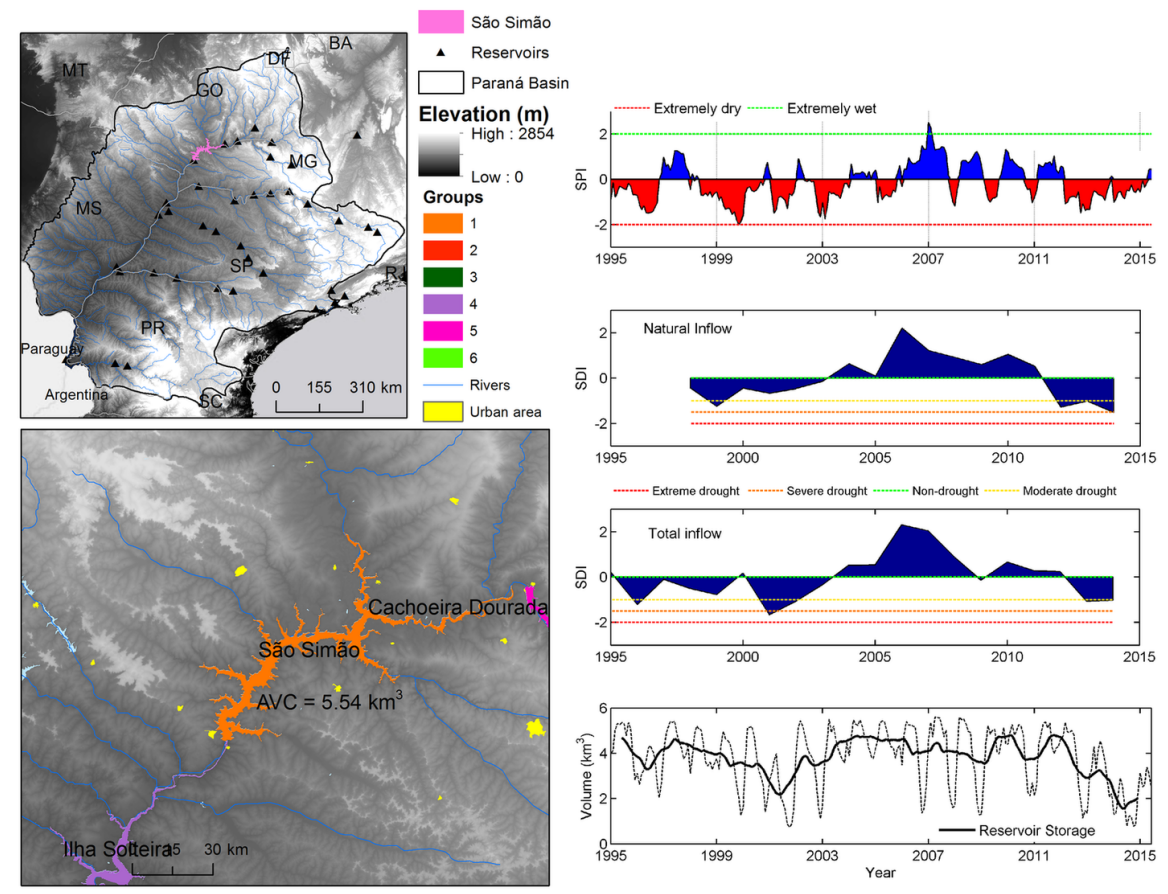

Figure S29. Time series of SDI, SPI and monthly storage: São Simão HEP
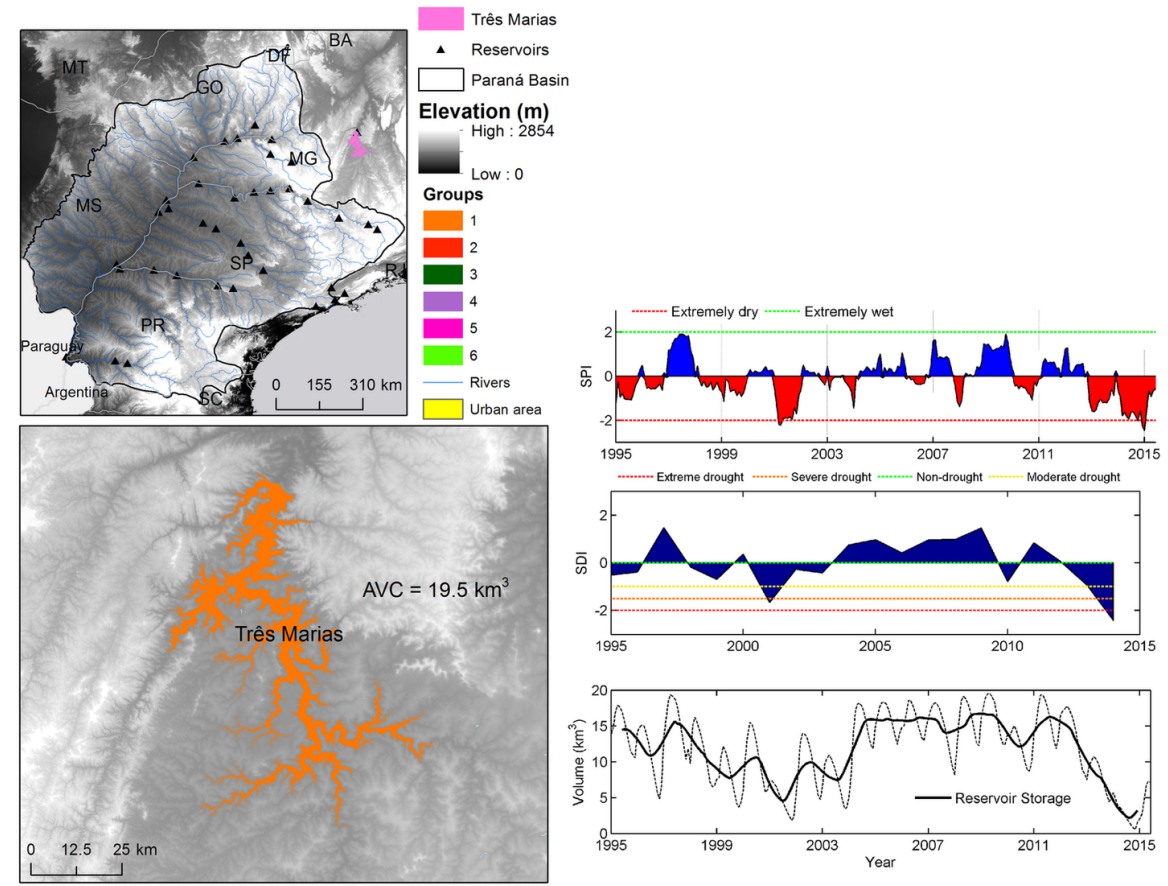

Figure S30. Time series of SDI, SPI and monthly storage: Três Marias HEP 

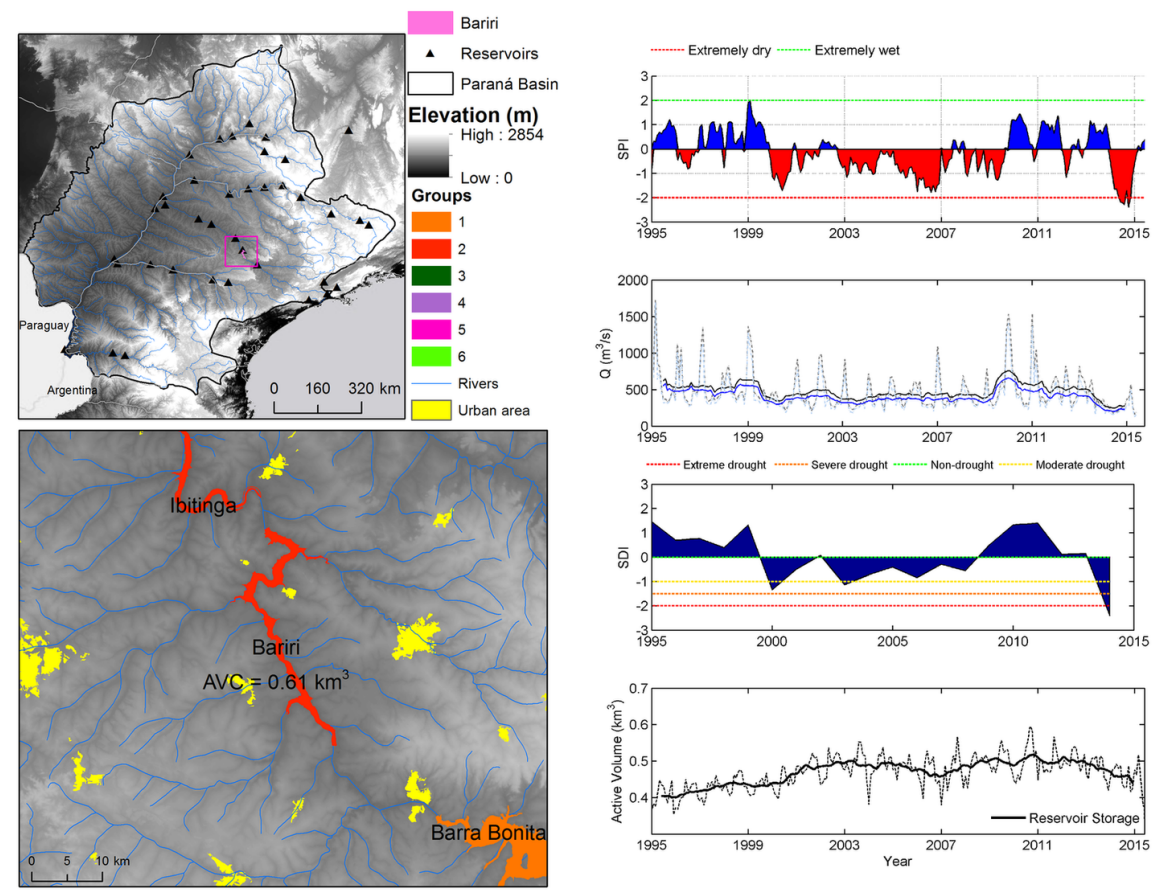

Figure S31. Time series of SDI, SPI and monthly storage: Bariri HEP
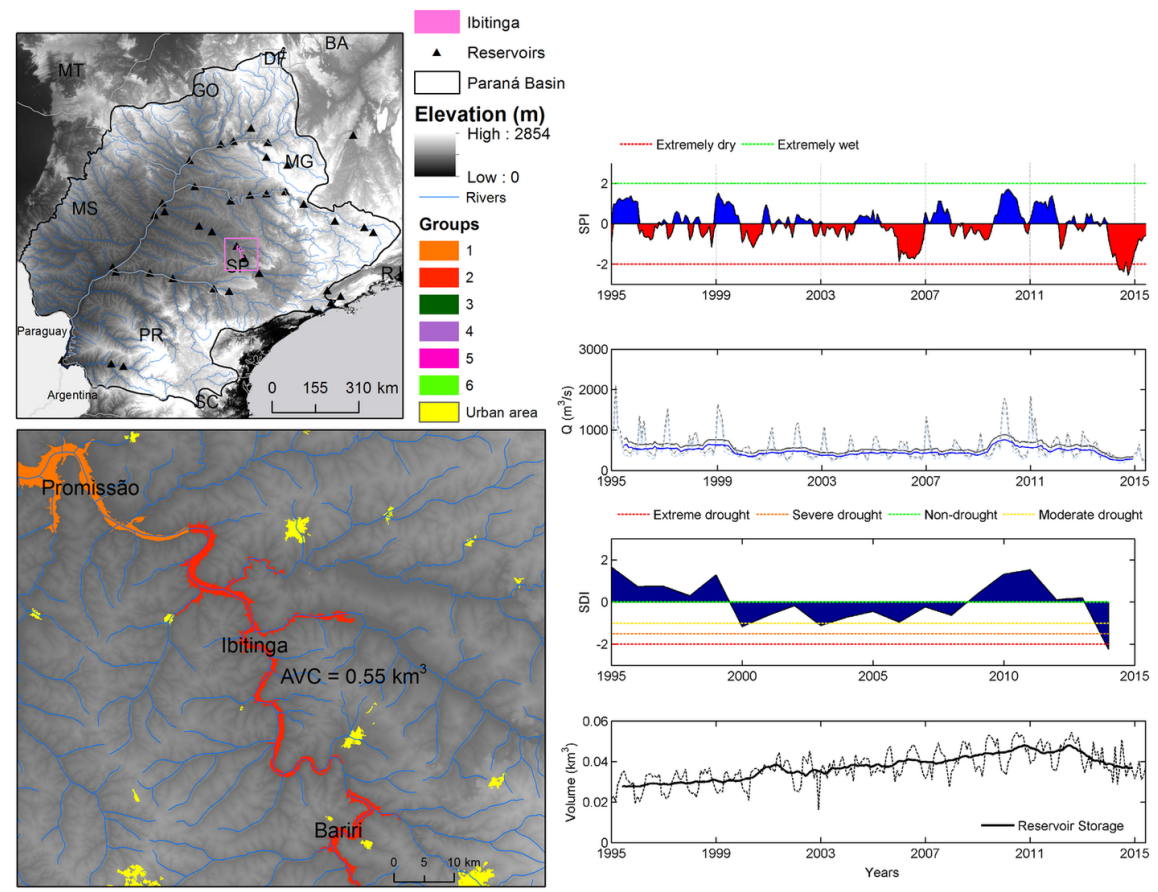

Figure S32. Time series of SDI, SPI and monthly storage: Ibitinga HEP 

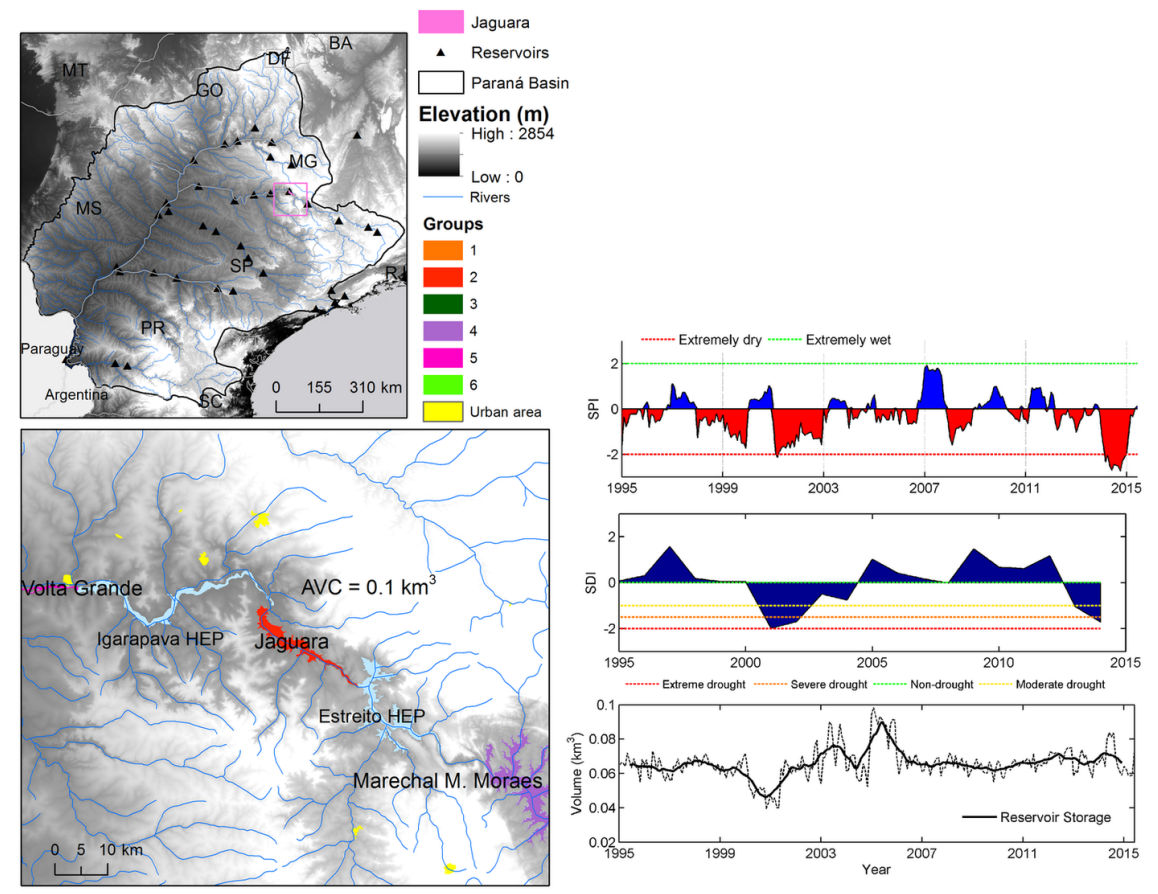

Figure S33. Time series of SDI, SPI and monthly storage: Jaguará HEP
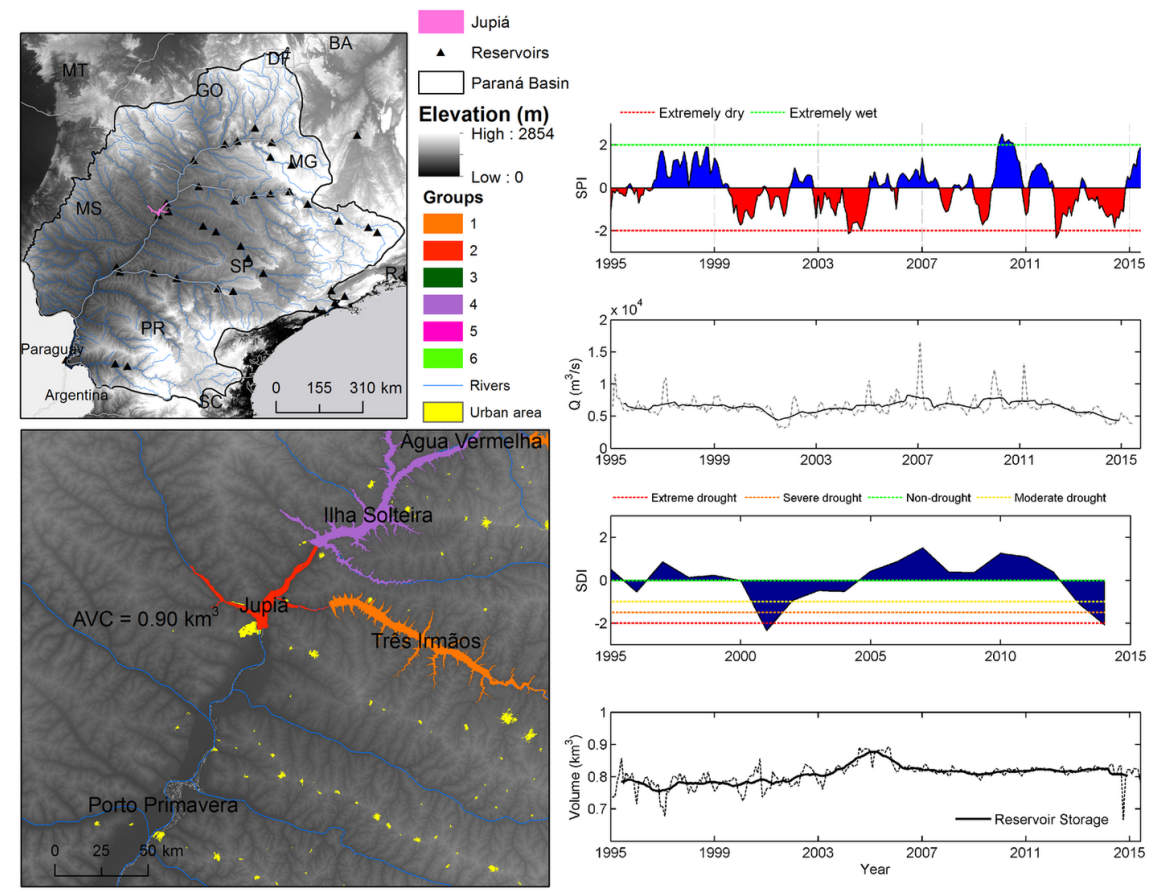

Figure S34. Time series of SDI, SPI and monthly storage: Jupiá HEP 

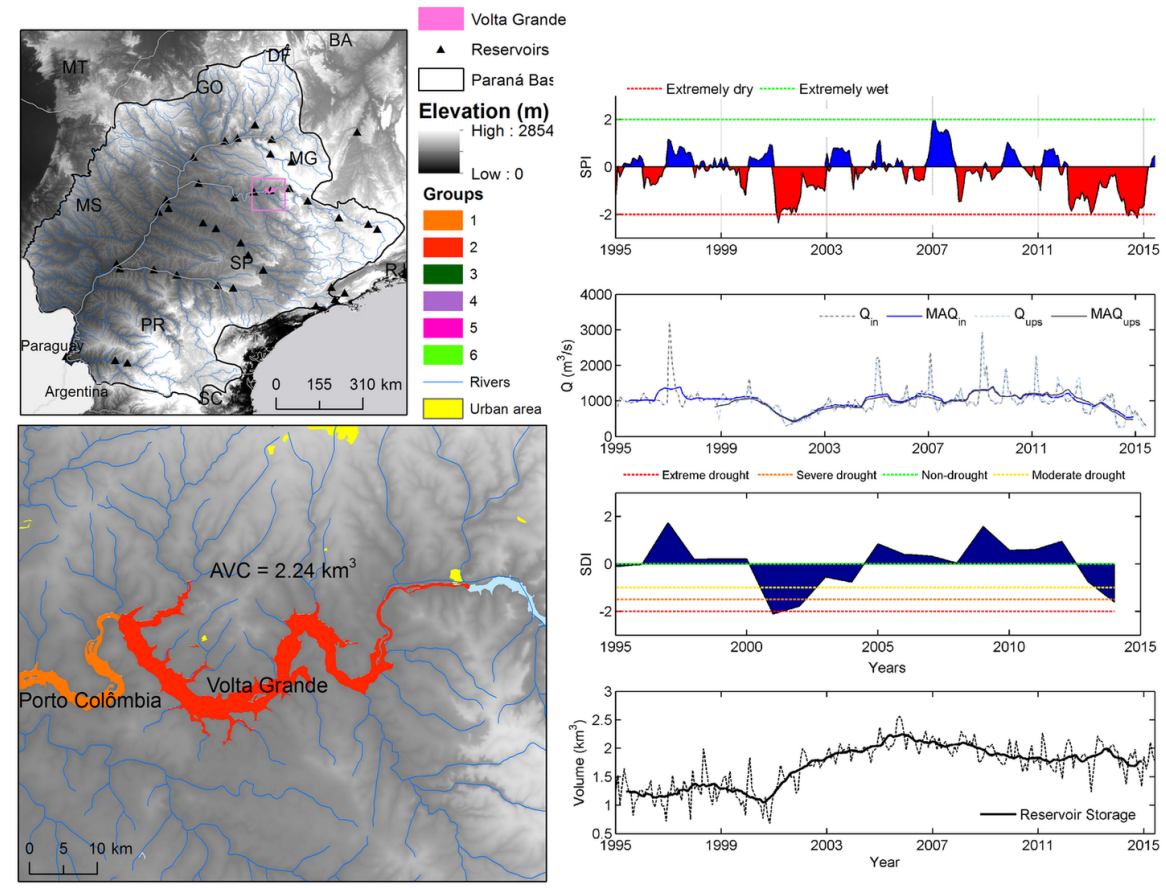

Figure S35. Time series of SDI, SPI and monthly storage: Volta Grande HEP
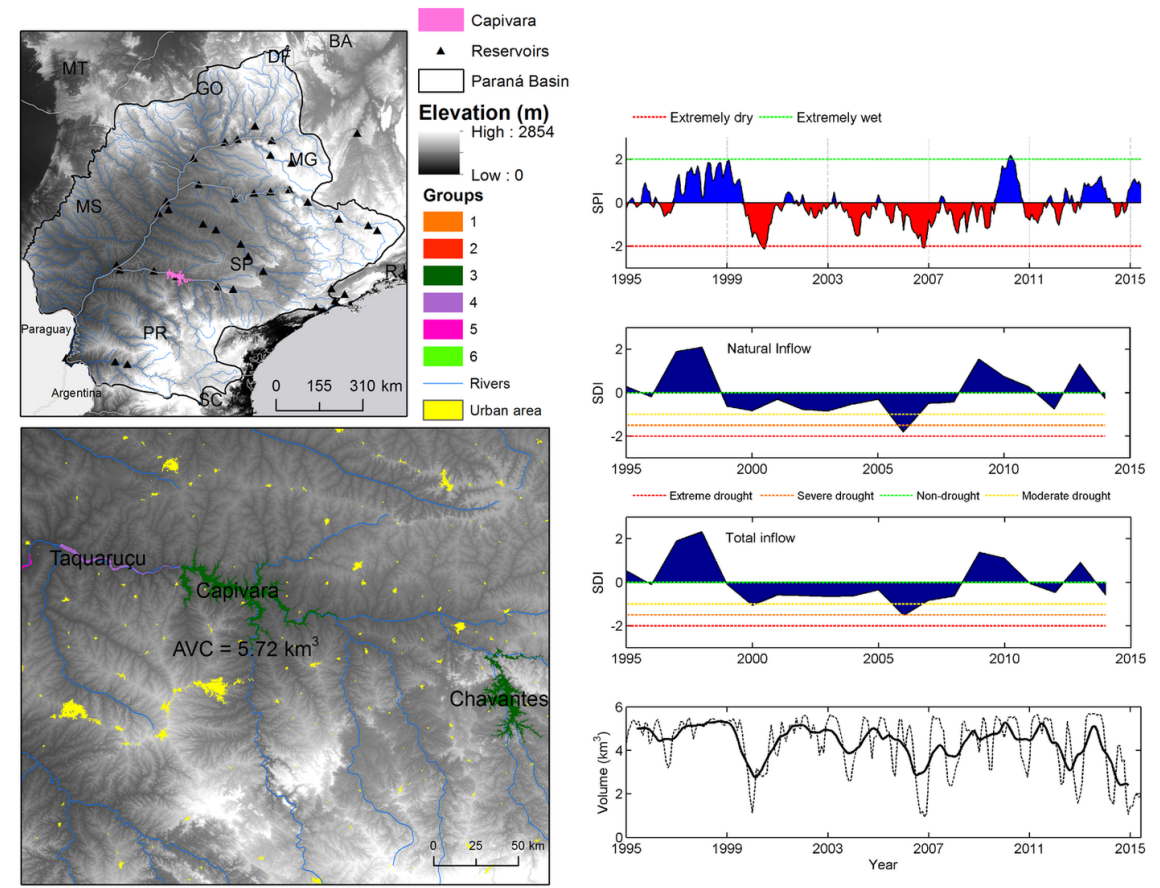

Figure S36. Time series of SDI, SPI and monthly storage: Capivara HEP 

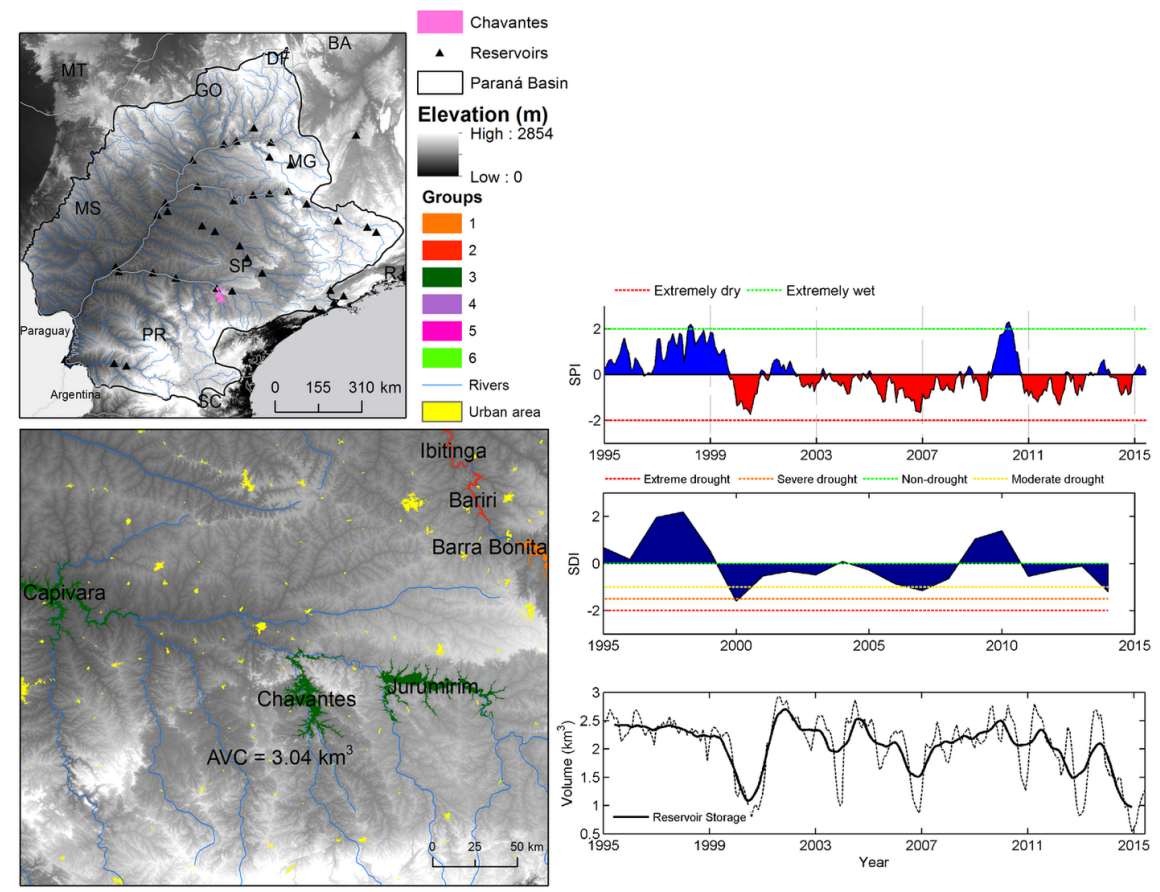

Figure S37. Time series of SDI, SPI and monthly storage: Chavantes HEP
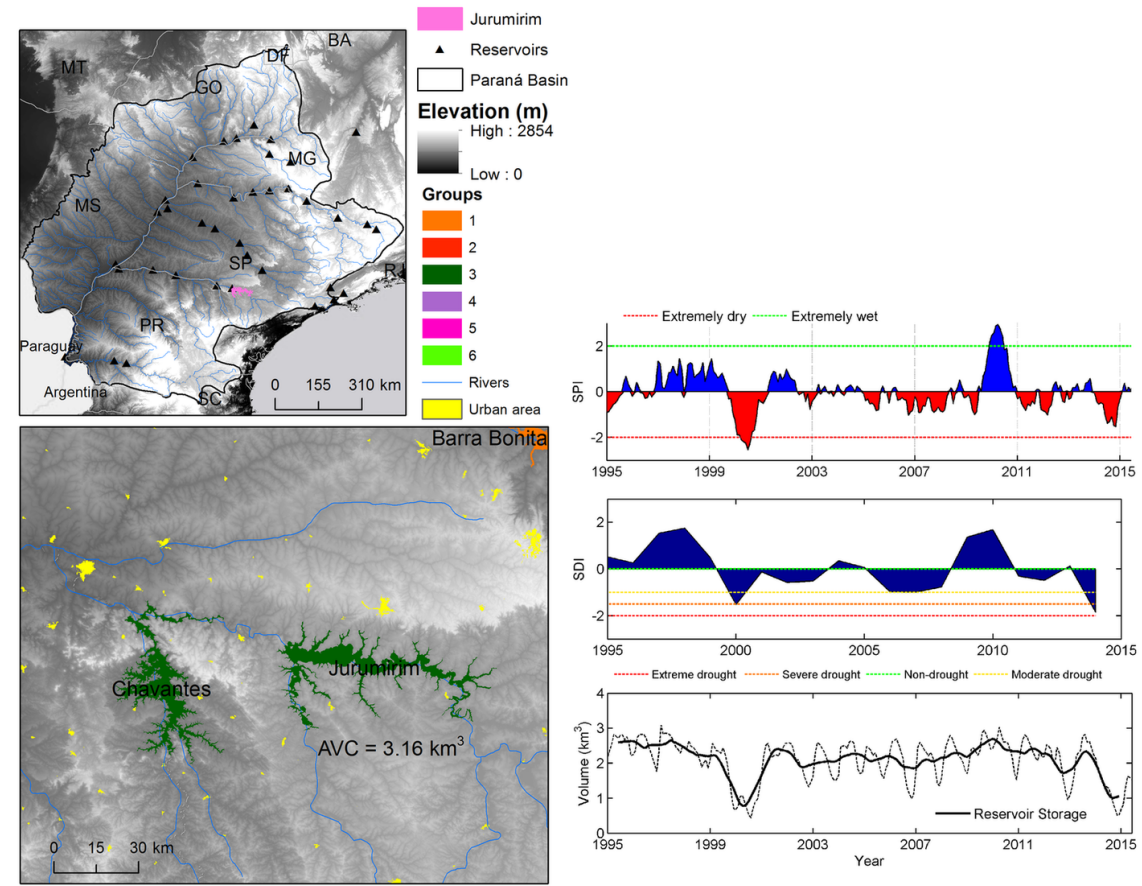

Figure S38. Time series of SDI, SPI and monthly storage: Jurumirim HEP 

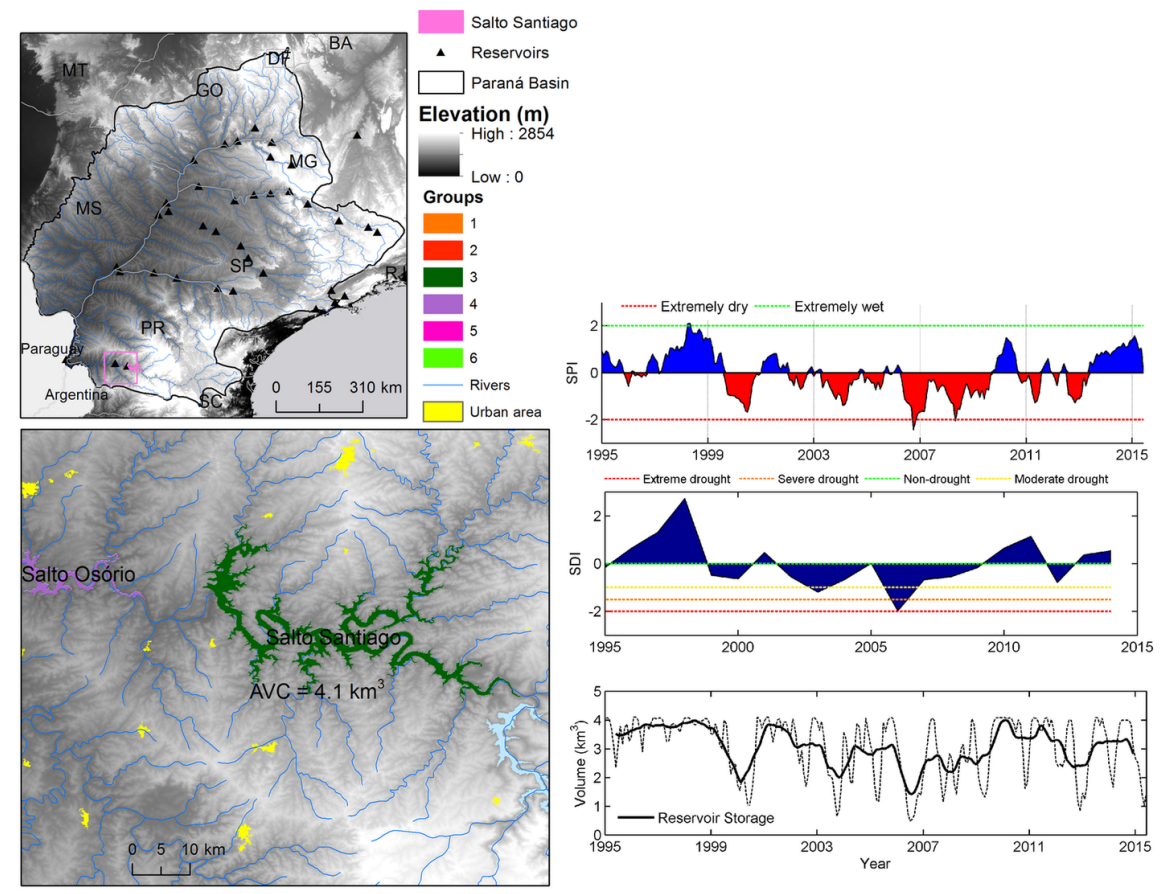

Figure S39. Time series of SDI, SPI and monthly storage: Salto Santiago HEP
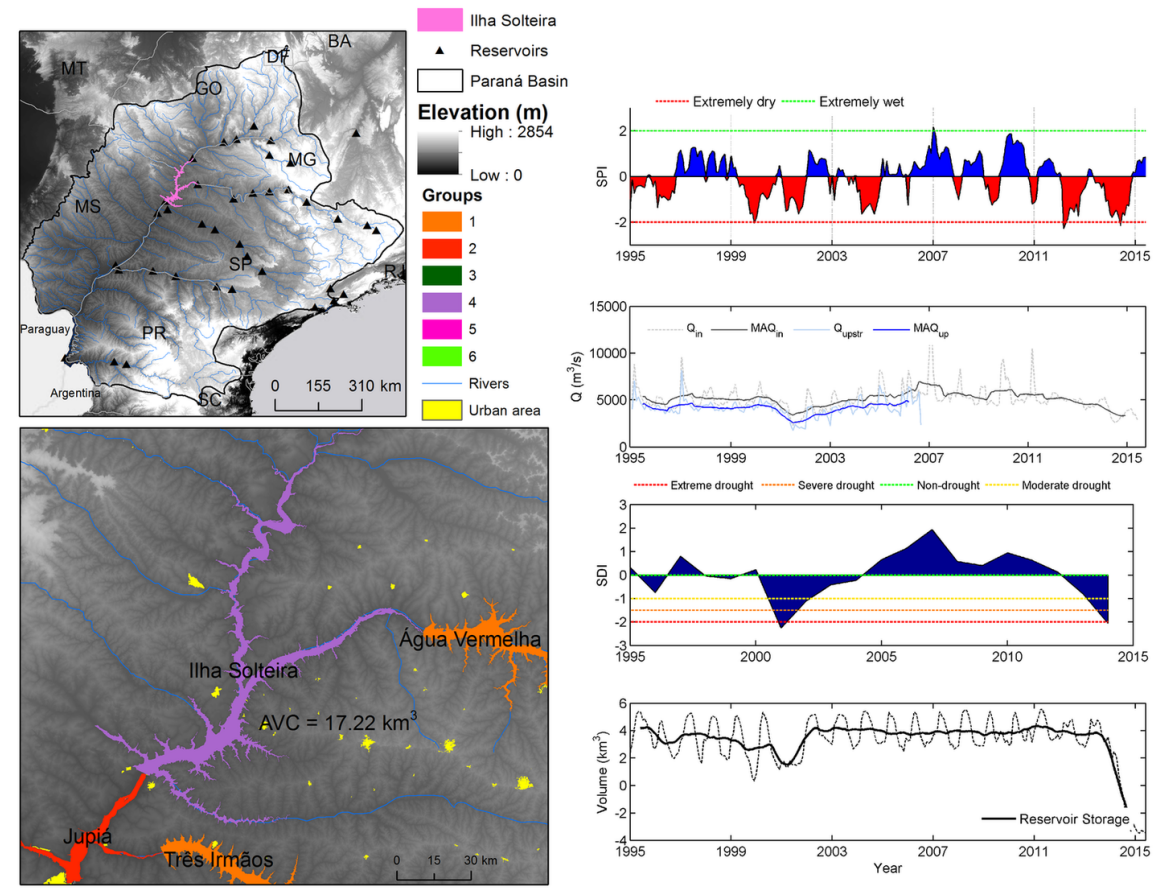

Figure S40. Time series of SDI, SPI and monthly storage: Ilha Solteira HEP 

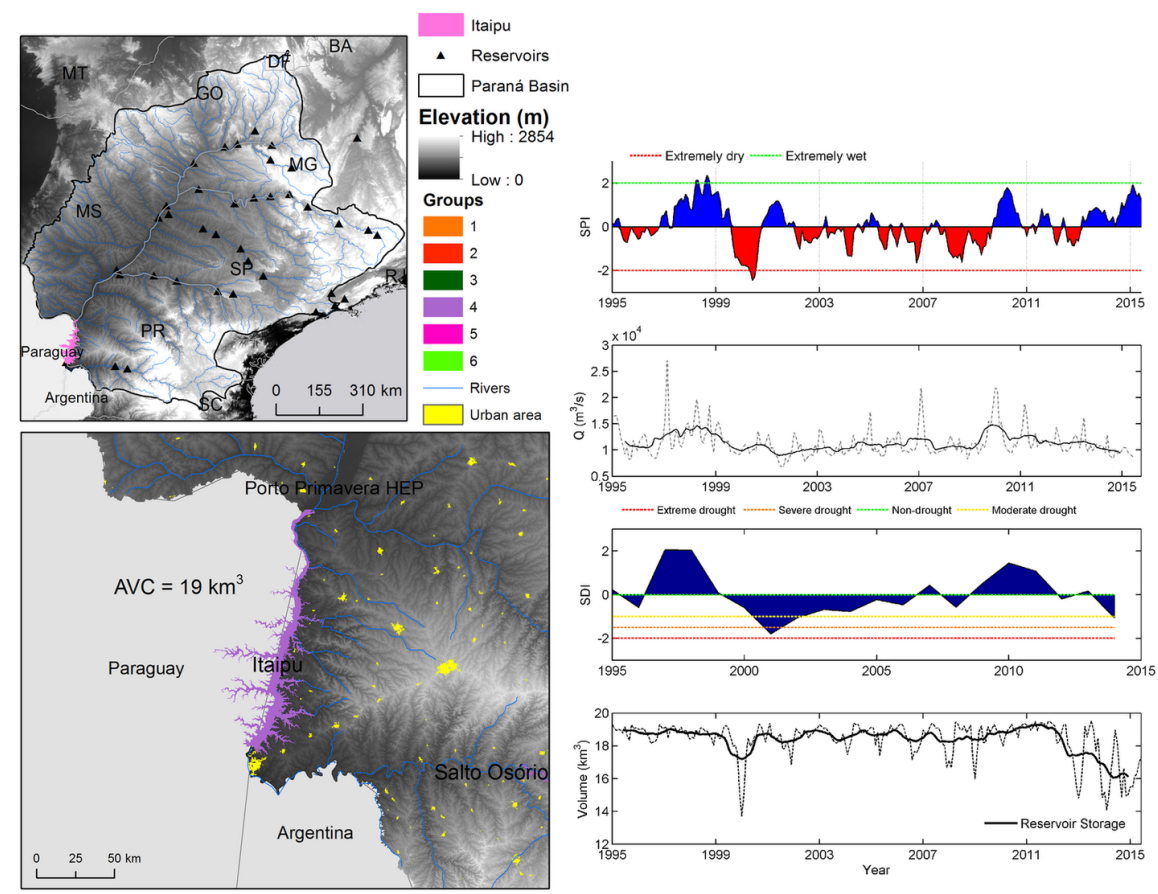

Figure S41. Time series of SDI, SPI and monthly storage: Itaipu HEP

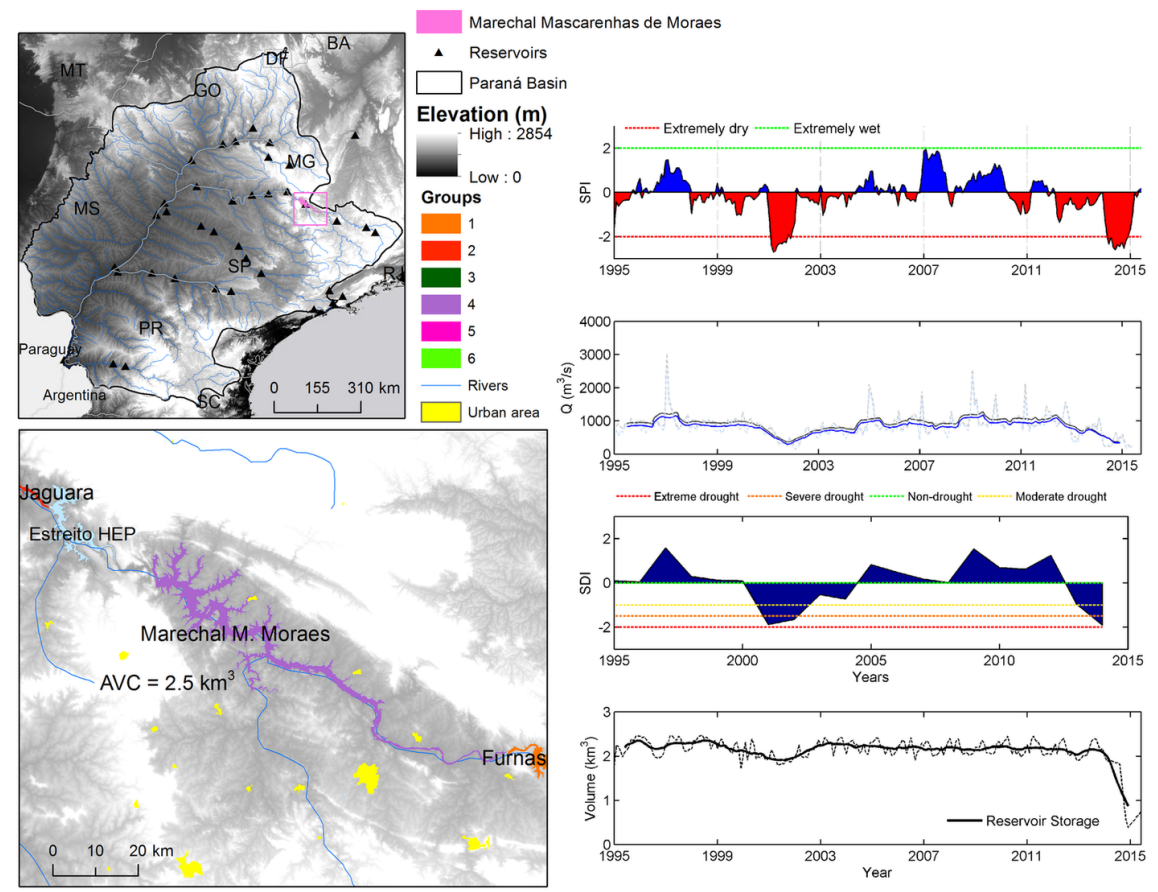

Figure S42. Time series of SDI, SPI and monthly storage: M. M. Moraes HEP 

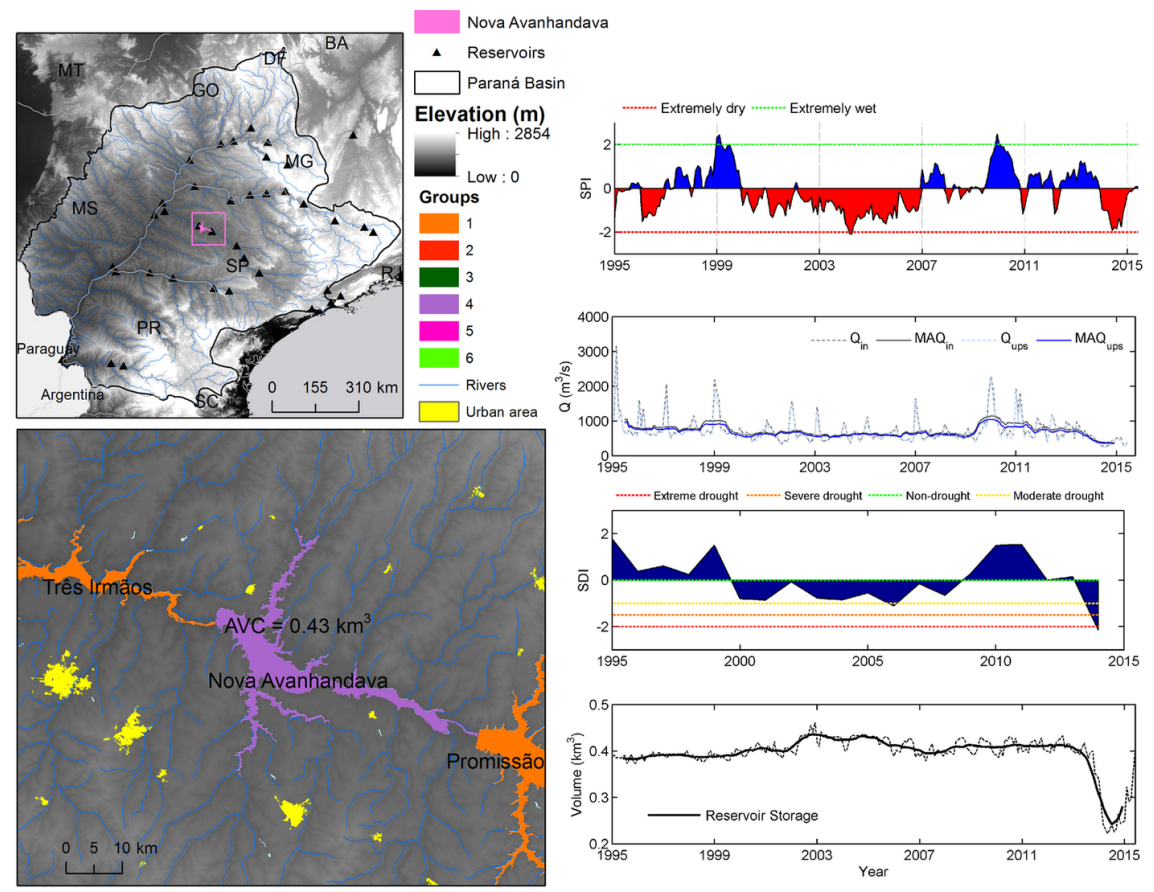

Figure S43. Time series of SDI, SPI and monthly storage: Nova Avanhandava HEP
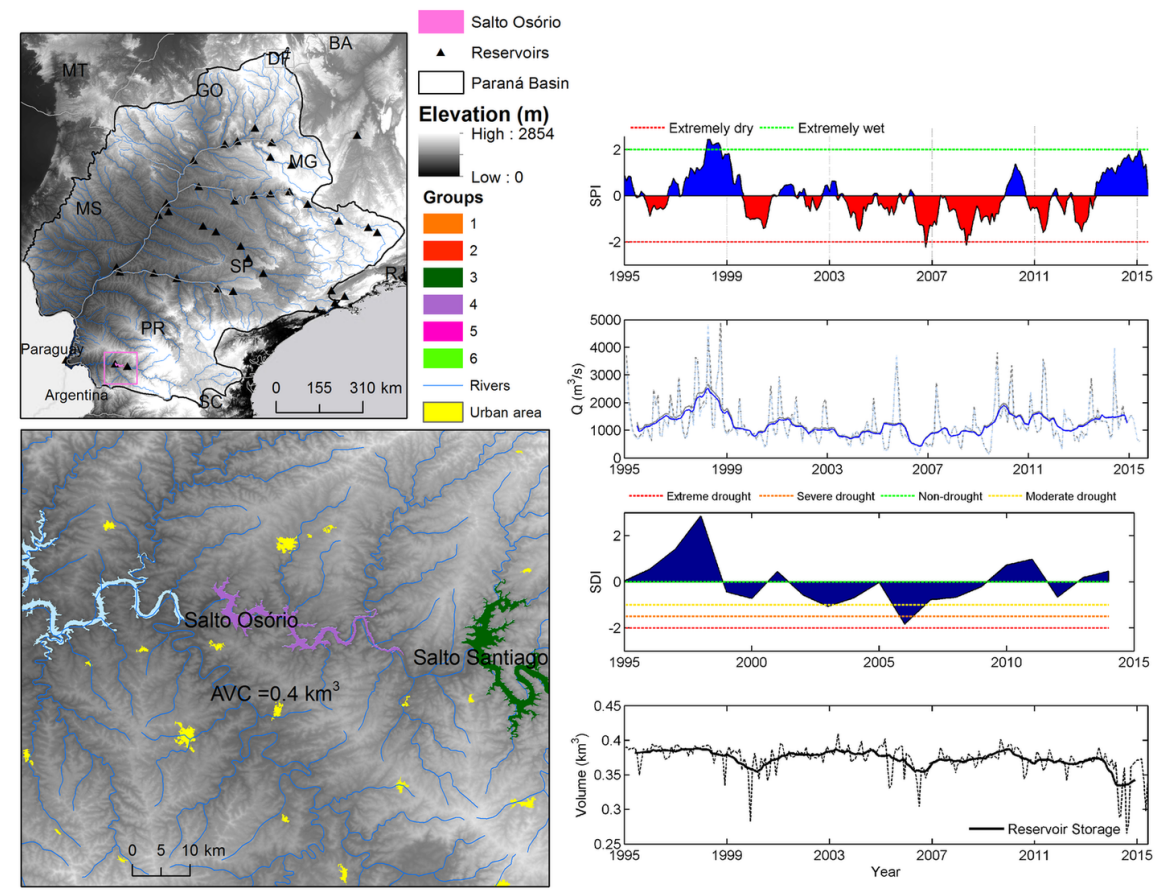

Figure S44. Time series of SDI, SPI and monthly storage: Salto Osório HEP 

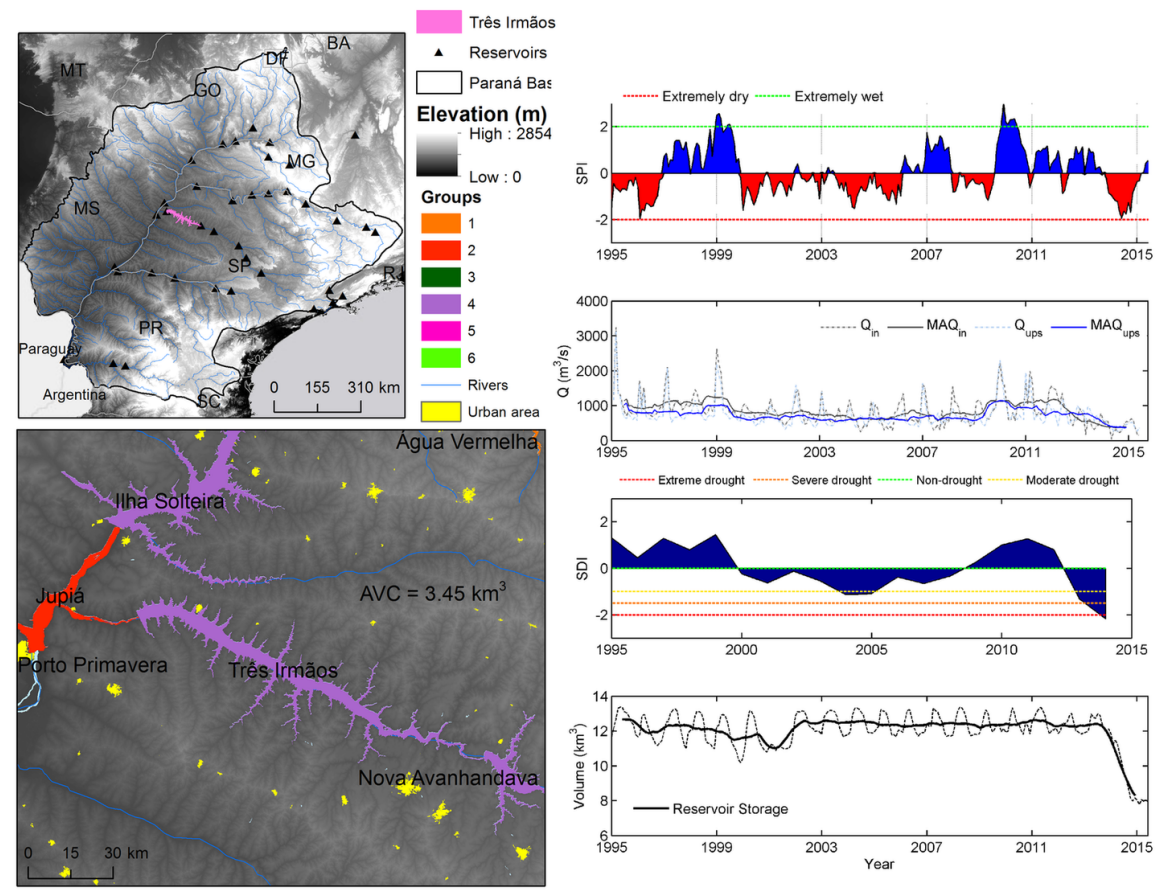

Figure S45. Time series of SDI, SPI and monthly storage: Três Irmãos HEP
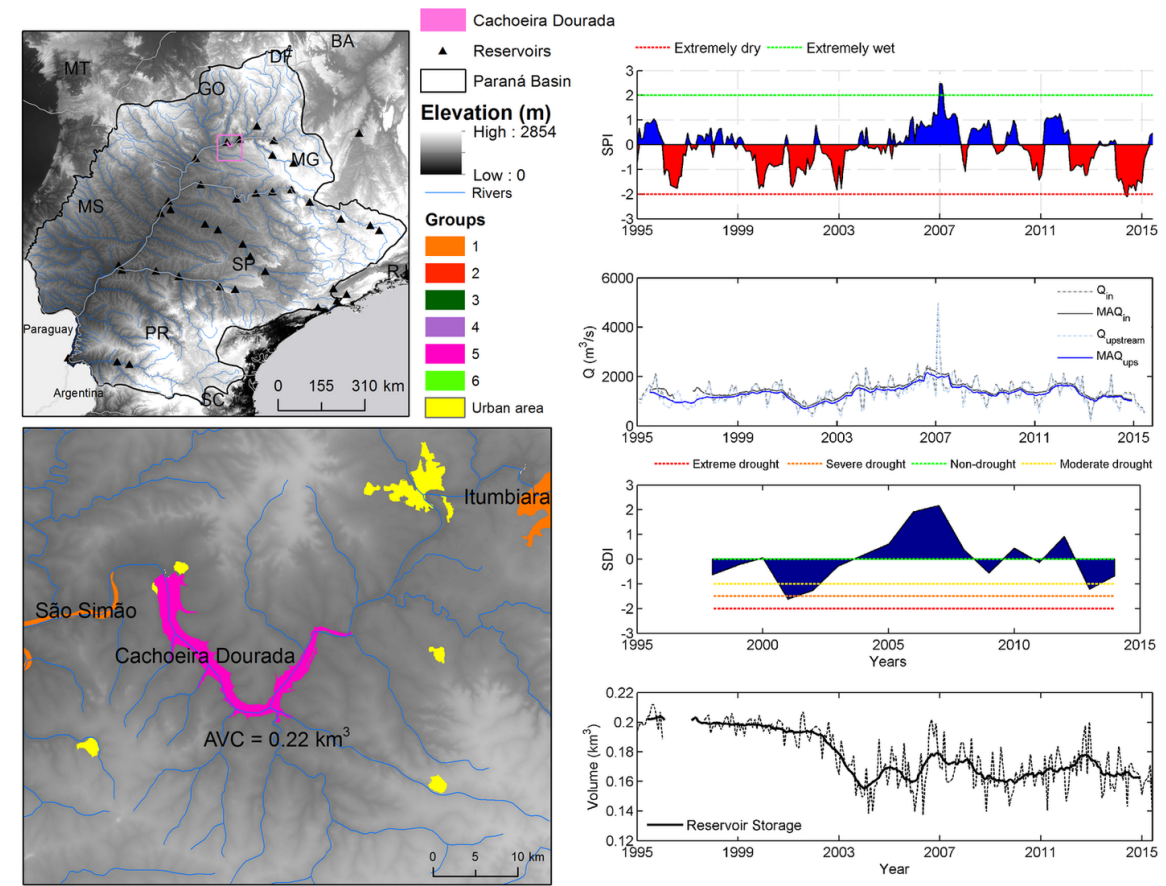

Figure S46. Time series of SDI, SPI and monthly storage: Cachoeira Dourada HEP 

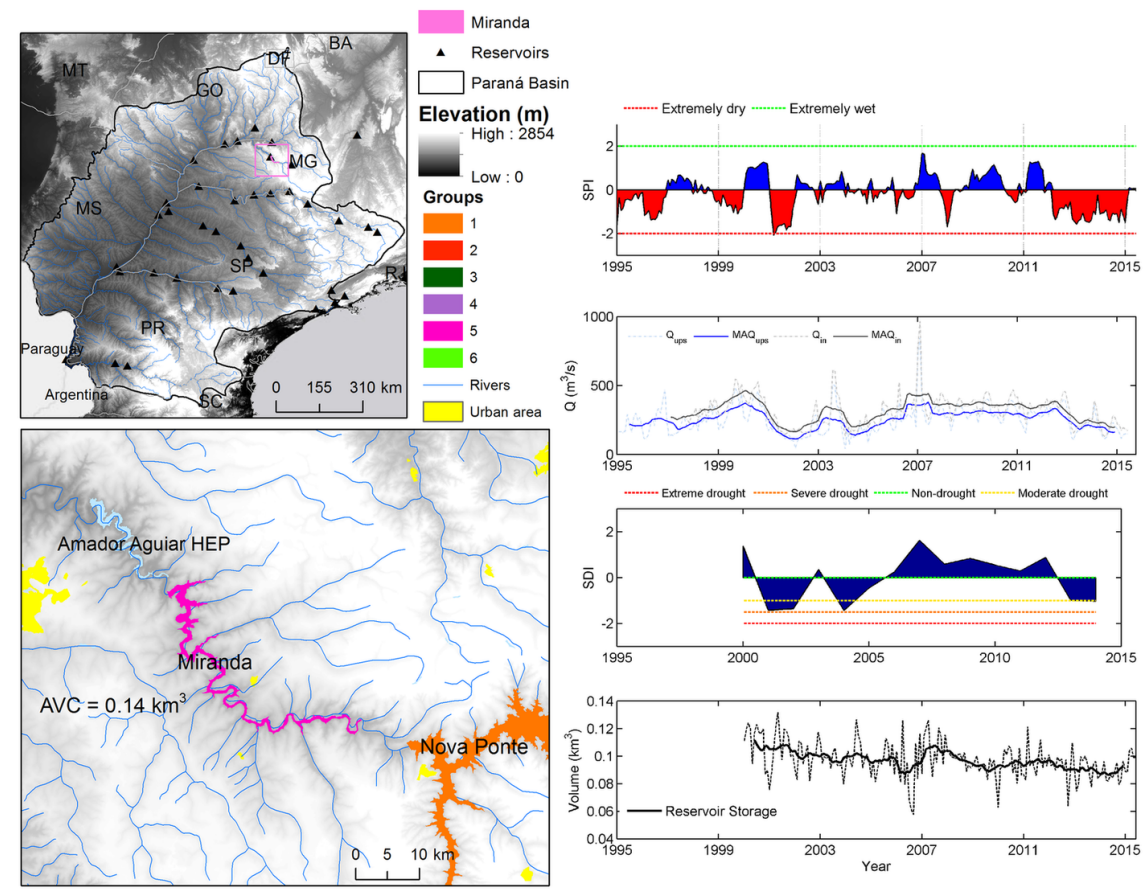

Figure S47. Time series of SDI, SPI and monthly storage: Miranda HEP
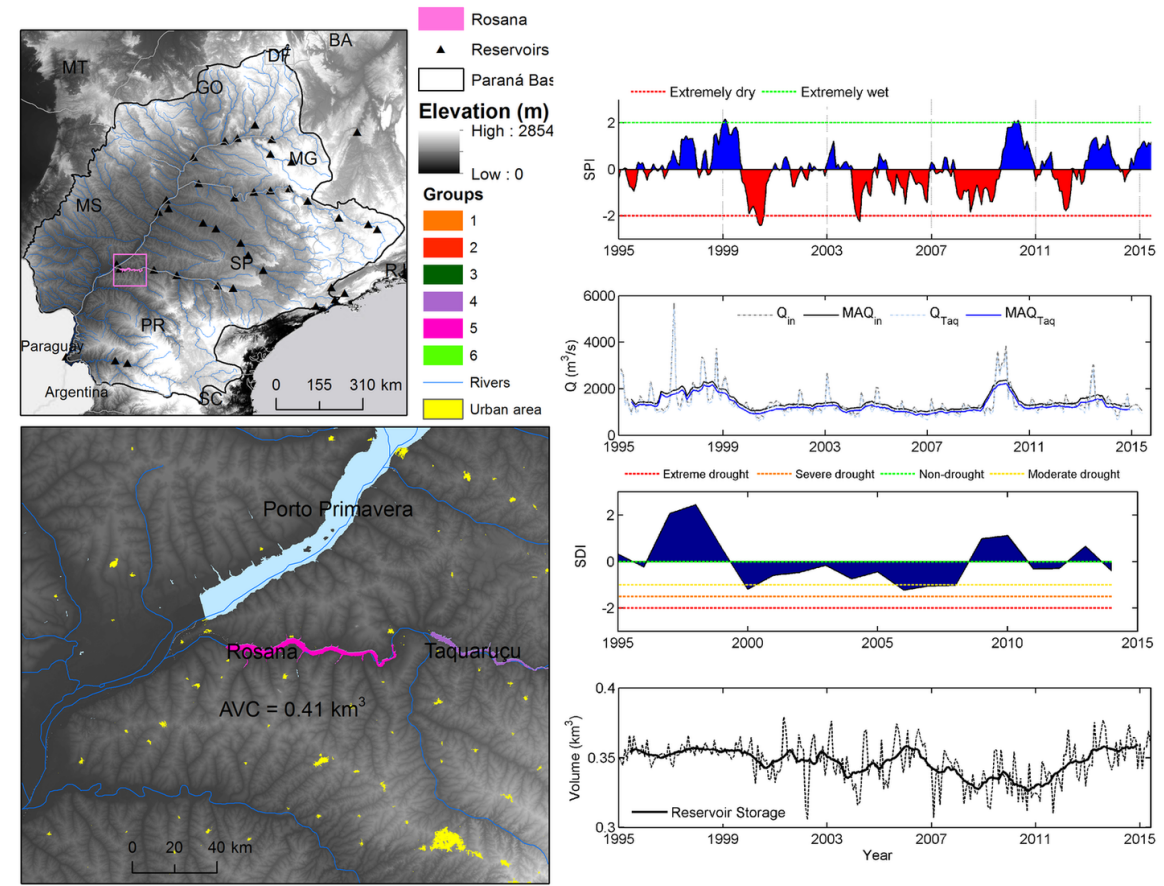

Figure S48. Time series of SDI, SPI and monthly storage: Rosana HEP 

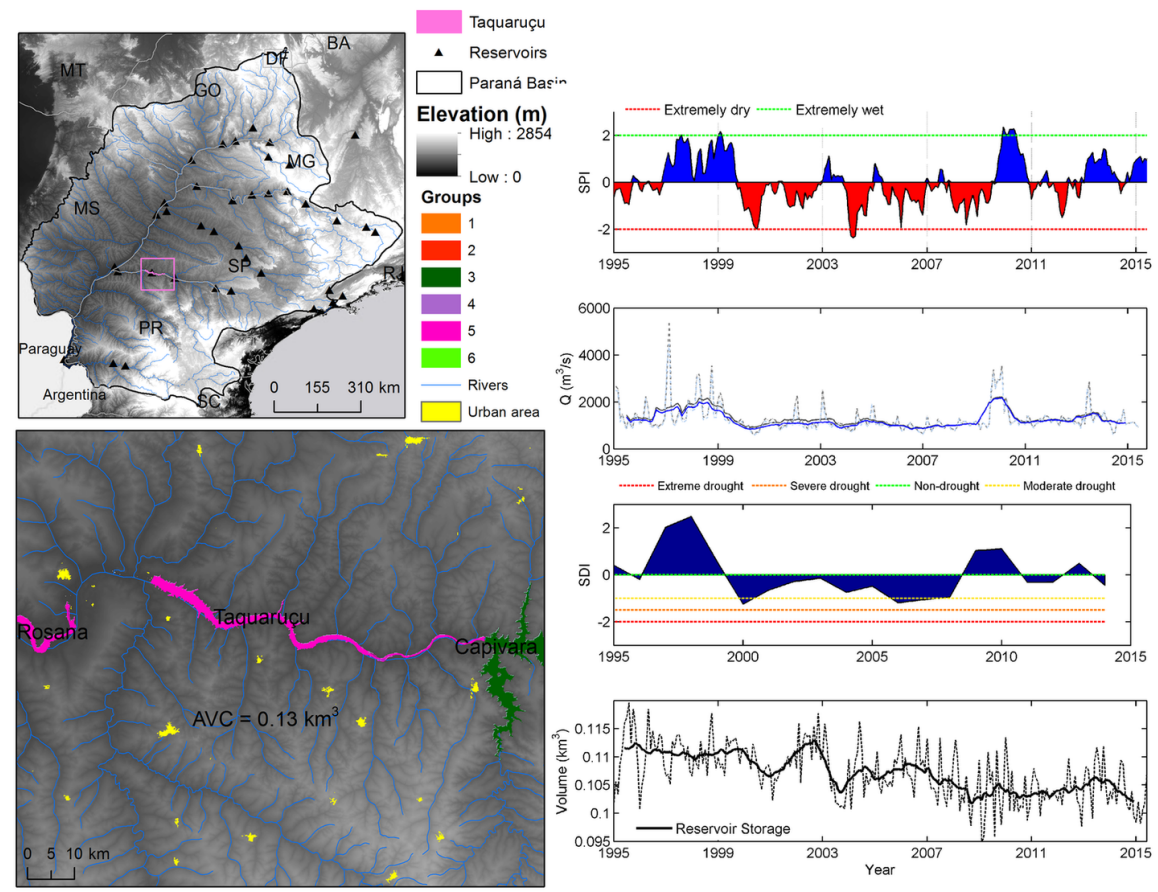

Figure S49. Time series of SDI, SPI and monthly storage: Taquaraću HEP
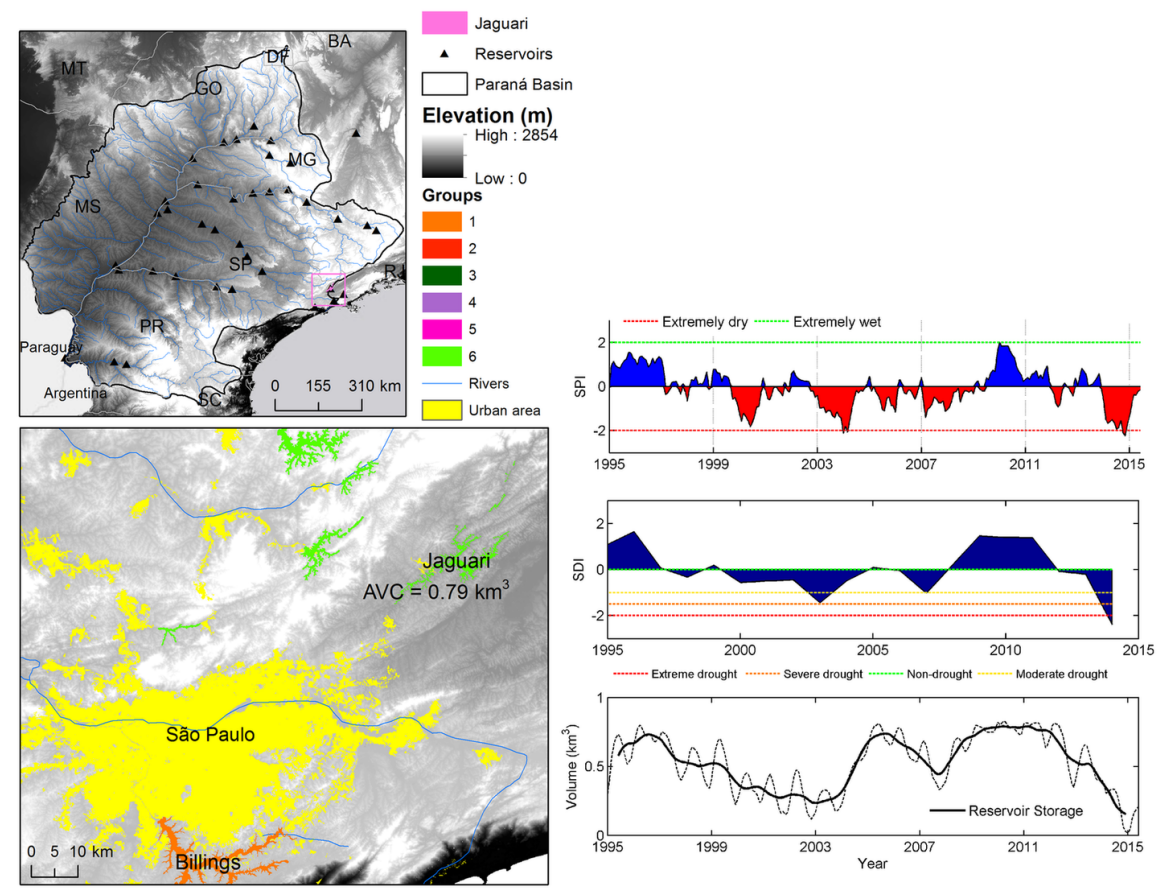

Figure S50. Time series of SDI, SPI and monthly storage: Jaguari HEP 

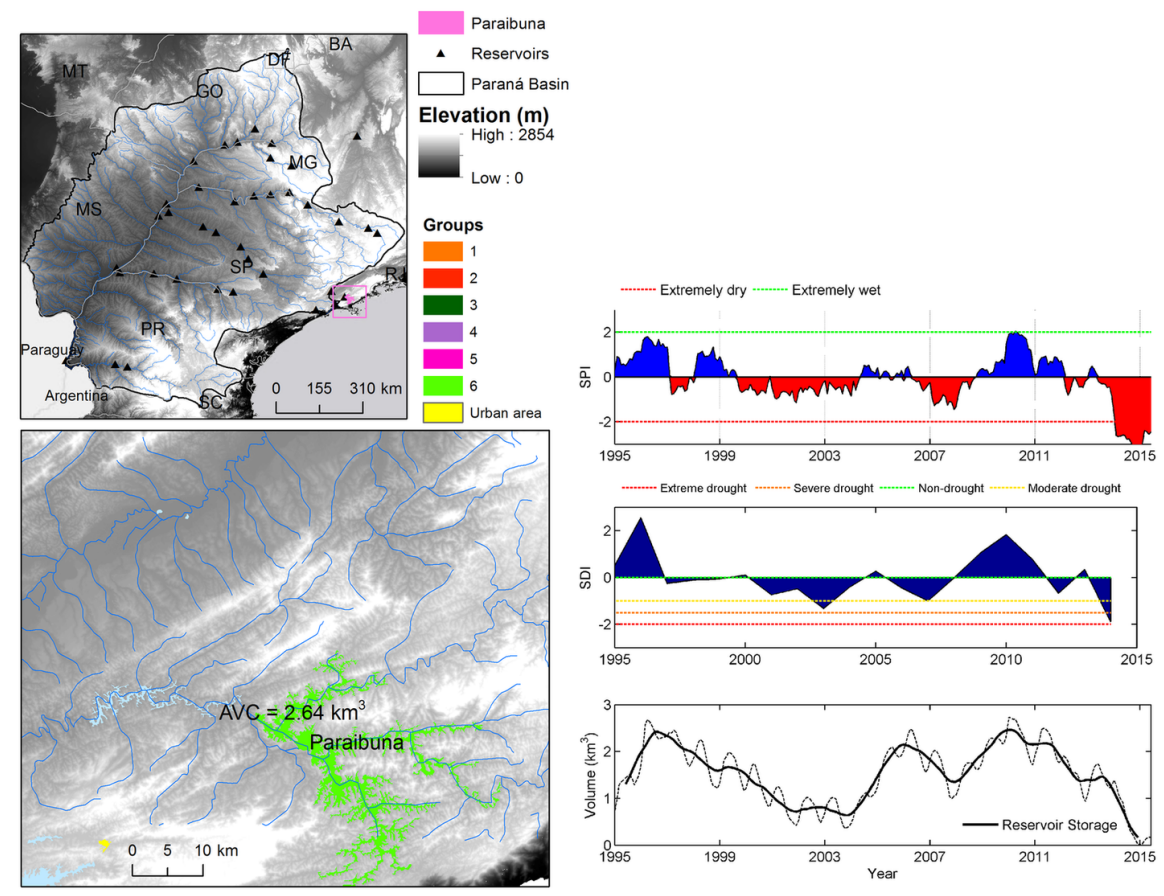

Figure S51. Time series of SDI, SPI and monthly storage: Paraibuna HEP
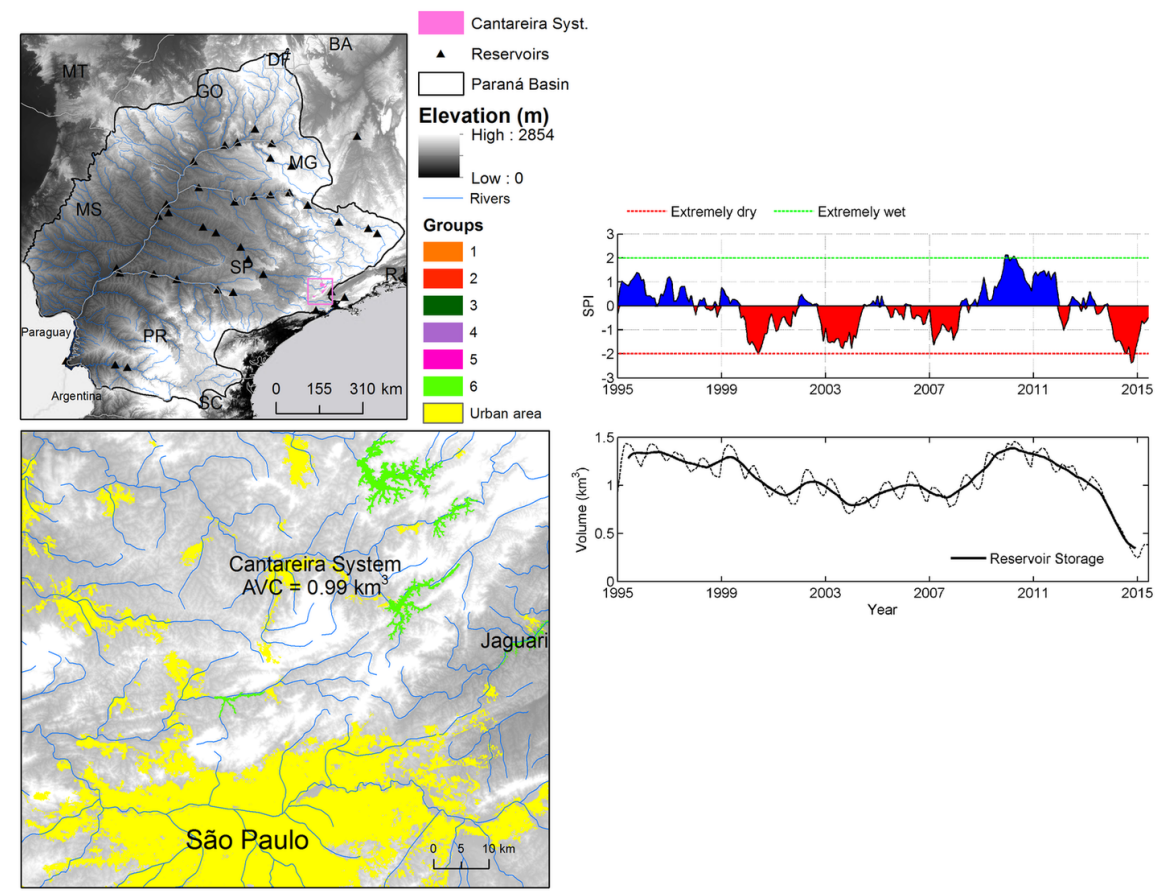

Figure S52. Time series of SDI, SPI and monthly storage: Cantareira System 